\title{
Self-Setting Calcium Orthophosphate Formulations: Cements, Concretes, Pastes and Putties
}

\author{
Sergey V. Dorozhkin
}

Kudrinskaja sq. 1-155, Moscow, 123242, Russia

\begin{abstract}
In early 1980s, researchers discovered self-setting calcium orthophosphate cements, which are a bioactive and biodegradable grafting material in the form of a powder and a liquid. Both phases after mixing form a viscous paste that after being implanted sets and hardens within the body as either a non-stoichiometric calcium deficient hydroxyapatite (CDHA) or brushite, sometimes blended with un-reacted particles and other phases. As both CDHA and brushite are remarkably biocompartible and bioresorbable (therefore, in vivo they can be replaced with a newly forming bone), self-setting calcium orthophosphate cements represent a good correction technique of non-weight-bearing bone fractures or defects and appear to be very promising materials for bone grafting applications. Besides, these cements possess an excellent osteoconductivity, molding capabilities, and easy manipulation. Nearly perfect adaptation to the tissue surfaces in bone defects and a gradual bioresorption followed by new bone formation are additional distinctive advantages of calcium orthophosphate cements. Besides, reinforced formulations are available; those are described as calcium orthophosphate concretes. Furthermore, formulations with high viscosity, such as pastes and putties are also known. The discovery of self-setting formulations has opened up a new era in the medical application of calcium orthophosphates; several commercial compositions have already been introduced as a result. Many more formulations are in experimental stages. In this review, an insight into the self-setting calcium orthophosphate formulations, as excellent biomaterials suitable for both dental and bone grafting applications, has been provided.
\end{abstract}

Keywords Calcium Orthophosphates, Hydroxyapatite, Cements, Concretes, Pastes, Putties, Self-Setting, Bioceramics, Biomaterials, Grafts, Biomedical Applications, Tissue Engineering

\section{Introduction}

Calcium orthophosphates have been studied as bone repair materials for the last 80 years. The first in vivo use of calcium orthophosphates was performed in 1920; that time the researchers implanted tricalcium phosphate (TCP) into animals to test its efficacy as a bone substitute[1]. In the following years, some other calcium orthophosphates were tested on animals to investigate their effect on the healing of nonunions[2]. However, it was 1951, when for the first time hydroxyapatite (HA) was implanted in rats and guinea pigs[3]. Those attempts might be characterized as initial medical trials with the first generation of bone substituting biomaterials. However, it was already the 1970-s, when other calcium orthophosphates were synthesized, characterized, investigated and tried in medicine[4-10]. The list of known calcium orthophosphates, including their standard abbreviations and the major properties, is shown in Table $1[11]$.

* Corresponding author:

sedorozhkin@yandex.ru (Sergey V. Dorozhkin)

Published online at http://journal.sapub.org/ijmc

Copyright (C) 2011 Scientific \& Academic Publishing. All Rights Reserved
It is generally considered, that the possibility to obtain a monolithic calcium orthophosphate bioceramics at ambient or body temperature via a cementation reaction was put forward by the scientists at the American Dental Association LeGeros et al.,[12] and Brown and Chow[13-16] in the early 1980-s. However, there is an opinion[17] that self-setting calcium orthophosphate formulations for orthopedic and dental restorative applications have first been described in the early 1970-s by Driskell et al.,[18]. More to the point, there are researchers, who worked with similar reactions even earlier. Namely, in 1950, Kingery investigated chemical interactions among oxides and/or hydroxides of various metals (including $\mathrm{CaO}$ ) with $\mathrm{H}_{3} \mathrm{PO}_{4}$ and discovered several self-hardening formulations[19]; thus, he appears to be the first. Leaving aside the priority topic, we will further discuss the material subject, which currently is known as calcium phosphate cements (commonly referred to as $\mathrm{CPC}$ ), and, due to their suitability for repair, augmentation and regeneration of bones, these biomaterials also named as calcium phosphate bone cements (occasionally referred to as CPBC)[20]. In order to stress the fact, that these cements consist either entirely or essentially from calcium orthophosphates, this review is limited to consideration of calcium orthophosphate-based formulations only. 
Sergey V. Dorozhkin: Self-Setting Calcium Orthophosphate Formulations: Cements, Concretes, Pastes and Putties

The readers interested in formulations based on other types of calcium phosphates are requested to read the original publications[21].

Due to a good bioresorbability, all self-setting calcium orthophosphate formulations belong to the second generation of bone substituting biomaterials[22]. These formulations are blends of amorphous and/or crystalline calcium orthophosphate powder(s) with an aqueous solution, which might be distilled water, phosphate-buffered saline (PBS), aqueous solutions of sodium orthophosphate $(\sim 0.25 \mathrm{M})$, orthophosphoric acid, citric acid $(\sim 0.5 \mathrm{M})$ [23], sodium silicate[24,25], magnesium hydroorthophosphate[26] or even the revised simulated body fluid (rSBF)[27]. After the calcium orthophosphate powder(s) and the solution are mixed together, a viscous and moldable paste is formed that sets to a firm mass within a few minutes. When the paste becomes sufficiently stiff, it can be placed into a defect as a substitute for the damaged part of bone, where it hardens in situ within the operating theatre. The proportion of solid to liquid or the powder-to-liquid $(\mathrm{P} / \mathrm{L})$ ratio is a very important characteristic because it determines both bioresorbability and rheological properties. As the paste is set and hardened at room or body temperature, direct application in healing of bone defects became a new and innovative treatment modality by the end of the XX-th century. Moreover, calcium orthophosphate cements can be injected directly into the fractures and bone defects, where they intimately adapt to the bone cavity regardless its shape. More to the point, they were found to promote development of osteoconductive pathways, possess sufficient compressive strengths, be non-cytotoxic, create chemical bonds to the host bones, restore contour and have both the chemical composition and $\mathrm{X}$-ray diffraction patterns similar to those of bone[28]. Finally but yet importantly, they are osteotransductive, i.e., after implantation, calcium orthophosphate cements are replaced by a new bone tissue[29-31].

The aim of biomimetic bone cements is to disturb bone functions and properties as little as possible and, until a new bone has been grown, to behave temporary in a manner similar to that of bone. From a biological point of view, this term defines cements that can reproduce the composition, structure, morphology and crystallinity of bone crystals $[32,33]$. Therefore, the discovery of self-setting calcium orthophosphate formulations was a significant step forward in the field of bioceramics for bone regeneration, since it established good prospects for minimally invasive surgical techniques that were less aggressive than the classical surgical methods[34]. Such formulations provide surgeons with a unique ability of manufacturing, shaping and implanting the bioactive bone substitute materials on a patient-specific base in real time in the surgery room. Implanted bone tissues also take benefits from initial setting characteristics of the cements that give, in an acceptable clinical time, a suitable mechanical strength for a shorter tissue functional recovery. The major advantages of the self-setting calcium orthophosphate formulations include a fast setting time, excellent moldability, outstanding bio- compatibility and easy manipulation; therefore, they are more versatile in handling characteristics than prefabricated calcium orthophosphate granules or blocks. Besides, like any other type of calcium orthophosphate bioceramics, the self-setting formulations provide with the opportunity for bone grafting using alloplastic materials, which are unlimited in quantity and provide no risk of infectious diseases [35-37].

Since self-setting calcium orthophosphate formulations are intended for using as implanted biomaterials for parenteral application, for their chemical composition one might employ all ionic compounds of oligoelements occurring naturally in a human body. The list of possible additives includes (but is not limited to) the following cations: $\mathrm{Na}^{+}$, $\mathrm{K}^{+}, \mathrm{Mg}^{2+}, \mathrm{Ca}^{2+}, \mathrm{Sr}^{2+}, \mathrm{H}^{+}$and anions: $\mathrm{PO}_{4}{ }^{3-}, \mathrm{HPO}_{4}{ }^{2-}, \mathrm{H}_{2} \mathrm{PO}_{4}^{-}$, $\mathrm{P}_{2} \mathrm{O}_{7}^{4-}, \mathrm{CO}_{3}^{2-}, \mathrm{HCO}_{3}^{-}, \mathrm{SO}_{4}^{2-}, \mathrm{HSO}_{4}^{-}, \mathrm{Cl}^{-}, \mathrm{OH}^{-}, \mathrm{F}^{-}$, $\mathrm{SiO}_{4}{ }^{4-}[29]$. Therefore, mixed-type self-setting formulations consisting of calcium orthophosphates and other calcium salts (e.g., calcium sulfates[38-47], calcium pyrophosphate[48-50], calcium polyphosphates[51,52], calcium carbonates [33, 53-55], calcium oxide[56-61], calcium hydroxide[62-64], calcium aluminate[26,65,66], calcium silicates[67-71], etc.), strontium orthophosphate[72-74], magnesium orthophosphate[74-78], magnesium oxide[79], Zn-containing compounds[80], as well as cements made of various ion substituted calcium orthophosphates (e.g., $\mathrm{Ca}_{2} \mathrm{KNa}\left(\mathrm{PO}_{4}\right)_{2}, \mathrm{NaCaPO}_{4}, \mathrm{Na}_{3} \mathrm{Ca}_{6}\left(\mathrm{PO}_{4}\right)_{5}$, magnesium substituted CDHA, strontium substituted CDHA, etc.)[81-90] are available. Furthermore, self-setting formulations might be prepared in the reaction-setting mixture of $\mathrm{Ca}(\mathrm{OH})_{2}-$ $\mathrm{KH}_{2} \mathrm{PO}_{4}$ system[91], as well as by treatment of calcium carbonates with orthophosphate solutions[92]. More to the point, self-setting formulations possessing magnetic properties due to incorporation of iron oxides have been developed as well[ $[93,94]$. However, with a few important exceptions, such ion-substituted formulations have not been considered in this review.

The purpose of this review is to evaluate the chemistry, physical and mechanical properties of the available self-setting calcium orthophosphate formulations with the specific reference to their biomedical applications in dentistry and surgery.

\section{General Information and Data}

This According to Wikipedia, the free encyclopedia: "In the most general sense of the word, cement is a binder, a substance that sets and hardens independently and can bind other materials together. The name "cement" goes back to the Romans who used the term "opus caementitium" to describe masonry, which resembled concrete and was made from crushed rock with burnt lime as binder. The volcanic ash and pulverized brick additives, which were added to the burnt lime to obtain a hydraulic binder, were later referred to as cementum, cimentum, cäment and cement"[95]. Thus, calcium orthophosphate cement appears to be a generic 
term to describe chemical formulations in the ternary system $\mathrm{Ca}(\mathrm{OH})_{2}-\mathrm{H}_{3} \mathrm{PO}_{4}-\mathrm{H}_{2} \mathrm{O}$ which can experience a transformation from a liquid or pasty state to a solid state and in which the end-product of the chemical reactions is a calcium orthophosphate.
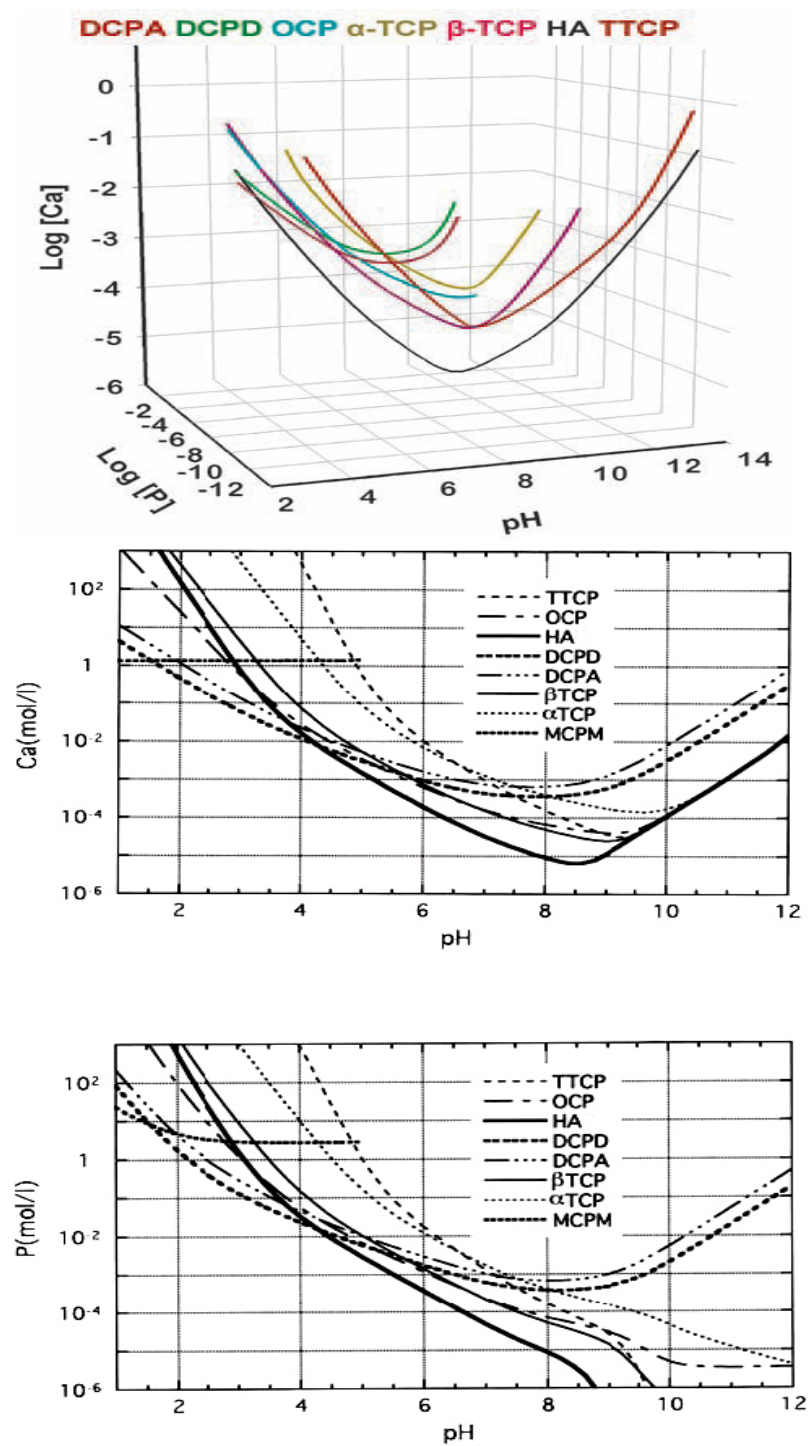

Figure 1. Top: a 3D version of the classical solubility phase diagrams for the ternary system $\mathrm{Ca}(\mathrm{OH})_{2}-\mathrm{H}_{3} \mathrm{PO}_{4}-\mathrm{H}_{2} \mathrm{O}$. Reprinted from Ref. [621] with permission. Middle and bottom: solubility phase diagrams in two-dimensional graphs, showing two logarithms of the concentrations of (a) calcium and (b) orthophosphate ions as a function of the $\mathrm{pH}$ in solutions saturated with various salts. Reprinted from Ref. [622] with permission

The first self-setting calcium orthophosphate cement formulation consists of the equimolar mixture of TTCP and dicalcium phosphate (DCPA or DCPD)[96] which is mixed with water at a $\mathrm{P} / \mathrm{L}$ ratio of $4: 1$; the paste hardened in about $30 \mathrm{~min}$ and formed CDHA[97,98]. This highly viscous, non-injectable paste can be molded and, therefore, is used mainly as a contouring material in craniofacial surgery. In 1990 -s, it was established that there were about 15 different binary combinations of calcium orthophosphates, which gave pastes upon mixing with water or aqueous solutions, so that the pastes set at room or body temperature into a solid cement. The list of these combinations is available in literature[99-101]. From these basic systems, secondary formulations could be derived containing additional or even non-reactive compounds but still setting like cements[29,58,99,102-116]. Concerning their viscosity, both pasty cement formulations[117-120] and putties[121] of a very high viscosity[122-125] are known as well.

According to the classical solubility data of calcium orthophosphates (Fig. 1), depending upon the $\mathrm{pH}$ value of a cement paste, after setting all calcium orthophosphate cements can form only two major end-products: a precipitated poorly crystalline $\mathrm{HA}$ or $\mathrm{CDHA}[126]$ at $\mathrm{pH}>4.2$ and DCPD (also called "brushite"[127]) at $\mathrm{pH}<4.2$ [128]. However, the $\mathrm{pH}$-border of 4.2 is shifted to a higher value of $\mathrm{pH}$ in the real cement formulations. Namely, DCPD might be formed at $\mathrm{pH}$ up to $\sim 6$, while CDHA normally is not formed at $\mathrm{pH}$ below $6.5-7$ (Table 1). The results of the only study on an ACP cement demonstrated that this end-product was rapidly converted into CDHA[113]; thus, it also belongs to apatite-forming formulations. Besides, there are some papers devoted to OCP-forming cements[129-132]; however, contrary to the reports of late 1980-s[129] and early 1990-s[130], in recent papers either simultaneous formation of OCP and CHDA has been detected[132] or no phase analysis has been performed[131]. Strong experimental evidences of the existence of a transient OCP phase during cement setting were found in still another study; however, after a few hours, the OCP phase disappeared giving rise to the final CDHA phase[25]. Thus, all existing formulations of calcium orthophosphate cements can be divided into two major groups: apatite cements and brushite cements[133]. The final hardened product of the cements is of the paramount importance because it determines the solubility and, therefore, in vivo bioresorbability. Since the chemical composition of mammalian bones is similar to an ion-substituted CDHA, apatite- forming cement formulations have been more extensively investigated. Nevertheless, many research papers on brushite cements have been published as well.

All self-setting calcium orthophosphate formulations are made of an aqueous solution and fine powders of one or several calcium orthophosphate(s). Here, dissolution of the initial calcium orthophosphate(s) (quickly or slowly depending on the chemical composition and solution $\mathrm{pH}$ ) and mass transport appear to be the primary functions of an aqueous environment, in which the dissolved reactants form a supersaturated (very far away from the equilibrium) microenvironment with regard to precipitation of the final product(s) $[135,136]$. The relative stability and solubility of various calcium orthophosphates (see Table 1) is the major driving force for setting reactions that occur in these cements. Therefore, mixing of a dry powder with an aqueous solution induces various chemical transformations, where crystals of the initial calcium orthophosphate(s) rapidly dissolve(s) and precipitate(s) into crystals of CDHA (preci- 
pitated HA) or DCPD with possible formation of intermediate precursor phases (e.g., ACP[113] and OCP[25,129132]). During precipitation, the newly formed crystals grow and form a web of intermingling microneedles or microplatelets of the final products, thus provide a mechanical rigidity to the hardened cements. In other words, entanglement of the newly formed crystals is the major reason of setting (Fig. 2). For the majority of apatite cements, water is not a reactant in the setting reaction. Therefore, the quantity of water, actually needed for setting of apatite cements, is very small[22,135,137]. However, for brushite cements, water always participates in the chemical transformations because it is necessary for DCPD formation. Due to this reason, brushite cements are always hydraulic, while usually this term is not associated with apatite cements.

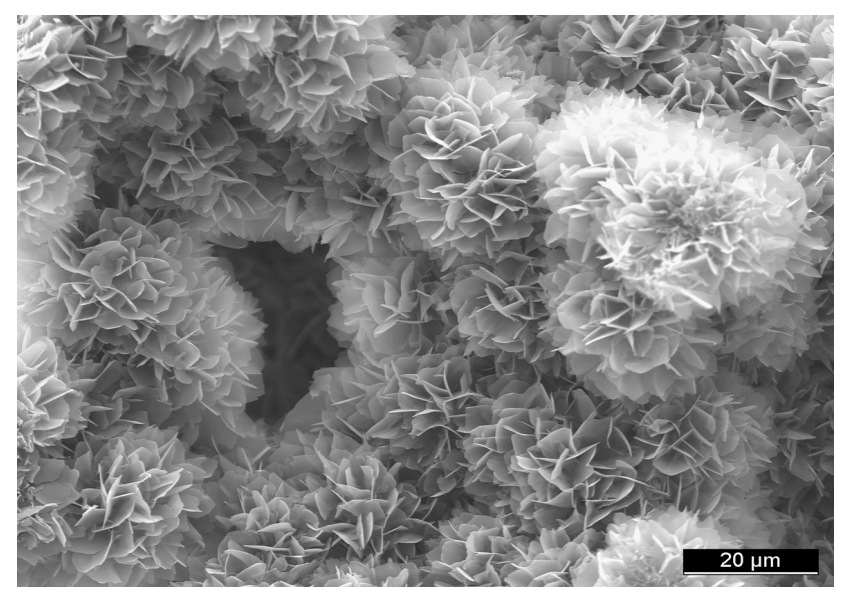

Figure 2. A typical microstructure of calcium orthophosphate cement after hardening. The mechanical stability is provided by the physical entanglement of crystals. Reprinted from Ref. [623] with permission

Setting of calcium orthophosphate cements is a continuous process that always starts with dissolution of the initial compounds in an aqueous system. This process supplies ions of calcium and orthophosphate into the solution, where they chemically interact and precipitate in the form of either the end-products or precursor phases, which causes the cement setting[138-140]. This was confirmed by Ishikawa and Asaoka, who showed that when TTCP and DCPA powders were mixed in double-distilled water, both powders were dissolved. The dissolved calcium and orthophosphate ions in the solution were then precipitated in the form of CDHA on the surface of the powders[141]. The precipitate can be either a gel or a conglomerate of crystals. Therefore, the hardening mechanism is either a sol-gel transition of ACP [113] or entanglement of the precipitated crystals of other calcium orthophosphates (Fig. 2)[29]. For example, for the classical Brown-Chow cement formulation, after the initial setting, petal or needle-like crystals enlarge epitaxially and are responsible for the adherence and interlocking of the crystalline grains, which result in hardening. After $\sim 2$ hours, the newly formed crystals become rod-like, resulting from higher crystallinity with the observation of more material at the inter-particle spaces. During this period, the cement setting reaction proceeded at a near-constant rate, suggest- ing that the reaction rate was limited by factors that are unrelated to the amounts of the starting materials and the reaction products present in the system. Such factors could be related to the surface area of DCPA or TTCP or to the diffusion distances over which the calcium and orthophosphate ions migrate in order to form CDHA[142-144]. At $~ 24$ hours, the crystals are completely formed, being very compacted in some areas of high density, and well separated in areas with more porosity[106,111,112].

The chemical reactions occurring during setting of calcium orthophosphate cements depend on their chemical composition. However, it can be stated that only two major chemical types of the setting reaction are possible. The first type occurs according to the classical rules of the acid-base interaction, i.e. a relatively acidic calcium orthophosphate reacts with a relatively basic one to produce a relatively neutral compound. The first cement by Brown and Chow is a typical example of this type because TTCP (basic) reacts with DCPA (slightly acidic) in an aqueous suspension to form a poorly crystalline precipitated HA (slightly basic) $[14,15]$ :

$$
2 \mathrm{Ca}_{4}\left(\mathrm{PO}_{4}\right)_{2} \mathrm{O}+2 \mathrm{CaHPO}_{4} \rightarrow \mathrm{Ca}_{10}\left(\mathrm{PO}_{4}\right)_{6}(\mathrm{OH})_{2}
$$

Earlier, it was believed that DCPA and TTCP reacted upon mixing with water to form the stoichiometric HA[13-16]. However, further investigations have shown that only the first nuclei consist of a nearly stoichiometric $\mathrm{HA}$, whereas further growth of these nuclei occurs in the form of CDHA[145]. Besides, there is a study demonstrating that the initially formed stoichiometric HA further interacts with remaining DCPD to form CDHA[146].

According to equation (1), formation of HA releases neither acidic nor basic by-products. Thus, the liquid phase of the cement remains at a near constant $\mathrm{pH}$ of $\sim 7.5$ for the TTCP + DCPD and $\sim 8.0$ for the TTCP + DCPA formulations, respectively[142-144]. Various deviations from the stoichiometry of chemical equation (1) were studied in details and various apatitic calcium orthophosphates with $\mathrm{Ca} / \mathrm{P}$ ionic ratio within $1.5-1.67$ were found as the end-product[147]. The effect of mixing ratio and $\mathrm{pH}$ on the reaction between TTCP and DCPA is well described elsewhere[148]. Furthermore, the influence of $\mathrm{Ca} / \mathrm{P}$ ionic ratio of TTCP on the properties of the TTCP + DCPD cement was studied as well[149].

A blend proposed by Lemaitre et al.,[150,151] is another example of the acid-base interaction where $\beta$-TCP (almost neutral) reacts with MCPM (acidic) to form DCPD (slightly acidic):

$$
\begin{gathered}
\beta-\mathrm{Ca}_{3}\left(\mathrm{PO}_{4}\right)_{2}+\mathrm{Ca}\left(\mathrm{H}_{2} \mathrm{PO}_{4}\right)_{2} \cdot \mathrm{H}_{2} \mathrm{O}+7 \mathrm{H}_{2} \mathrm{O} \rightarrow \\
4 \mathrm{CaHPO}_{4} \cdot 2 \mathrm{H}_{2} \mathrm{O}
\end{gathered}
$$

In chemical equation (2) MCPM might easily be substituted by orthophosphoric acid[152-155] or MCPA, while $\beta$-TCP might be replaced by either $\alpha$-TCP $[156,157]$, $\mathrm{CDHA}[158,159]$ or $\mathrm{HA}[160]$. For example:

$$
\begin{gathered}
\mathrm{Ca}_{9}\left(\mathrm{HPO}_{4}\right)\left(\mathrm{PO}_{4}\right)_{5}(\mathrm{OH})+3 \mathrm{H}_{3} \mathrm{PO}_{4}+17 \mathrm{H}_{2} \mathrm{O} \rightarrow \\
9 \mathrm{CaHPO}_{4} \cdot 2 \mathrm{H}_{2} \mathrm{O}
\end{gathered}
$$


Furthermore, self-setting formulations based on mixtures of ACP $+\alpha$-TCP[161], ACP + DCPD[162,163], DCPA + $\alpha$-TCP [157], ОСР + TTCP[164], ОCP $+\alpha$-TCP $[165,166]$ and partially crystallized calcium orthophosphate + DCPA [167] as the initial reagents, are also available.

The second type of the setting reaction might be defined as hydrolysis of a metastable calcium orthophosphate in aqueous media. As the result, both the initial and final compounds have the same $\mathrm{Ca} / \mathrm{P}$ ionic ratio. Due to the fact, that only one calcium orthophosphate is used; the solid part of such formulations might be called as a single-phase (or single-component) cement powder[168]. Cements made of $\mathrm{ACP}+$ an aqueous solution[169,170], $\alpha-\mathrm{TCP}+$ an aqueous solution[171-178], $\beta$-TCP + an aqueous solution[175,179], $\mathrm{DCPA}+$ an aqueous solution[24], CDHA + an aqueous solution[25], TTCP + an aqueous solution[26,180,181] or $\gamma$-radiated TTCP + an aqueous solution[182-184] are the typical examples; the majority of them are re-crystallized to CDHA during setting:

$$
\begin{gathered}
\mathrm{Ca}_{\mathrm{x}} \mathrm{H}_{\mathrm{y}}\left(\mathrm{PO}_{4}\right)_{\mathrm{z}} \cdot \mathrm{nH}_{2} \mathrm{O}+\mathrm{H}_{2} \mathrm{O} \rightarrow \\
\mathrm{Ca}_{10-x}\left(\mathrm{HPO}_{4}\right)_{x}\left(\mathrm{PO}_{4}\right)_{6-x}(\mathrm{OH})_{2-x}+\mathrm{nH}_{2} \mathrm{O} \\
3(\alpha-\text { or } \beta-) \mathrm{Ca}_{3}\left(\mathrm{PO}_{4}\right)_{2}+\mathrm{H}_{2} \mathrm{O} \rightarrow \mathrm{Ca}_{9}\left(\mathrm{HPO}_{4}\right)\left(\mathrm{PO}_{4}\right)_{5}(\mathrm{OH}) \\
3 \mathrm{Ca}_{4}\left(\mathrm{PO}_{4}\right)_{2} \mathrm{O}+3 \mathrm{H}_{2} \mathrm{O} \rightarrow \\
\mathrm{Ca}_{9}\left(\mathrm{HPO}_{4}\right)\left(\mathrm{PO}_{4}\right)_{5}(\mathrm{OH})+3 \mathrm{Ca}(\mathrm{OH})_{2}
\end{gathered}
$$

\begin{tabular}{|c|c|c|c|c|c|}
\hline $\begin{array}{l}\mathrm{Ca} / \mathrm{P} \text { molar } \\
\quad \text { ratio }\end{array}$ & Compound & Formula & $\begin{array}{l}\text { Solubility at } \\
25^{\circ} \mathrm{C},-\log \left(K_{s}\right)\end{array}$ & $\begin{array}{l}\text { Solubility at } \\
25^{\circ} \mathrm{C}, \mathrm{g} / \mathrm{L}\end{array}$ & $\begin{array}{c}\mathrm{pH} \text { stability } \\
\text { range in aqueous } \\
\text { solutions at } 25^{\circ} \mathrm{C} \\
\end{array}$ \\
\hline 0.5 & $\begin{array}{l}\text { Monocalcium phosphate monohy- } \\
\text { drate (MCPM) }\end{array}$ & $\mathrm{Ca}\left(\mathrm{H}_{2} \mathrm{PO}_{4}\right)_{2} \cdot \mathrm{H}_{2} \mathrm{O}$ & 1.14 & $\sim 18$ & $0.0-2.0$ \\
\hline 0.5 & $\begin{array}{l}\text { Monocalcium phosphate anhydrous } \\
\text { (MCPA or MCP) }\end{array}$ & $\mathrm{Ca}\left(\mathrm{H}_{2} \mathrm{PO}_{4}\right)_{2}$ & 1.14 & $\sim 17$ & [c] \\
\hline 1.0 & $\begin{array}{l}\text { Dicalcium phosphate dihydrate } \\
\text { (DCPD), mineral brushite }\end{array}$ & $\mathrm{CaHPO}_{4} \cdot 2 \mathrm{H}_{2} \mathrm{O}$ & 6.59 & $\sim 0.088$ & $2.0-6.0$ \\
\hline 1.0 & $\begin{array}{l}\text { Dicalcium phosphate anhydrous } \\
\text { (DCPA or DCP), mineral monetite }\end{array}$ & $\mathrm{CaHPO}_{4}$ & 6.90 & $\sim 0.048$ & [c] \\
\hline 1.33 & $\begin{array}{l}\text { Octacalcium phosphate } \\
\text { (OCP) }\end{array}$ & $\mathrm{Ca}_{8}\left(\mathrm{HPO}_{4}\right)_{2}\left(\mathrm{PO}_{4}\right)_{4} \cdot 5 \mathrm{H}_{2} \mathrm{O}$ & 96.6 & $\sim 0.0081$ & $5.5-7.0$ \\
\hline 1.5 & $\begin{array}{l}\alpha \text {-Tricalcium phosphate } \\
(\alpha \text {-TCP) }\end{array}$ & $\alpha-\mathrm{Ca}_{3}\left(\mathrm{PO}_{4}\right)_{2}$ & 25.5 & $\sim 0.0025$ & [a] \\
\hline 1.5 & $\begin{array}{l}\beta \text {-Tricalcium phosphate } \\
(\beta-\mathrm{TCP})\end{array}$ & $\beta-\mathrm{Ca}_{3}\left(\mathrm{PO}_{4}\right)_{2}$ & 28.9 & $\sim 0.0005$ & [a] \\
\hline $1.2-2.2$ & $\begin{array}{l}\text { Amorphous calcium phosphates } \\
\text { (ACP) }\end{array}$ & $\mathrm{Ca}_{x} \mathrm{H}_{y}\left(\mathrm{PO}_{4}\right)_{z} \cdot n \mathrm{H}_{2} \mathrm{O}, n=3-4.5 ; 15-20 \% \mathrm{H}_{2} \mathrm{O}$ & {$[b]$} & {$[\mathrm{b}]$} & $\sim 5-12^{[\mathrm{d}]}$ \\
\hline $1.5-1.67$ & 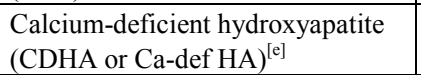 & $\mathrm{Ca}_{10-x}\left(\mathrm{HPO}_{4}\right)_{x}\left(\mathrm{PO}_{4}\right)_{6-x}(\mathrm{OH})_{2-x}(0<x<1)$ & $\sim 85$ & $\sim 0.0094$ & $6.5-9.5$ \\
\hline 1.67 & $\begin{array}{l}\text { Hydroxyapatite } \\
\text { (HA, HAp or OHAp) }\end{array}$ & $\mathrm{Ca}_{10}\left(\mathrm{PO}_{4}\right)_{6}(\mathrm{OH})_{2}$ & 116.8 & $\sim 0.0003$ & $9.5-12$ \\
\hline 1.67 & $\begin{array}{l}\text { Fluorapatite } \\
\text { (FA or FAp) }\end{array}$ & $\mathrm{Ca}_{10}\left(\mathrm{PO}_{4}\right)_{6} \mathrm{~F}_{2}$ & 120.0 & $\sim 0.0002$ & $7-12$ \\
\hline 1.67 & $\begin{array}{l}\text { Oxyapatite } \\
(\mathrm{OA}, \text { OAp or OXA })^{[\mathrm{f}]}\end{array}$ & $\mathrm{Ca}_{10}\left(\mathrm{PO}_{4}\right)_{6} \mathrm{O}$ & $\sim 69$ & $\sim 0.087$ & [a] \\
\hline 2.0 & $\begin{array}{l}\text { Tetracalcium phosphate (TTCP or } \\
\text { TetCP), mineral hilgenstockite }\end{array}$ & $\mathrm{Ca}_{4}\left(\mathrm{PO}_{4}\right)_{2} \mathrm{O}$ & $38-44$ & $\sim 0.0007$ & [a] \\
\hline
\end{tabular}

Table 1. Existing calcium orthophosphates and their major properties[11]

${ }^{[a]}$ These compounds cannot be precipitated from aqueous solutions.

${ }^{[\mathrm{b}]}$ Cannot be measured precisely. However, the following values were found: $25.7 \pm 0.1(\mathrm{pH}=7.40), 29.9 \pm 0.1(\mathrm{pH}=6.00), 32.7 \pm 0.1$ (pH $\left.=5.28\right)$. The comparative extent of dissolution in acidic buffer is: ACP $>>\alpha$-TCP $>>\beta$-TCP $>$ CDHA $>>$ HA $>$ FA.

${ }^{[c]}$ Stable at temperatures above $100^{\circ} \mathrm{C}$.

[d] Always metastable.

${ }^{[\mathrm{e}]}$ Occasionally, it is called "precipitated HA (PHA)".

${ }^{[\mathrm{f}]}$ Existence of OA remains questionable.

Table 2. Some self-setting calcium orthophosphate cement formulations having the $510(\mathrm{k})$ clearance from the FDA[20,137,202]. The technical data on these cements might be found in literature[22]

\begin{tabular}{|c|c|c|}
\hline Product $^{*}$ & Manufacturer & Applications $^{*}$ \\
\hline BoneSource $^{\mathrm{TM} * *}$ & Striker Howmedica Osteonics (Rutherford, NJ) & Craniofacial \\
\hline$\alpha$-Bone Substitute Material $\left(\alpha-\mathrm{BSM}^{\circledR}\right)^{* * *}$ & Etex Corporation (Cambridge, MA) & Filling of bone defects and voids, dental, craniofacial \\
\hline Skeletal Repair Systems $\left(\mathrm{SRS}^{\circledR}\right)$ & Norian Corporation (Cupertino, CA) & Skeletal distal radius fractures, craniofacial \\
\hline
\end{tabular}

*** Europe, other applications may apply, and the materials may be sold with a different commercial name.

${ }_{* * *}^{* *}$ BoneSource ${ }^{\mathrm{TM}}$ is the original formulation of calcium orthophosphate cement developed by Brown and Chow.

${ }^{* * * *}$ In Europe, it is distributed by Biomet Merck (Zwijndrecht, The Netherlands) as Biobon ${ }^{\mathbb{B}}$ [137], while in North America it is marketed by Walter Lorenz Surgical (Jacksonville, FL) as Embarc ${ }^{\mathbb{B}}$ [22]. 
The experimental details on TTCP hydrolysis under a near-constant composition condition might be found elsewhere[185]. The details on $\alpha$-TCP hydrolysis are also available. The results indicated that setting of $\alpha$-TCP was initially controlled by surface dissolution; therefore, it depended on the surface area of the reactants[186-189]. Hydrolysis of DCPD to CDHA was studied as well[190]. Addition of $\sim 2$ wt. $\%$ of a precipitated poorly crystalline HA (i.e., CDHA) as a seed to $\alpha$-TCP powder phase might be useful to accelerate the kinetics of reaction (5)[191].

Further, there is a single-phase cement powder consisting of $\mathrm{K}$ - and $\mathrm{Na}$ - containing $\mathrm{CDHA}$ (with the $\mathrm{Ca} / \mathrm{P}$ ionic ratio of $1.64 \pm 0.02$ ) that sets and hardens after mixing with an aqueous solution of sodium citrate and sodium orthophosphate[17]. After setting, this formulation gives rise to formation of a weak cement (the compressive strength of $15 \pm$ $3 \mathrm{MPa}$ ) consisting of the ion-substituted CDHA again (presumably, with another $\mathrm{Ca} / \mathrm{P}$ ionic ratio), mimicking the bone mineral. Unfortunately, neither the setting reaction nor the setting mechanism of this cement has been disclosed in literature[17]. What's more, a self-setting cement might be prepared from the thermal decomposition product of HA[192].

The hydration process of calcium orthophosphate cements is slightly exothermic (which is beneficial for biomedical applications) and undergoes five periods: initiating period, induction period, accelerating period, decelerating period and terminating period[193]. For the classical Brown-Chow cement formulation, the activation energy of the hydration reaction is $176 \mathrm{~kJ} / \mathrm{mol}[194]$. The rate of heat liberation during the solidification of calcium orthophosphate cements is low. The results of adiabatic experiments showed that the temperature rise arrived at the highest value of $37^{\circ} \mathrm{C} 3 \mathrm{~h}$ later, which would cause no harm to surrounding tissues[193]. The results show that the hardening process of this cement is initially controlled by dissolution of the reactants in a $4 \mathrm{~h}$ period and subsequently by diffusion through the product layer of CDHA around the grains [112]. In general, setting of calcium orthophosphate cements occurs mostly within the initial $\sim 6$ hours, yielding an $\sim 80 \%$ conversion to the final products. The volume of the cements stays almost constant during setting. However, after hardening, calcium orthophosphate cements always form brittle ceramics with the tensile strength of 5 to 20 times lower than the compression strength[195,196]. Since this material is weak under tensile forces, these cements can only be used either in combination with metal implants or in non-load bearing (e.g., craniofacial) applications[137,197199]. This is confirmed by the mechanical characterization of a bone defect model filled with ceramic cements[200].

To conclude this part, one must stress, that chemical equations (1) - (6) of the cement setting are valid for the in vitro conditions only. There are evidences that samples of calcium orthophosphate cement retrieved $12 \mathrm{~h}$ after hardening in vivo already contained carbonateapatite, even though the initial cement mixture did not contain carbonate as one of the solid components[201]. The mass fraction of carbonate in the $12 \mathrm{~h}$ samples was about $1 \%$. The results suggest that under the in vivo conditions, carbonate is readily available and this allows formation of carbonateapatite in favor of carbonate-free CDHA[201].

The United States Food and Drug Administration (FDA) has approved several cement formulations for clinical use[22,202]. Some examples are given in Table 2. The same formulations have also received a Conformite Europene (CE) mark for certain maxillofacial indications and for use as a bone-void filler in the specific non-load-bearing orthopedic indications[137]. The major properties of these formulations are available in literature[22]. An extended list of the cement formulations is presented in Table 3[125]. Other lists of the commercially available injectable bone cements with their chemical composition (when obtainable) might be found elsewhere[34,144,203,204], while various types of bone cements and fillers are listed in still another review[198]. A general appearance of two randomly chosen commercial calcium orthophosphate cements is shown in Fig. 3. Besides, even more cement formulations are in experimental stages.

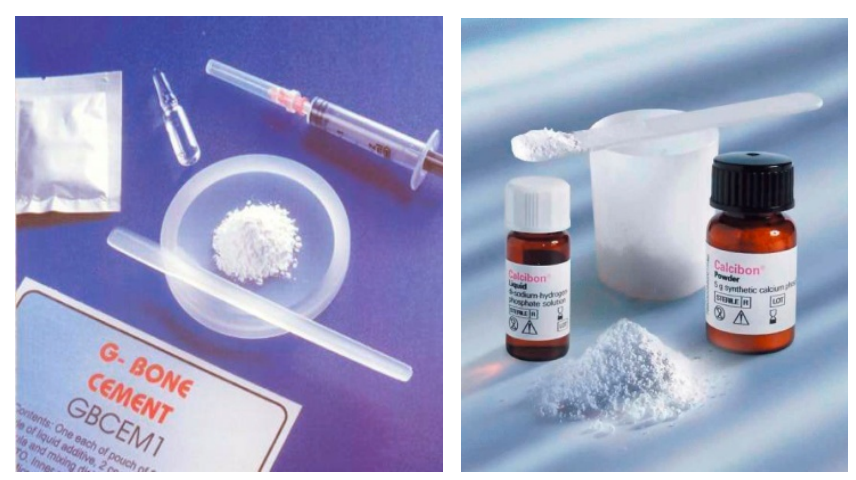

Figure 3. A presentation of two randomly chosen commercial calcium orthophosphate cements

\section{Two Major Types of Calcium Orthophosphate Cements}

\subsection{Apatite Cements}

Typically, apatite cement formulations have a precipitated poorly crystalline HA and/or CDHA as the end product of the setting reaction (see chemical equations (1), (4) - (6)), although traces of the unreacted starting materials can be present[106]. A FA-forming cement is also known; it might be prepared by the same way but in the presence of $\mathrm{F}^{-}$ions [205]. Due to the initial presence of carbonates, such commercial formulations as Norian SRS ${ }^{\circledR}$ and Biocement $\mathrm{D}^{\circledR}$ form a non-stoichiometric carbonatapatite or dahllite $\left(\mathrm{Ca}_{8.8}\left(\mathrm{HPO}_{4}\right)_{0.7}\left(\mathrm{PO}_{4}\right)_{4.5}\left(\mathrm{CO}_{3}\right)_{0.7}(\mathrm{OH})_{1.3}\right)$ as the end-product $[53,206]$. As both CDHA and carbonateapatite are formed in an aqueous environment and have a low crystallinity, they appear to be similar to biological apatite of bones and teeth. These properties are believed to be responsible for their excellent in vivo resorption characteristics. Conventional apatite cements contain TCP and/or TTCP phases in their 
powder components[34], while a single component cement powder consisting of $\mathrm{K}$ - and Na- containing CDHA is also available[17]. The reactivity of TCP-based apatite cements varies as a function of TCP crystal phase, crystallinity and particle size[207,208]. Generally, a higher reactivity is observed with a thermodynamically less stable phase (from $\beta$-TCP to $\alpha$-TCP and further to ACP) and with a smaller particle size[175]. Nominally, it might be stated that formation of apatites through a cementation reaction is a sort of a biomimetic process because it occurs in physiological en- vironment and at body temperature[37]; however, both the crystallization kinetics and a driving force are very far away from the biomimeticity. A unique feature of the hardened apatite cements is that the force linking the newly formed crystals (of both CDHA and carbonatapatite) is weak; therefore, the crystals can be easily detached from the bulk of hardened cement, especially after dissolution has partly occurred. When this happens, osteoclasts and other cells can easily ingest the apatite crystals[209].

Table 3. A list of the commercial self-setting calcium orthophosphate formulations with the producer, product name, composition (when available) and main end-product. The main end-product of the reaction can be either an apatite (CDHA, carbonateapatite, etc...) or brushite (= DCPD) [125]

\begin{tabular}{|c|c|c|c|}
\hline Producer & Commercial name & Composition & Product \\
\hline \multirow{2}{*}{$\begin{array}{l}\text { Berkeley Advanced } \\
\text { Biomaterials (US) }\end{array}$} & Cem-Ostetic ${ }^{\mathrm{TM}}$ & $\begin{array}{l}\text { Powder: calcium orthophosphates (details unknown); } \\
\text { Solution: Sterile water }\end{array}$ & apatite \\
\hline & Tri-Ostetic ${ }^{\mathrm{TM}}$ & $\begin{array}{l}\text { Powder: calcium orthophosphates (details unknown); } \\
\text { Solution: Sterile water }\end{array}$ & apatite \\
\hline Biomatlante (FR) & $\mathrm{MCPC}$ & $\begin{array}{l}\text { Powder: mainly } \alpha-\mathrm{TCP}, \mathrm{ACP}, \mathrm{BCP}(\mathrm{HA}+\beta-\mathrm{TCP}) \\
\text { Solution: phosphate buffered solution }\end{array}$ & apatite \\
\hline \multirow{3}{*}{$\begin{array}{l}\text { Biomet (US) Inter- } \\
\text { pore (US) Walter } \\
\text { Lorenz Surgical } \\
\quad \text { (GER) }\end{array}$} & Calcibon ${ }^{\circledR}$ & $\begin{array}{l}\text { Powder: } \alpha-\mathrm{TCP}(61 \%), \text { DCPA }(26 \%), \mathrm{CaCO}_{3}(10 \%), \mathrm{CDHA}(3 \%) \text {; } \\
\text { Solution: } \mathrm{H}_{2} \mathrm{O}, \mathrm{Na}_{2} \mathrm{HPO}_{4}\end{array}$ & apatite \\
\hline & $\operatorname{Mimix}^{\mathrm{TM}}$ & $\begin{array}{l}\text { Powder: TTCP, } \alpha \text {-TCP, trisodium citrate; } \\
\text { Solution: citric acid aqueous solution }\end{array}$ & apatite \\
\hline & Quick Set Mimix ${ }^{\mathrm{TM}}$ & $\begin{array}{l}\text { Powder: Calcium orthophosphate powders, trisodium citrate; } \\
\text { Solution: citric acid aqueous solution }\end{array}$ & apatite \\
\hline Calcitec (US) & Osteofix & $\begin{array}{l}\text { Powder: calcium orthophosphate and calcium oxide powders; } \\
\text { Solution: phosphate buffer }\end{array}$ & apatite \\
\hline \multirow{5}{*}{ ETEX (US) } & $\alpha-\mathrm{BSM} \mathbb{\circledR} ;$ Embarc; Biobon & $\begin{array}{l}\text { Powder: ACP }(50 \%) \text {, DCPD }(50 \%) \\
\text { Solution: Un-buffered aqueous saline solution }\end{array}$ & apatite \\
\hline & $\beta-\mathrm{BSM} ®$ & $\begin{array}{l}\text { Composition: could not be found (it has apparently a higher compressive } \\
\text { strength and better injectability than } \alpha \text {-BSM } ₫ \text { ) }\end{array}$ & apatite \\
\hline & $\gamma$-BSM ${ }^{\circledR}$ & $\begin{array}{l}\text { Composition: could not be found } \\
\text { (putty consistency) }\end{array}$ & apatite \\
\hline & OssiPro & $\begin{array}{l}\text { Composition: could not be found; } \\
\text { the cement is claimed to be macroporous after hardening }\end{array}$ & apatite \\
\hline & CarriGen & $\begin{array}{l}\text { Composition: synthetic calcium orthophosphate, sodium carboxymethylcellu- } \\
\text { lose, sodium bicarbonate and sodium carbonate }\end{array}$ & apatite \\
\hline \multirow{2}{*}{ Graftys (FR) } & Graftys ${ }^{\circledR}$ HBS & $\begin{array}{l}\text { Powder: mainly } \beta-\mathrm{TCP}, \mathrm{ACP}, \mathrm{BCP}(\mathrm{HA}+\beta-\mathrm{TCP}) \\
\text { Solution: phosphate buffered solution }\end{array}$ & apatite \\
\hline & Graftys ${ }^{\circledR}$ Quickset & $\begin{array}{l}\text { Composition: calcium orthophosphate salts, hydroxypropylmethylcellulose } \\
\text { and orthophosphate-based aqueous solution }\end{array}$ & apatite \\
\hline \multirow{2}{*}{ Kasios (FR) } & Jectos Eurobone ${ }^{\circledR}$ & $\begin{array}{l}\text { Powder: } \beta \text {-TCP }(98 \%), \mathrm{Na}_{2} \mathrm{P}_{2} \mathrm{O}_{7}(2 \%) \\
\text { Solution: } \mathrm{H}_{2} \mathrm{O}, \mathrm{H}_{3} \mathrm{PO}_{4}(3.0 \mathrm{M}), \mathrm{H}_{2} \mathrm{SO}_{4}(0.1 \mathrm{M})\end{array}$ & brushite \\
\hline & Jectos + & $\begin{array}{l}\text { Composition: could not be found } \\
\text { (likely to be close to that of Jectos) }\end{array}$ & brushite \\
\hline Kyphon (US) & $\mathrm{KyphOs}^{\mathrm{TM}}$ & $\begin{array}{l}\text { Powder: } \beta \text {-TCP }(77 \%), \mathrm{Mg}_{3}\left(\mathrm{PO}_{4}\right)_{2}(14 \%), \mathrm{MgHPO}_{4}(4.8 \%), \mathrm{SrCO}_{3}(3.6 \%) \text {; } \\
\text { Solution: } \mathrm{H}_{2} \mathrm{O},\left(\mathrm{NH}_{4}\right) 2 \mathrm{HPO}_{4}(3.5 \mathrm{M})\end{array}$ & apatite \\
\hline \multirow{2}{*}{$\begin{array}{l}\text { Mitsubishi Materials } \\
\qquad(\mathrm{J})\end{array}$} & Biopex ${ }^{\circledR}$ & $\begin{array}{l}\text { Powder: } \alpha \text {-TCP (75\%), TTCP (20-18\%), DCPD (5\%), HA (0-2\%) Solution: } \\
\mathrm{H}_{2} \mathrm{O} \text {, Na succinate (12-13\%), Na chondroitin sulfate }(5-5.4 \%)\end{array}$ & apatite \\
\hline & Biopex ${ }^{\circledR}-\mathrm{R}$ & $\begin{array}{l}\text { Powder: } \alpha \text {-TCP, TTCP, DCPD, } \mathrm{HA}, \mathrm{Mg}_{3}\left(\mathrm{PO}_{4}\right)_{2}, \mathrm{NaHSO}_{3} \\
\text { Solution: } \mathrm{H}_{2} \mathrm{O}, \mathrm{Na} \text { succinate, Na chondroitin sulfate }\end{array}$ & apatite \\
\hline $\begin{array}{l}\text { Produits Dentaires } \\
\text { SA }(\mathrm{CH}) \text { CalciphOs } \\
\quad(\mathrm{CH})\end{array}$ & VitalOs4 & $\begin{array}{l}\text { Solution 1: } \beta \text {-TCP }(1.34 \mathrm{~g}), \mathrm{Na}_{2} \mathrm{H}_{2} \mathrm{P}_{2} \mathrm{O}_{7}(0.025 \mathrm{~g}), \mathrm{H}_{2} \mathrm{O} \text {, salts }(0.05 \mathrm{M} \text { PBS solu- } \\
\text { tion, } \mathrm{pH} \text { 7.4); Solution } 2: \mathrm{MCPM}(0.78 \mathrm{~g}), \mathrm{CaSO}_{4} \cdot 2 \mathrm{H}_{2} \mathrm{O}(0.39 \mathrm{~g}), \mathrm{H}_{2} \mathrm{O}, \mathrm{H}_{3} \mathrm{PO}_{4} \\
(0.05 \mathrm{M})\end{array}$ & brushite \\
\hline $\begin{array}{l}\text { Shanghai Rebone } \\
\text { Biomaterials } \mathrm{Co}(\mathrm{CN})\end{array}$ & Rebone & Powder: TTCP, DCPA; Solution: H2O & apatite \\
\hline $\begin{array}{c}\text { Skeletal Kinetics } \\
\text { (US) }\end{array}$ & Callos ${ }^{\mathrm{TM}}$ & Composition: $\alpha-\mathrm{TCP}, \mathrm{CaCO}_{3}, \mathrm{MCPM}$; Solution: sodium silicate & apatite \\
\hline
\end{tabular}




\begin{tabular}{|c|c|c|c|}
\hline & Callos Inject ${ }^{\mathrm{TM}}$ & $\begin{array}{l}\text { Composition: } \alpha \text {-TCP and unknown compounds } \\
\text { (likely to be close to that of Callos }{ }^{\mathrm{TM}} \text { ) }\end{array}$ & apatite \\
\hline & OsteoVation EX Inject & $\begin{array}{l}\text { Probably similar to Callos Inject }{ }^{\mathrm{TM}} \\
\text { (Product produced by S.K. but sold by OsteoMed) }\end{array}$ & apatite \\
\hline $\begin{array}{l}\text { Stryker (US) Leibin- } \\
\text { ger (GER) }\end{array}$ & BoneSource ${ }^{\mathrm{TM}}$ & $\begin{array}{l}\text { Powder: TTCP }(73 \%) \text {, DCPD }(27 \%) \text {; } \\
\text { Solution: } \mathrm{H}_{2} \mathrm{O} \text {, mixture of } \mathrm{Na}_{2} \mathrm{HPO}_{4} \text { and } \mathrm{NaH}_{2} \mathrm{PO}_{4}\end{array}$ & apatite \\
\hline Stryker (US) & HydroSet $^{\mathrm{TM}}$ & $\begin{array}{l}\text { Powder: TTCP, DCPD, trisodium citrate; Solution: } \mathrm{H}_{2} \mathrm{O} \text {, polyvynilpyrrolidone, } \\
\text { Na orthophosphate }\end{array}$ & apatite \\
\hline \multirow{4}{*}{ Synthes (US) } & $\begin{array}{l}\text { Norian }{ }^{\circledR} \text { SRS Norian }{ }^{\circledR} \\
\text { CRS }\end{array}$ & $\begin{array}{l}\text { Powder: } \alpha \text {-TCP }(85 \%), \mathrm{CaCO}_{3}(12 \%), \operatorname{MCPM}(3 \%) \\
\text { Solution: } \mathrm{H}_{2} \mathrm{O}, \mathrm{Na}_{2} \mathrm{HPO}_{4}\end{array}$ & apatite \\
\hline & $\begin{array}{c}\text { Norian } ® \text { SRS Fast Set } \\
\text { Putty Norian }{ }^{\circledR} \text { CRS Fast } \\
\text { Set Putty } \\
\end{array}$ & $\begin{array}{l}\text { Composition: could not be found } \\
\text { (likely to be close to that of Norian SRS/CRS) }\end{array}$ & apatite \\
\hline & Norian Drillable & $\begin{array}{l}\text { Composition: calcium orthophosphate powder, } \\
\text { bioresorbable fibers and Na hyaluronate solution }\end{array}$ & apatite \\
\hline & chronOS ${ }^{\mathrm{TM}}$ Inject & $\begin{array}{l}\text { Powder: } \beta \text {-TCP (73\%), MCPM (21\%), } \mathrm{MgHPO}_{4} \cdot 3 \mathrm{H}_{2} \mathrm{O}(5 \%), \mathrm{MgSO}_{4}(<1 \%) \text {, } \\
\mathrm{Na}_{2} \mathrm{H}_{2} \mathrm{P}_{2} \mathrm{O}_{7}(<1 \%) \text {; Solution: } \mathrm{H}_{2} \mathrm{O} \text {, Na hyaluronate }(0.5 \%)\end{array}$ & brushite \\
\hline \multirow{2}{*}{ Teknimed (FR) } & Cementek ${ }^{\circledR}$ & $\begin{array}{l}\text { Powder: } \alpha-\mathrm{TCP}, \mathrm{TTCP}, \mathrm{Na} \text { glycerophosphate; } \\
\text { Solution: } \mathrm{H}_{2} \mathrm{O}, \mathrm{Ca}(\mathrm{OH})_{2}, \mathrm{H}_{3} \mathrm{PO}_{4}\end{array}$ & apatite \\
\hline & Cementek ${ }^{\circledR} \mathrm{LV}$ & $\begin{array}{l}\text { Powder: } \alpha \text {-TCP, TTCP, Na glycerophosphate, dimethylsiloxane; } \\
\text { Solution: } \mathrm{H}_{2} \mathrm{O}, \mathrm{Ca}(\mathrm{OH})_{2}, \mathrm{H}_{3} \mathrm{PO}_{4}\end{array}$ & apatite \\
\hline
\end{tabular}

Immediately after implantation, any cement becomes exposed to blood and other tissue fluids that delays the setting time. Intrinsic setting time for apatite cements has been extensively studied and it appeares to be rather long. For example, for the original formulation by Brown and Chow it ranges from 15 to $22 \min [14,15]$. This may result in procedural complications. To remedy this, the amount of liquid might be reduced to a possible minimum. Therefore, all apatite cements look like viscous and easily moldable pastes which tend to be difficult to inject. Besides playing with the $\mathrm{P} / \mathrm{L}$ ratio, the setting time can also be reduced by using additives to the liquid phase (which is distilled water in the Brown-Chow formulation[14,15]). The list of additives includes phosphoric acid, MCPM and other soluble orthophosphates. These additives promote dissolution of the initial solids by lowering the solution $\mathrm{pH}$. In such cases, a setting time in the range of $10-15$ minutes can be obtained[169,171-177,210]. The influence of soluble orthophosphates (e.g., $\mathrm{Na}_{2} \mathrm{HPO}_{4}$ or $\mathrm{NaH}_{2} \mathrm{PO}_{4}$ ) on the setting time of apatite cements is explained by the fact that dissolution of DCPA and formation of CDHA during setting occur in a linear fashion, thus avoiding early formation of CDHA. This is important because too early formation of CDHA might engulf un-reacted DCPA, which slows down DCPA dissolution and thus the setting kinetics becomes slower, while the presence of sodium orthophosphates prevents DCPA particles from being isolated[211]. Particle size[191,212,213], temperature of the liquid phase and initial presence of $\mathrm{HA}$ as a seed in the solid phase are other factors that influence the setting time[14,15,37,207,208]; however, in vitro studies demonstrated that these parameters did not affect significantly[106]. On the other hand, a reduction in particle size was found to result in a significant decrease in both initial and final setting times[191,212,213], an acceleration of the hardening rate[191] and hydration kinetics of the hardening cement[213]. Besides, the crystallite sizes of the final product can be strongly reduced by increasing the specific surface of the starting powder, which allows developing calcium orthophosphate cements with tailored structures at the micro and nano-scale levels[191]. Unfortunately, an unclear correlation was found between the particle dimensions of the initial calcium orthophosphates and mechanical properties of the hardened cements: namely, a significant increase in compressive strength and storage modulus was reported for some formulations[212,213] but a minor effect on compressive strength was discovered for other ones[191]. This inconsistence is not surprising because the manufacturing method used to produce test samples varies from one author to the other. Therefore, the only remaining fact is that calcium orthophosphate cements are brittle and hence worthless for load-bearing applications[197,198].

Setting process of the most types of apatite cements occurs according to just one chemical reaction (see chemical equations (1), (4) - (6)) and at near the physiological pH. The latter may additionally contribute to the high biocompatibility observed for these materials[142-144]. For the classical formulation by Brown and Chow, the transmission electron microscopy results suggested the process for early-stage apatite formation as follows: when TTCP and DCPA powders were mixed in an orthophosphate-containing solution, TTCP powder quickly dissolved due to its higher solubility in acidic media. Then the dissolved ions of calcium and orthophosphate, along with ions already existing in the solution, were precipitated predominantly onto the surface of DCPA particles. Few apatite crystals were observed on the surface of TTCP powder. At a later stage of the reaction, an extensive growth of apatite crystals or whiskers effectively linked DCPA particles together and bridged the larger TTCP 
particles causing the cement setting[214].

However, Norian SRS ${ }^{\circledR}$ and Cementek ${ }^{\circledR}$ were found to set according to two chemical reactions: precipitation of DCPD, followed by precipitation of either $\mathrm{CDHA}$ or carbonatapatite:

$$
\begin{gathered}
\alpha-\mathrm{Ca}_{3}\left(\mathrm{PO}_{4}\right)_{2}+\mathrm{Ca}\left(\mathrm{H}_{2} \mathrm{PO}_{4}\right)_{2} \cdot \mathrm{H}_{2} \mathrm{O}+7 \mathrm{H}_{2} \mathrm{O} \rightarrow \\
4 \mathrm{CaHPO}_{4} \cdot 2 \mathrm{H}_{2} \mathrm{O} \\
5.2 \mathrm{CaHPO}_{4} \cdot 2 \mathrm{H}_{2} \mathrm{O}+3.6 \mathrm{CaCO}_{3} \rightarrow \\
\mathrm{Ca}_{8.8}\left(\mathrm{HPO}_{4}\right)_{0.7}\left(\mathrm{PO}_{4}\right)_{4.5}\left(\mathrm{CO}_{3}\right)_{0.7}(\mathrm{OH})_{1.3} \\
+2.9 \mathrm{CO}_{2}+12 \mathrm{H}_{2} \mathrm{O}
\end{gathered}
$$

The initial chemical reaction (7) was very fast and provoked DCPD formation and setting of the cement pastes within seconds. The second step was slower: DCPD reacted completely within several hours with remaining $\alpha-\mathrm{Ca}_{3}\left(\mathrm{PO}_{4}\right)_{2}$ and $\mathrm{CaCO}_{3}$ forming carbonatapatite according to equation (8). The latter step caused the cement hardening. A similar two-step hardening mechanism was established for a cement consisting of MCPM and $\mathrm{CaO}$ : in the first step, during the mixing time, MCPM reacted with $\mathrm{CaO}$ immediately to give DCPD, which, in the second step, reacted more slowly with the remaining $\mathrm{CaO}$ to give $\mathrm{CDHA}[58]$.

In addition, the setting mechanism of an apatite cement was investigated in details for a three component mixture of TTCP, $\beta$-TCP and MCPM dry powders in convenient proportions and with the overall atomic $\mathrm{Ca} / \mathrm{P}$ ratio equal to 1.67. Two liquid phases in a raw were used to damp the cement powder, initially it was water + ethanol (ethanol was added to slow down the hardening) and afterwards orthophosphoric acid and sodium glycerophosphate were added to water to prepare a reactive liquid[135]. At the very beginning, DCPD was found to form according to two chemical reactions:

$$
\begin{gathered}
\mathrm{Ca}\left(\mathrm{H}_{2} \mathrm{PO}_{4}\right)_{2} \cdot \mathrm{H}_{2} \mathrm{O}+\beta-\mathrm{Ca}_{3}\left(\mathrm{PO}_{4}\right)_{2}+7 \mathrm{H}_{2} \mathrm{O} \rightarrow \\
4 \mathrm{CaHPO} \mathrm{HOH}_{4} \cdot 2 \mathrm{H}_{2} \mathrm{O}
\end{gathered}
$$

$\mathrm{Ca}_{4}\left(\mathrm{PO}_{4}\right)_{2} \mathrm{O}+2 \mathrm{H}_{3} \mathrm{PO}_{4}+7 \mathrm{H}_{2} \mathrm{O} \rightarrow 4 \mathrm{CaHPO}_{4} \cdot 2 \mathrm{H}_{2} \mathrm{O}(10)$

The formation reactions of DCPD were fast and corresponded to the setting stage. Afterwards, TTCP reacted with the previously formed DCPD and with $\beta$-TCP to give CDHA according to the reactions:

$$
\begin{gathered}
2 \mathrm{Ca}_{4}\left(\mathrm{PO}_{4}\right)_{2} \mathrm{O}+2 \mathrm{CaHPO}_{4} \cdot 2 \mathrm{H}_{2} \mathrm{O} \rightarrow \\
\mathrm{Ca}_{10-x}\left(\mathrm{HPO}_{4}\right)_{x}\left(\mathrm{PO}_{4}\right)_{6-x}(\mathrm{OH})_{2-x}+x \mathrm{Ca}(\mathrm{OH})_{2}+(4-x) \mathrm{H}_{2} \mathrm{O} \\
2 \mathrm{Ca}_{4}\left(\mathrm{PO}_{4}\right)_{2} \mathrm{O}+4 \beta-\mathrm{Ca}_{3}\left(\mathrm{PO}_{4}\right)_{2}+(2+2 x) \mathrm{H}_{2} \mathrm{O} \rightarrow \\
2 \mathrm{Ca}_{10-x}\left(\mathrm{HPO}_{4}\right)_{x}\left(\mathrm{PO}_{4}\right)_{6-x}(\mathrm{OH})_{2-x}+2 x \mathrm{Ca}(\mathrm{OH})_{2}
\end{gathered}
$$

The formation reactions of the CDHA phase were quite slow and corresponded to the hardening stage. Although OCP was not detected in that study, its formation as an intermediate phase was postulated for this formulation[135]. A similar suggestion on the intermediate formation of OCP was made for the setting mechanism of Brown-Chow classical cement formulation[101,106]; however, a reliable evidence for its presence is still lacking $[172,215]$. In both cases, OCP was suggested to appear as an intermediate because it was a faster forming phase than CDHA. This hypothesis is based upon the classical studies performed by Prof. W. E. Brown et al., about the precursor phase formation during chemical crystallization of apatites in aqueous solutions[216-218].

Solubility of the hardened apatite cements in aqueous solutions is expected to be rather similar to that of bone mineral. This means that they are relatively insoluble at neutral $\mathrm{pH}$ and increasingly soluble as $\mathrm{pH}$ drops down; this is an important characteristic of normal bone mineral that facilitates controlled dissolution by osteoclasts[206].

To conclude this part, one should mention, that in 2000 the US bone substitute market for Norian SRS ${ }^{\circledR}$ accounted for $15 \%$ of the total sales, followed by BoneSource ${ }^{\mathrm{TM}}$ at $\sim 13 \%$, and $\alpha-\mathrm{BSM}^{\circledR}$ at $\sim 8.5 \%[137]$.

\subsection{Brushite Cements}

As indicated by its name, DCPD is the major end-product of the setting reaction of brushite cements (chemical equations (2) and (3)). Mirtchi and Lemaître[150] and independently Bajpai et al.,[151] introduced this type of the cements in 1987. Up to now, several formulations have been already proposed, e.g., $\beta$-TCP + MCPM[150,152], $\beta-\mathrm{TCP}+\mathrm{H}_{3} \mathrm{PO}_{4}$ $[151,153,154]$ and TTCP $+\mathrm{MCPM}+\mathrm{CaO}[219]$. All brushite cements are set by the acid-base interaction only. As DCPD can only precipitate at the solution $\mathrm{pH}<6$, the paste of brushite cement is always acidic during setting[153,220]. For example, during setting of a $\beta$-TCP + MCPM formulation, the cement $\mathrm{pH}$ varies from very acidic $\mathrm{pH}$ values of $~$ 2.5 , to almost neutral $\mathrm{pH}$ values of $\sim 6.0[153]$. Replacing MCPM by orthophosphoric acid renders the cement paste very acidic for the initial $\sim 30 \mathrm{~s}$ but then the $\mathrm{pH}$ profile follows that obtained with MCPM. It is important to notice, that $\beta$-TCP $+\mathrm{H}_{3} \mathrm{PO}_{4}$ formulations have several advantages over $\beta-\mathrm{TCP}+\mathrm{MCPM}$ formulations, namely: (i) easier and faster preparation, (ii) a better control of the chemical composition and reactivity, (iii) improved physico-chemical properties, such as longer setting times and larger tensile strengths due to a higher homogeneity. However, the use of orthophosphoric acid might impair the biocompatibility of the cement formulation, due to low $\mathrm{pH}$ values during setting[153]. If a cement formulation contains an excess of a basic phase, the equilibrium $\mathrm{pH}$ will be given by the intersection of the solubility isotherms of the basic phase with that of DCPD. For example, the equilibrium $\mathrm{pH}$ values of $\beta$-TCP + MCPM, HA + MCPM and TTCP + MCPM mixtures are 5.9, 4.2 and 7.6, respectively[197,198].

As the solubility of calcium orthophosphates decreases with increasing of their basicity (Table 1 and Fig. 1), the setting time of brushite cements much depends on the solubility of a basic phase: the higher its solubility, the faster the setting time. Therefore, the setting time of the cements made of MCPM + a basic calcium orthophosphate increases in the order: HA $>\beta$-TCP $>\alpha$-TCP $[197,198]$. For example, HA + MCPM mixtures have a setting time of several minutes, $\beta$-TCP + MCPM mixtures - of 30 to 60 seconds and $\alpha-\mathrm{TCP}+$ MCPM mixtures - of a few seconds[150,151]. Follow-up of the chemical composition by ${ }^{31} \mathrm{P}$ solid state NMR enabled to show that the chemical setting process for $\beta$-TCP + MCPM formulation appeared to reach an end after $\sim 20 \min [221]$. Nevertheless, despite this initial high reactivity, the hardening reaction of brushite cements typically lasts one day until 
completion[207,208]. Additives that inhibit the crystal growth of DCPD have successfully been used to increase the setting time of $\beta$-TCP + MCPM mixtures[222]. In contrast to apatite cements, the brushite cements can be initially liquid and still set within a short period of time[197,198].

By itself, brushite is remarkably biocompatible and bioresorbable[220]. Due to both a better solubility of DCPD if compared to that of CDHA (Table 1 and Fig. 1) and metastability of DCPD under physiological conditions[223], after implantation brushite cements are faster degradable than apatite ones[224-226]. They are quickly resorbed in vivo and suffered from a rapid decrease in strength (although the mechanical properties of the healing bone increase as bone ingrowth occurs[35]). Short setting times, low mechanical strength and limited injectability seem to prevent brushite cements from a broader clinical application. However, the major reason why brushite cements are not more widespread is probably not related to the mechanical issues but just to a later arrival on the market. Use of sodium citrate or citric acid as setting retardants is an option to get more workable and less viscous pastes of brushite cements[23,227-230]. Similar effect might be achieved by addition of chondroitin 4-sulfate[231] and glycolic acid[232]. For the cement formulations with orthophosphoric acid as the initial reactant (see chemical equation (3)), acid deficient formulations were also found to improve the workability. In this case, the setting reaction might be described by the following chemical equation[230]:

$$
\begin{gathered}
3.7 \beta-\mathrm{Ca}_{3}\left(\mathrm{PO}_{4}\right)_{2}+\mathrm{H}_{3} \mathrm{PO}_{4}+27.8 \mathrm{H}_{2} \mathrm{O} \rightarrow \\
3 \mathrm{CaHPO}_{4} \cdot 2 \mathrm{H}_{2} \mathrm{O}+2.7 \beta-\mathrm{Ca}_{3}\left(\mathrm{PO}_{4}\right)_{2}+21 \mathrm{H}_{2} \mathrm{O}
\end{gathered}
$$

Although, several studies revealed that too much of DCPD in a given volume was not detrimental to the biological properties of brushite cements[35,206,219], occasionally, when large quantities of brushite cements were used, a certain degree of tissue inflammation during the first weeks of in vivo implantation were reported[226,230,233]. Further investigations indicated that the inflammatory could be due to a partial transformation of DCPD into CDHA with release of orthophosphoric acid[234]:

$$
\begin{gathered}
(10-x) \mathrm{CaHPO}_{4} \cdot 2 \mathrm{H}_{2} \mathrm{O} \rightarrow \mathrm{Ca}_{10-x}\left(\mathrm{HPO}_{4}\right)_{x}\left(\mathrm{PO}_{4}\right)_{6-x}(\mathrm{OH})_{2-x} \\
+(4-x) \mathrm{H}_{3} \mathrm{PO}_{4}+(18-x) \mathrm{H}_{2} \mathrm{O}
\end{gathered}
$$

Transformation of DCPD into CDHA occurs via two successive processes: dissolution and precipitation[235] and can be retarded by adding magnesium ions to the cement paste, thus reducing the possibility of inflammation[197, 198]. The aforementioned case of acid deficient formulations of brushite cements (chemical equation (13)) is an alternative, because it reduces the amount of unreacted acid in the cement[230] with an option to consume liberating in chemical equation (14) orthophosphoric acid by the excess of $\beta$-TCP. Implantation of previously set brushite cement might be the third option, because a solid material was found to be better tolerated than paste implants. Besides, more bone was formed at the solid implant contact and the solid material degraded not so rapidly[236]. For brushite cements, a linear degradation rate of $0.25 \mathrm{~mm} /$ week was reported[237]. This rapid degradation rate might lead to formation of an immature bone. Adding $\beta$-TCP granules to the cement paste could solve this problem because $\beta$-TCP granules might act as bone anchors and encourage formation of a mature bone[237, 238].

\section{Various Properties}

\subsection{Setting and Hardening}

Generally, self-setting calcium orthophosphate formulations must set slowly enough to provide sufficient time to a surgeon to perform implantation but fast enough to prevent delaying the operation. Ideally, good mechanical properties should be reached within minutes after initial setting. Two main experimental approaches are used to study the cement setting process: a batch approach and a continuous approach. In the batch approach, the setting reaction is stopped at various times and the resulting samples are analyzed to determine e.g., the composition and compressive strength of the samples[207, 208]. There are currently two standardized methods to apply this approach, namely, Gillmore needles method (ASTM C266-89)[239] and Vicat needle method (ASTM C191-92)[240]. The idea of both methods is to examine visually the surface of cement samples to decide whether the cement has already set, i.e. if no mark can be seen on the surface after indentation. Besides, the setting process might be monitored in real time by non-destructive methods (the continuous approach), e.g., pulse-echo ultrasound technique[241,242], isothermal differential scanning calorimetry[174,175,243-248] and alternating current (AC) impedance spectroscopy[249]. For example, calorimetry measurements suggested that in equation (2) the endothermic MCPM dissolution and the highly exothermic $\beta$-TCP dissolution occurred simultaneously, followed by the exothermic crystallization of DCPD[247]. Moreover, acid-base reactions (1) - (3) can be and have been analyzed by measuring the $\mathrm{pH}$ evolution of a diluted cement paste[207]. Finally yet importantly, methods of Fourier-transform infrared spectroscopy[24-26,248,250], solid state NMR[221], X-ray diffraction[24,26,50,156,251] and energy dispersive X-ray diffraction[24-26,252,253] might be applied as well. The latter techniques proved to be powerful even though they have limitations such as the time required for each measurement (250 s for an X-ray diffraction scan is a problem for fast setting reactions); besides the analysis is located at the surface of the sample where evaporation and thermal effects can modify the reaction rate of the surface compared to that of the bulk. Furthermore, the continuous approach is an indirect one, which markedly complicates an interpretation of the collected data, particularly in complex cement formulations[207].

A way to assess the rate of a cement hardening is to measure its setting time, which means the time required to reach a certain compressive strength, generally close to 1 $\mathrm{MPa}$. The most straightforward approach is to prepare cement samples with a well-controlled geometry (e.g., cylind- 
ers), incubating these samples for various times in the right environment (temperature, humidity) and assessing the composition and mechanical properties of the samples as a function of time[207]. One should stress, that setting time for calcium orthophosphate cements often corresponds to an earlier stage in the overall setting reaction, typically $5-15 \%$ of the overall reaction, while the end of the cement setting is typically reached after several days[106,172]. Gillmore needles have been used with success to measure the initial $(I)$ and final $(F)$ setting times of calcium orthophosphate cements[99]. Namely, a light and thick needle is used to measure the initial setting time $I$, while a heavy and thin needle for the final setting time $F[134]$. The clinical meaning is that the cement paste should be implanted before time $I$ and that the wound can be closed after time $F$ (Fig. 4).

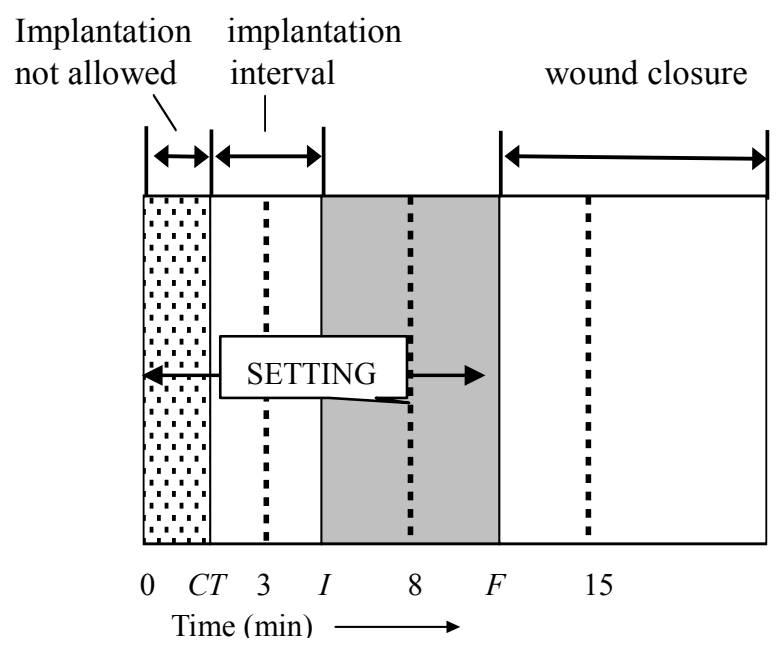

Figure 4. A diagram of the setting parameters relevant for a self-setting calcium orthophosphate cement: $C T$ - cohesion time; $I$ - initial setting time; $F$ - final setting time. Adapted from Ref. [29] with permission

The cement should not be deformed between times $I$ and $F$ because in that stage of the setting process any deformation could induce cracks[29]. The following handling requirements (in minutes) have been formulated for calcium orthophosphate cements, as a result[134,254]:

$$
\begin{gathered}
3 \leq I<8 \\
I-C T \geq 1 \\
F \leq 15
\end{gathered}
$$

These parameters are represented schematically in Fig. 4. The second requirement means, that the cohesion time $(C T)$ must be at least $1 \mathrm{~min}$ before $I$, so that a clinician has at least $1 \mathrm{~min}$ to apply and to mold the material. $C T$ is the time from which a cement no longer disintegrates when immersed in Ringer's solution[134]. As the mixing in a mortar is about 1 min, the shortest $C T$ that can be allowed is about $2 \mathrm{~min}$, so that a clinician has at least $1 \mathrm{~min}$ to collect the paste from the mortar and put it on a pallet knife or into a syringe with which it is to be transferred to the wound after $C T$ and before $I[134]$. For dental applications, time $I$ must be close to $3 \mathrm{~min}$, whereas for orthopedic applications it must be close to $8 \mathrm{~min}$. However, in no case it will be tolerable for the clinicians if time $F$ becomes greater than $15 \min [29,134]$.

\subsection{Mixing}

In the clinical situation, self-setting calcium orthophosphate formulations can be either applied by the fingertips of a surgeon or injected from a syringe to the defect area of a bone. The first type of the clinical application requires formulation of high-viscosity cement pastes and putties, which can be applied manually as dough, while the second type requires formulation of low-viscosity compositions, which can be applied by injection from a syringe[134]. Currently, injection appears to be the preferred method between these two major options. Thus, a trade-off must be found between a high viscosity leading to too high injection forces and a low viscosity increasing the risk of cement extravasations. Viscosity values in the range of $100-2000 \mathrm{~Pa} \cdot \mathrm{s}$ are generally considered to be adequate[255].

In any case, before using a surgeon needs to have a cement powder and a liquid be mixed properly and thoroughly (to avoid the powder/liquid encapsulation) within the prescribed time. This process must be performed in a sterile environment. Therefore, a mixing procedure is very important because prior to be injected, a cement paste must be transferred from a mixing chamber into a syringe. Ideally, this should be done without trapping air bubbles by the cement paste[256]. Earlier, most calcium orthophosphate cements were manually mixed with aqueous solutions using a mortar and either a pestle or a spatula. That time, some concerns were raised about an insufficient and inhomogeneous mixing thus compromising the implant strength, as well as on inconsistencies between operators causing unpredictable variations in graft performance[257]. Mechanical mixing (e.g., by either an electrically powered mixing machine of Norian SRS/CRS ${ }^{\circledR}$ or Mini-malax ${ }^{\circledR}$ mixing system for Cementek ${ }^{\circledR}$ cement, produced by Teknimed S.A.) is the modern approach. It allows mixing the cement paste within $60-80 \mathrm{~s}$ and enables a rapid and reliable filling of the application syringe[34]. Besides, a cement powder and an aqueous solution might be placed into a syringe and mixed inside a shaker to produce a consistent cement paste of the desired viscosity[256]. A mechanical mixing was found to decrease both the mean viscosity of the curing cement paste and variability in the viscosity at a given time[258]. However, it did not improve the mechanical strength of the cement[197,198].

Of the commercial formulations, listed in Table 2, Norian $\mathrm{SRS}^{\circledR}$ is sold as a reactant pack containing two components: a mixture of dry powders $\left(\mathrm{MCPM}+\alpha-\mathrm{TCP}+\mathrm{CaCO}_{3}\right)$ and a liquid (aqueous solution of $\mathrm{Na}_{2} \mathrm{HPO}_{4}$ ). The components are mixed in the operating room. The paste that is formed is malleable and injectable for $\sim 5$ minutes; it hardens within $\sim$ 10 minutes after injection[22,206]. However, data are available that out of $4.5 \mathrm{ml}$ Norian $\mathrm{SRS}^{\circledR}$ cement paste $\sim 3 \mathrm{ml}$ is injectable only, whereas up to $1.5 \mathrm{ml}$ of the cement might remain uninjectable from the syringe[29]. This phenomenon is prescribed to the cement rheology and its interaction with the hydraulic forces of the syringe. $\alpha$-Bone Substitute Material $\left(\alpha-\mathrm{BSM}^{\circledR}\right)$ is also a two-component system; it is prepared from a mixture of ACP and DCPD powders and a 
saline solution[169]. Biopex ${ }^{\circledR}$ consists of four different calcium orthophosphates: 75 wt. $\% \alpha$-TCP, 18 wt. \% TTCP, 5 wt. $\%$ DCPD and 2 wt. \% HA. The aqueous solution contains 12 wt. \% sodium succinate and 5 wt. \% sodium chondroitin sulfate[259]. Effects of liquid phase on the basic properties of Biopex ${ }^{\circledR}$ were investigated. When mixed with neutral sodium hydrogen orthophosphate or succinic acid disodium salt solution, the initial setting times of the cement were 19.4 \pm 0.55 and $11.8 \pm 0.45$ minutes, respectively. These setting times were much shorter than that of distilled water, $88.4 \pm$ 0.55 minutes[260]. Biopex ${ }^{\circledR}$ is mixed with a spatula inside a syringe that can be opened from the front. After mixing, the front part is closed, a needle is inserted into this front part and the cement paste can be manually injected[197,198].

Several systematic studies on the influence of composition and concentration of the liquids used in preparing of calcium orthophosphate cements were performed as well[23,227]. Unfortunately, the results appeared to be rather unclear. For example, for several cements, mixing with sodium citrate or citric acid resulted in some effects on the initial setting time[23,228], while for other cements the effect was insignificant[227]. Concentration increasing of sodium citrate solution resulted in initial setting time increasing[23,227], although the injectability variations of the cement pastes were inconsistent[23,228].

\subsection{Rheological Properties of the Self-Setting Formulations}

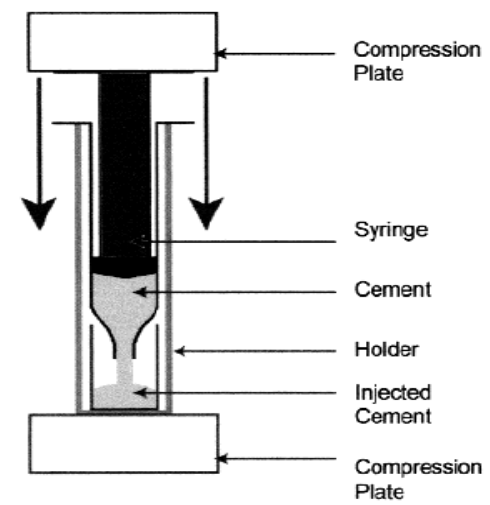

Figure 5. A schematic representation of the experimental setup used to quantify the injectability of the calcium phosphate cements. Reprinted from Ref. [267] with permission

Good injectability, adequate viscosity and satisfactory cohesion are required for the successful biomedical applications of the self-setting calcium orthophosphate formulations[261,262]. Injectability is an ability of a paste to be extruded through a small hole of a long needle (e.g., $2 \mathrm{~mm}$ diameter and $10 \mathrm{~cm}$ length)[263,264] (other needles are also applied[265,266]); and for certain applications, injectability is even a prerequisite. It is measured by the weight percentage of the cement paste that could be injected without demixing from a standard syringe by either a hand or a force of $100 \mathrm{~N}$ maximum (Fig. 5). Usually, injectability of a cement paste varies inversely with its viscosity, the $\mathrm{P} / \mathrm{L}$ ratio, as well as the time after starting the mixing of liquid and powd- er[56,264,267]. Furthermore, injectability is improved with smaller particle sizes, with shorter and larger diameter cannula, as well as at smaller flow rates[263]. Moreover, particle shape of the powder is also expected to have effects on the injectability. Namely, powders with spherical shape or round particles may contribute good injectability. Spherical powder itself is easy to roll and thus good handling properties and injectability are found when a paste is prepared using spherical powder. Besides, it should be noted that the paste could become fluid with less amount of liquid phase since no captured liquid exists in the case of spherical powder[268].

Unfortunately, when a cement paste, which is a biphasic mixture of a finely divided ceramic (powder, granules) and a liquid, is submitted to a pressure gradient, the liquid may flow faster than the solid, resulting in local changes of the paste composition. Specifically, the paste present in the region of the highest pressure (e.g., close to the plunger of a syringe) may become so depleted in liquid that the biphasic mixture in this zone is not longer a paste but a wet powder[263,265]. Contrarily, the paste in the zone of the lowest pressure (e.g., at the cannula tip) is enriched in liquid. Since these effects are dynamic, the size of the zone depleted in liquid (wet powder) increases during injection, eventually reaching the tip of the injection device and plugging it. The phenomenon, in which the pressure applied to the cement paste provokes a phase separation after a certain injection time, is generally referred as filter pressing, phase separation or phase migration[125] (see the aforementioned example for Norian $\operatorname{SRS}^{\circledR}$ [29], in which a thick mass remained inside a syringe).

Possible mechanisms underlying the limited injectability of hydraulic calcium orthophosphate cements have been discussed in literature[266,269]. In the case of demixing, the exact composition of the extruded part of the paste becomes unknown. Moreover, due to a deviation from the initial P/L ratio, it becomes unclear whether the setting behavior and the mechanical and histological properties of the extruded part are still clinically acceptable. Therefore, a good cohesion of the paste is necessary in order to avoid these problems[270].

Cohesion (= cohesiveness, "non-decay") is the ability of a paste to keep its geometrical integrity in an aqueous solution[125]. For cements, a bad cohesion may prevent setting and may lead to negative in vivo reactions due to the release of microparticles[271]. Since a high cohesion is the result of strong attractive forces among the particles, factors enhancing van der Waals forces (attractive) and decreasing electrostatic forces (repulsive) can be used to improve cohesion[125]. For example, an appropriate cohesion was achieved when no disintegration of the cement paste was observed in the fluid[134,270]. This can be accomplished by keeping a high viscosity for the cement paste[22] or using cohesion promoters (e.g., $1 \%$ aqueous solution of sodium alginate[176,272,273] and other chemicals[176,274-276]). Some calcium orthophosphate cements fulfill both criteria, e.g., Norian SRS ${ }^{\circledR}$, but others fulfill only one or even none of these requirements. For example, BoneSource ${ }^{\mathrm{TM}}[103]$ and Cementek $^{\circledR}$ are not injectable and blood must be kept away 
from the implanting site until setting[197, 198]. A poor cohesion has been associated to a poor biocompatibility that might lead to inflammatory reactions[271]. Further details on the cohesion properties of various calcium orthophosphate pastes are available in literature[270].

Viscosity is a measure of the resistance of a fluid, which is being deformed by either shear stress or tensile stress. Generally, the cement viscosity in the range of $100-1000 \mathrm{~Pa} \cdot \mathrm{s}$ appears to be ideal[277] and, if possible, a cement should have a constant viscosity in the indicated range. Unfortunately, cement viscosity is not a constant value, which, after a decrease in the first seconds after mixing, increases considerably during curing, eventually leading to hardening. Furthermore, viscosity should be high enough to prevent extravasation; therefore, it is very important to define an adequate injection window[277].

\subsection{Properties Improving}

As written above, properties of the existing self-setting calcium orthophosphate formulations are not ideal. Several ways can be adopted to improve them. The first approach consists of injectability improvement. There are two options for this. Firstly, the injection device can be modified. For example, shorter cannulas with a larger diameter, as well as smaller injection rates favor a good injectability. The last option is not so straightforward: for example, Habib et al. have shown that large injection rates are not detrimental to injectability because of the shear-thinning behavior of many calcium orthophosphate cements[266]. Secondly, the cement composition can also be adapted. Namely, a decrease of the particle size, the $\mathrm{P} / \mathrm{L}$ ratio and the plastic limit was found to contribute to a better injectability[263,267]. For example, injectability was found to be unaffected by $\mathrm{P} / \mathrm{L}$ ratio within the range of $3.85-4.50 \mathrm{~g} / \mathrm{ml}$ but drops by nearly $100 \%$ between $\mathrm{P} / \mathrm{L}$ ratio of 4.50 and $5.00 \mathrm{~g} / \mathrm{ml}$ [23]. However, a decrease in $\mathrm{P} / \mathrm{L}$ ratio leads to a decrease in the mechanical properties of the cements and cohesion might be destroyed. Furthermore, both the initial and final setting times decreased markedly with the $\mathrm{P} / \mathrm{L}$ ratio increasing[227,278]. Therefore, variations in the $\mathrm{P} / \mathrm{L}$ ratio appear to be valid to a certain extent only. That is why the manufacturer of Biopex ${ }^{\circledR}$ suggests using a $\mathrm{P} / \mathrm{L}$ ratio of 2.8 or $3.3 \mathrm{~g} / \mathrm{ml}$.

Particle size decreasing of calcium orthophosphate crystals is the second approach for the injectability improvement. For example, $\alpha-\mathrm{BSM}^{\circledR}$ is well injectable because it consists of small particles. Even though small particles require a larger amount of mixing liquid to obtain a paste, injectability and cohesion of the cements are generally very good[197, 198]. An indirect approach is to add calcium orthophosphate particles those act as spacers between other particles. For example, DCPA is added to the formulation of Biocement $\mathrm{D}^{\circledR}$ to improve injectability[197,198]. Similarly, there is an apatite cement containing spherical particles of TTCP to improve injectability[279].

Using various additives (this approach transforms cements into composites) is the second way to improve the physical properties of calcium orthophosphate cements[280]. For example, water demand of calcium orthophosphate cements can be reduced by ionically modifying the liquid component, e.g., by adding nontoxic sodium salts of $\alpha$-hydroxy di- and tri- acids[281,282]. A list of additives, that have been already studied, includes fluidificants, air-entraining agents, porogens, workability-improvement agents, setting time controllers and reinforcing additives[162,203,283]. Besides, various radiopacifiers might be used to simplify an un- invasive in vivo monitoring of the implanted cements[284287]. The main role of fluidificants is to reduce a mixing time of the cement. Citric acid is an example of this reagent; it retards the dissolution-precipitation reactions in cements, decreases the compressive strength during initial setting, but increases its strength in the final stages of the cement hardening[228]. Furthermore, data are available, that citric acid decreases the setting time and improves the mechanical properties of the hardened cements[288]. Adding of surfactants to calcium orthophosphate cements was found to have two different meanings: they might act as both air- entraining agents by lowering the surface tension[289,290] and interaction modifiers by shifting the isoelectric point[291].

Besides, studies are available, in which calcium orthophosphate cements have been modified by various bioorganic compounds in attempts to influence the bone healing process[292-295]. For example, in a recent study, a calcium orthophosphate cement was set in the presence of cocarboxylase, glucuronic acid, tartaric acid, $\alpha$-glucose-1- phosphate, L-arginine, L-aspartic acid and L-lysine, respectively, with the aim to influence formation and growth of CDHA crystals through the functional groups of these biomolecules[295]. Except for glucuronic acid, all these modifications were found to result in the formation of smaller and more agglomerated CDHA particles, which had a positive impact on the biological performance indicated by first experiments with the human osteoblast cell line hFOB 1.19. Moreover, initial adhesion of human bone marrow-derived mesenchymal stem cells was improved on the cement modifications with cocarboxylase, arginine and aspartic acid. Furthermore, cell proliferation was enhanced on the cement formulations modified with cocarboxylase and arginine whereas osteogenic differentiation remained unaffected. Besides, the cement modifications with arginine and aspartic acid, but not with cocarboxylase, led to a higher BMP-2 binding[295].

Porosity is a very important property to provide good in vivo bioresorption of implanted biomaterials. Thus, various air-entraining agents and porogens are commonly used to induce macroporosity inside calcium orthophosphate cements without affecting their normal setting. For example, crystals of mannitol, $\mathrm{CH}_{2} \mathrm{OH}(\mathrm{CHOH})_{4} \mathrm{CH}_{2} \mathrm{OH}$, were tested as an air-entraining agent; however, both loss of workability during the cement mixing and severe depreciation of mechanical properties were discovered simultaneously[296301]. Other porogenic agents (e.g., oxygen peroxide[302] in the liquid phase and/or iced[303], sucrose granules, $\mathrm{NaHCO}_{3}$ 
and $\mathrm{Na}_{2} \mathrm{HPO}_{4}$ crystals of $125-250 \mu \mathrm{m}$ in size[304], poly(D,L-lactic-co-glycolic acid) microparticles with the average size of $66 \pm 25 \mu \mathrm{m}[305-310]$, pectin microspheres [311], calcium sulfate[46], calcite[219], $\mathrm{NaCl}$ crystals varying in size from $420 \mu \mathrm{m}$ to $1 \mathrm{~mm}[312,313]$, gelatin microspheres[314,315], vesicants[316], cetyltrimethyl ammonium bromide[317], polytrimethylene carbonate[318], some immiscible liquids) have been also tested to create porosity. These additives could be applied on pre-set cements only, while the solubility degree of the particulates during the setting reaction influences both the content and dimensions of the macroporosity. After cement hardening, dissolution of the remaining soluble porogens in either water or body fluids produces macropores with the dimensions and shapes of the dissolved crystals. One important limitation that can be envisaged from this route is the need to add a large amount of porogenic agent to guarantee interconnectivity of the porosity, thus compromising not only the excellent biocompatibility and bioactivity of calcium orthophosphate cements but also the cements' injectability. Another shortcoming is the lack of strength of the resulting material, especially if particulates dissolve quickly, greatly limiting its applications. An innovative approach that aims at overcoming the lack of interconnectivity and initial strength consists in using resorbable fibers[319-326]. These fibers have the function of reinforcing the cement, providing the needed short-term strength and toughness, and gradually dissolving afterwards, leaving behind macropores suitable for bone ingrowth. One interesting advantage of long fibers over particulates and short fibers is the fact that once resorbed they can form interconnected pores inside the cement structure facilitating bone tissue regeneration[327].

One more approach consists in adding solid $\mathrm{NaHCO}_{3}$ to the starting cement powder and using two different liquids: first, a basic liquid to form the paste, and later an acid liquid to obtain $\mathrm{CO}_{2}$ bubbles to create porosity[328]. Besides, pore forming $\mathrm{CO}_{2}$ bubbles appear at hardening of an apatite cement, consisting of an acidic calcium orthophosphate, such as MCPM or DCPD, and either $\mathrm{CaCO}_{3}[33,53-55]$ or $\mathrm{NaHCO}_{3}$ [329-331]. Furthermore, addition of an effervescent porogen formulation comprised from $\mathrm{NaHCO}_{3}(54.52 \%)$ and citric acid monohydrate (45.48 \%) has been suggested [332]. More to the point, the liquid phase of a cement formulation might be foamed and subsequently mixed with the powder phase. Further, the setting reactions of a calcium orthophosphate cement transforms the liquid foam into a solid, which ideally maintains the geometry, size and shape of the bubbles of the liquid foam. Thus, the liquid foam acts as a template for the macroporosity of the solid foam[333, 334]. In addition, several other porosity creation techniques in calcium orthophosphate cements are known and, for further details on the subject, the interested readers are referred to an excellent review[327].

The major examples of workability-improvement agents, which are added to the cement powders, include water-soluble polymers. Specifically, polysaccharides[97,108, 335-338], gelatin[278,339-345] and polyacrylic acid[346-
348] are of an interest due to their biocompatibility and good rheological properties. Only small amounts (a few weight \%) are needed to dramatically increase the viscosity of the cement pastes. Besides, the cement paste becomes more cohesive and highly resistant to washout immediately after mixing. For example, a 5 wt. \% sodium chondroitin sulfate solution is used as mixing liquid in Biopex ${ }^{\circledR}[197,198]$. In the case of gelatin, more than a $50 \%$ improvement of the compressive strength was detected[341]. The gelatin-cement after setting was found to exhibit reduced crystallinity, much smaller CDHA crystals and a more compact microstructure; all these phenomena might be accounted for the improved mechanical properties[342]. The presence of gelatin improved mechanical properties of the cements; in particular, calcium orthophosphate cements containing $2 \mathrm{wt}$ \% gelatin were found to harden in an acceptable time and were recommended for clinical applications[345]. In general, the use of gelling agents widened a possible application of calcium orthophosphate cements because these cements can be used even when complete homeostasis is difficult. In some cases addition of a gelling agent might cause an increase in hardening time[349] but this was remedied by the use of a sodium orthophosphate solution as the cement liquid[143,144]. Most polysaccharide solutions are thixotropic, i.e., the viscosity of the solution decreases as the shear rate increases. Certain polysaccharides, such as sodium alginate, pectize in contact with calcium ions. This property can be used to make putty-like cement pastes[22]. However, only few polysaccharides are accepted for parenteral use[197,198].

Of two families of calcium orthophosphate cements, brushite cements react generally much faster than apatite ones. As a result, to satisfy the clinical requirements (Fig. 4), the setting time of brushite cements has to be prolonged, whereas that of apatite cements has to be shortened[197,198]. In general, setting reactions of any calcium orthophosphate cements consist of three successive stages: (1) dissolution of reactants to saturate the mixing liquid in calcium and orthophosphate ions; (2) nucleation of crystals; (3) growth of crystals. Therefore, experimental approaches to modify the setting reaction of calcium orthophosphate cements are to be targeted to these three stages. The available approaches have been summarized in Table 4[207]. Furthermore, seven strategies have been described to control the setting time of calcium orthophosphate cements[208]. They are: (i) mean particle size decreasing of the initial powders; (ii) the $\mathrm{P} / \mathrm{L}$ ratio increasing; (iii) $\mathrm{pH}$ drop of the mixing liquid to increase calcium orthophosphate solubility and hence accelerate the chemical transformations; (iv) a nucleating phase addition, such as a nano-sized HA powder; (v) adding orthophosphate and/or calcium ions into the mixing liquid to accelerate the setting reaction according to the common-ion effect; (vi) solubility reducing of the reaction end-product, for example, by adding fluoride ions into the mixing liquid; (vii) solubility increasing of the starting material by amorphization, e.g., by prolonged milling. For further details on these strategies and approaches, as well as for application examples, the interested readers are referred to the original papers[207, 208]. 
Table 4. List of strategies and approaches to modify reactivity of calcium orthophosphate cements[207]

\begin{tabular}{|c|c|c|}
\hline Strategy & Approach & Sub-approaches \\
\hline \multirow{8}{*}{ 1. Dissolution rate } & \multirow{2}{*}{ 1.1. Change contact area between reagent and mixing liquid } & 1.1.1. Change milling duration \\
\hline & & 1.1.2. Use nano- or micron-sized powders \\
\hline & \multirow{2}{*}{ 1.2. Change solubility in the mixing liquid } & 1.2.1. Use more/less soluble phase \\
\hline & & 1.2.2. Change of reaction $\mathrm{pH}$ \\
\hline & 1.3. Change saturation of the mixing liquid & \\
\hline & 1.4. Use dissolution inhibitors in the mixing liquid & \\
\hline & \multirow{2}{*}{ 1.5. Modify reagent surface } & 1.5.1. Chemical change (pre-reaction) \\
\hline & & 1.5.2. Physical change (dissolution pits) \\
\hline \multirow{4}{*}{ 2. Nucleation rate } & 2.1. Use crystallization nuclei & \\
\hline & \multirow{2}{*}{ 2.2. Change the saturation of the reaction product in the mixing liquid } & 2.2.1. Change of saturation \\
\hline & & 2.2.2. Change of end-product solubility \\
\hline & 2.3. Use nucleation inhibitors & \\
\hline \multirow{3}{*}{ 3. Growth rate } & \multirow{2}{*}{ 3.1. Change the saturation of the reaction product in the mixing liquid } & 3.1.1. Change of saturation \\
\hline & & 3.1.2. Change of end-product solubility \\
\hline & 3.2. Use crystal growth inhibitors & \\
\hline
\end{tabular}

Various setting time controllers (accelerators and retardants) are used to influence the setting time. They include sodium hydrogen pyrophosphate $\left(\mathrm{Na}_{2} \mathrm{H}_{2} \mathrm{P}_{2} \mathrm{O}_{7}\right)$ and magnesium sulfate (according to another study, ions of citrate, sulfate and pyrophosphate are necessary[222]), which are added in amounts $<1$ wt. \%[350]. Application of biocompatible $\alpha$-hydroxylated organic acids (glycolic, lactic, malic, tartaric and citric acids) and their calcium and sodium salts for modification of both rheological and setting properties of calcium orthophosphate cements is well described elsewhere[351,352]. Besides, aqueous solutions of sodium orthophosphates[97,211,309,353-356] and gelatinized starch [357] are also known as setting time accelerators. An extensive list of the compounds, which might be suitable as accelerators, retarders, additives or reactants in calcium orthophosphate cement formulations, might be found in literature[99]. Interestingly, but in some cases a simple thermal treatment of the initial reagents (in that particular case, $\alpha$-TCP powder) at $\sim 500^{\circ} \mathrm{C}$ could extend the initial part of the setting reaction from a few minutes to a few hours hence providing a potential approach to better control the setting process[358].

The subject of the reinforcing additives is discussed in details below in section 7. Reinforced self-setting formulations and concretes.

Concerning storage stability and shelf life, the factors, significantly influencing these properties for the initial dry powders of calcium orthophosphate cements, were found to be temperature, humidity and a mixing regime of the powders. Various storage conditions appeared to be effective in prolonging the stability of dry brushite cements. In the order of effectiveness, they were ranged: adding solid citric acid retardant $>$ dry argon atmosphere $\approx$ gentle mixing (minimal mechanical energy input) $\gg$ low temperature[354]. Finally, the cement formulations must be sterilized before a clinical use. A detailed description of the sterilization techniques for calcium orthophosphate cements might be found elsewhere [359].

\section{Bioresorption and Replacement of the Self-Setting Formulations by Bones}

Due to the excellent bioresorbability of DCPD and CDHA, a newly forming woven bone might substitute the hardened calcium orthophosphate cements. For example, the implants made of hardened BoneSource ${ }^{\mathrm{TM}}$ (an apatite cement) were partly resorbed and replaced by natural bone, depending upon the size of the cranial defect[103]. Replacement of BoneSource ${ }^{\mathrm{TM}}$ by bone with a minimal invasion of connective tissue was detected in another study, while ChronOS ${ }^{\mathrm{TM}}$ Inject (a brushite cement) samples exhibited a higher rate of connective tissue formation and an insufficient osseointegration[360]. $\alpha-\mathrm{BSM}^{\circledR}$ was evaluated in a canine femoral slot model. New bone was found to form in 3 weeks via an osteoconductive pathway. After 4 weeks, only $1.7 \%$ of the implanted material was observed. The hybrid bone possessed the strength of normal, unoperated bone after 12 weeks. In 26 weeks, the boundary between old and new bones was virtually indistinguishable, with only $0.36 \%$ of the implant recognizable[169]. Neither influence on general health, limb specific function and pain, nor associated complications with $\alpha-\mathrm{BSM}^{\circledR}$ application were found past 2 years in another study[361]. Norian SRS ${ }^{\circledR}$ was evaluated in canine tibial and femoral metaphyseal defects. The cement appeared to be gradually remodeled over time, with blood vessels penetrating through it. However, some amounts of Norian SRS ${ }^{\circledR}$ were detected in the 
medullary area as long as 78 weeks after being implanted in dog femurs[32]. An interesting study on the in vitro resorption of three apatite cements (conventional, fast-setting and anti-washout) by osteoclasts if compared with a similar resorption of sintered HA and a cortical bone revealed an intermediate behavior of the cements: they were resorbed slower than bone but faster than HA[362]. Furthermore, bone neo-formation was seen 7 seven days after implantation of an $\alpha$-TCP cement[363]. The biodegradation rate of the cements might be influenced by ionic substitutions in calcium orthophosphates[364]. Evidences of the direct contact of bone and a calcium orthophosphate cement without soft tissue interposition might be found in literature[ $[365,366]$.

Different studies reported on both cement bioresorption and the progress of bone formation around calcium orthophosphate cements which in certain cases demonstrated both osteoconductive and osteoinductive properties[367]. However, there are studies in which the osteoinductive properties of calcium orthophosphate cements were not confirmed[368]. Besides, inflammatory reactions were noticed when the cement did not set[271]. As solubility of a non-stoichiometric CDHA is higher than that of stoichiometric HA, $\alpha$ - and $\beta$-TCP (Table 1) and the particle dimensions of a precipitated CDHA is smaller than those of sintered calcium orthophosphates, the biodegradability of apatite cements is always better than that of dense bioceramics made of the sintered stoichiometric calcium orthophosphates. For example, histologically, at 2 weeks, spicules of living bone with normal bone marrow and osteocytes in lacunae could be seen in an implanted cement. At 8 weeks, the cement was almost totally surrounded by mature bone. At this stage, no resorption of the cement was observed[369]. Only $30 \%$ decrease of the implanted amount of Norian SRS ${ }^{\circledR}$ was reported after 24 months in a rabbit femur[370]. Moreover, several differences could be expected depending on the cement type. For example, as the end-product of BoneSource ${ }^{\mathrm{TM}}$ and Cementek ${ }^{\circledR}$ is a crystalline CDHA, BoneSource ${ }^{\mathrm{TM}}$ and $\mathrm{Cementek}^{\circledR}$ are expected to resorb slower than other apatite cements. Indeed no resorption of BoneSource ${ }^{\mathrm{TM}}$ was observed after several years implantation; though some resorption of Biobone ${ }^{\mathbb{R}}$ was detected. However, porosity appears to be the main biodegradability factor at play: a more porous (for cells) hardened cement degrades faster than a less porous one[371]. For example, as Biobone ${ }^{\circledR}$ is more porous than BoneSource ${ }^{\mathrm{TM}}$, the discovered diversity could be due to the differences in the cement porosity[197,198]. The latter conclusion is confirmed by the results of other studies: a positive influence of the cement porosity on the resorption rate was found[273]. The interested readers are referred to the study on the suitability of porous calcium orthophosphate cements as scaffold material for bone regeneration, using a rabbit model[372].

The resorption properties of bioceramics are generally believed to relate to the solubility of their constitutive phases. The implanted calcium orthophosphates might be resorbed by two possible mechanisms, namely: an active resorption, mediated by the cellular activity of macrophages, osteoclasts and other types of living cells (so called phagocytosis or literally "cell-eating")[373-375] and a passive resorption due to either chemical dissolution[11] or chemical hydrolysis (brushite cements only)[230] in the body fluids. Unfortunately, the factors concerning the biodegradation of calcium orthophosphate biomaterials have not been completely elucidated yet. The chemical composition, physical characteristics and crystal structures certainly play an important role in the biological behavior of calcium orthophosphates. In addition, biodegradation may be influenced by the conditions, such as experimental models, implantation sites and animal species[374].

The data are available that macrophages and giant cells decompose quickly resorbed calcium orthophosphates (e.g., brushite cements)[226], while slowly (from months to years) resorbed apatite cements are decomposed by osteoclast-type cells[30,209,376]. Clearly, a fast resorption of brushite cements can only be achieved if the resorption occurs before conversion DCPD to CDHA according to equation (14)[48]. Both types of the resorption mechanisms (active + passive) might occur almost simultaneously, if a hardened cement consists of two different calcium orthophosphates, e.g., from DCPD and $\beta$-TCP. For example, the biphasic brushite cement ChronOSTM Inject was found to resorb by dissolution with cement disintegration and particle formation followed by the phagocytosis of the cement particles through macrophages[377]. A similar cement was found to be degraded through a dissolution process associated with a cellular process. The observations suggested that cell activities could be influenced by a small particle size, without close correlation between the particle size and the cell activities but with a correlation between particle concentration and the cell activities[374]. To get further details on this topic, the interested readers are referred to a very interesting review on the cellular mechanisms of calcium orthophosphate ceramic degradation[378].

The summary of studies on brushite cement implantation in various animal models and defect locations is available in literature[230]. Generally, in the same animal model, a degradation rate decreases with a sample size increases, as does DCPD to CDHA conversion time. The compositional changes of a brushite cement after implantation in sheep is well described elsewhere[350,379].

The kinetics of passive resorption depends on porosity of the samples, ionic substitutions in calcium orthophosphates (when applicable), crystallinity and $\mathrm{pH}$ of the cement-tissue interface. The active resorption is due to cellular activity; however, it is also related to the passive one. Namely, the solution $\mathrm{pH}$ near macrophages and osteoclasts can drop to 5 by excretion of lactic acid, which increases the solubility (Fig. 1), whereas near osteoblasts (bone forming cells) solution $\mathrm{pH}$ can become as high as 8.5 by excretion of ammonia[29]. Dissolution chemistry of CDHA (therefore, of hardened apatite cements) in acidic media (calcium orthophosphates are almost insoluble in alkaline solutions (Fig. 1)) might be described as a slightly modified sequence of 
four successive chemical equations[380, 381]:

$$
\begin{gathered}
\mathrm{Ca}_{10-x}\left(\mathrm{HPO}_{4}\right)_{x}\left(\mathrm{PO}_{4}\right)_{6-x}(\mathrm{OH})_{2-x}+(2-x) \mathrm{H}^{+} \rightarrow \\
\mathrm{Ca}_{10-x}\left(\mathrm{HPO}_{4}\right)_{x}\left(\mathrm{PO}_{4}\right)_{6-x}\left(\mathrm{H}_{2} \mathrm{O}\right)_{2-x}{ }^{(2-x)^{+}} \\
\mathrm{Ca}_{10-x}\left(\mathrm{HPO}_{4}\right)_{x}\left(\mathrm{PO}_{4}\right)_{6-x}\left(\mathrm{H}_{2} \mathrm{O}\right)_{2-x}{ }^{(2-x)^{+}} \rightarrow 3 \mathrm{Ca}_{3}\left(\mathrm{PO}_{4}\right)_{2} \\
+(1-x) \mathrm{Ca}^{2+}+(2-x) \mathrm{H}_{2} \mathrm{O} \\
\mathrm{Ca}_{3}\left(\mathrm{PO}_{4}\right)_{2}+2 \mathrm{H}^{+} \rightarrow \mathrm{Ca}^{2+}+2 \mathrm{CaHPO}_{4} \\
\mathrm{CaHPO}_{4}+\mathrm{H}^{+} \rightarrow \mathrm{Ca}^{2+}+\mathrm{H}_{2} \mathrm{PO}_{4}^{-}
\end{gathered}
$$

Obviously, the dissolution chemistry of DCPD (therefore, of hardened brushite cements) in acidic media is described by equation (18). One should stress, that in equation (18) water is omitted for simplicity. Therefore, dissolution of DCPA is written instead.

The mechanism of bone healing caused by calcium orthophosphate cements is very multifactorial because the surface of the cements is rapidly colonized by cells. Several types of these cells degrade calcium orthophosphates by either phagocytotic mechanisms (fibroblasts, osteoblasts, monocytes/macrophages) or an acidic mechanism with a proton pump to reduce the $\mathrm{pH}$ of the microenvironment and resorb the hardened bioceramics (osteoclasts)[378,382]. Various mesenchymal cells located at the implantation sites can induce solubilization of calcium orthophosphates. Upon the cells arrival, various active enzymes, such as acid phosphatase, are secreted that causes dissolution of the hardened cements[383-385]. Much more biology, than chemistry and material science altogether, is involved into this very complex process and many specific details still remain unknown.

It is well known that various polypeptides and growth factors present in bone matrix might be adsorbed onto HA[386-388] and modulate the local milieu of cells. This is supported by many purification protocols of growth factors and bone morphogenetic proteins/osteogenins involving HA chromatography[389,390]. However, osteoblasts are not found in direct contact with calcium orthophosphates. A complex proteinaceous layer, usually osteoid, directly contacts the osteoblasts. After implantation of calcium orthophosphate cements, mitogenic events could occur either during the initial mesenchymal cell contact or after osteoid degradation by osteoblast collagenase. In a dense, mineralized material such as calcium orthophosphate cements, which provides a barrier to the free diffusion of circulating hormones, growth factors, and cytokines, it is questionable whether the local responses at the periphery of the material regulate osteoconduction[22]. The tissue response to injectable calcium orthophosphate cements is well described in literature[329,362,376,391,392]. Recent histological and mechanical evaluation of self-setting calcium orthophosphate cements in a sheep vertebral bone void model is available elsewhere[393]. The interested readers are also advised to get through a paper on the in vitro biodegradation of brushite cements by a macrophage cell-line[128].

To conclude this part, one should note that calcium orthophosphate cements are able to provide short-term biologically desirable properties and then be replaced by a new bone, which is very important[394]. The growth rate of a newly forming bone depends on age, sex and general metabolic health of the recipient as well as on the anatomic site, porosity, bulk site, crystallinity, chemical composition (brushite or apatite), particle sizes and $\mathrm{P} / \mathrm{L}$ ratio of the cements. Considering all these factors, it might take from 3 to 36 months for different calcium orthophosphate cements to be completely resorbed and replaced by bones[202]. However, additional sound scientific data to determine the exact degree of biodegradability for calcium orthophosphate cements are still needed, viz. animal studies performed in a critical-size defect model. One must stress that the rate of cement resorption should be balanced with the rate of new bone formation to avoid collapse at the fracture site, which might occur if the resorption is too fast. Interestingly, but to advance calcium orthophosphate cements as bioabsorbable bone replaceable materials, it is essential to utilize the patient's own blood in combination with the cements[395].

\section{The Mechanical Properties}

As in most clinical applications self-setting calcium orthophosphate formulations are applied in direct contact with human trabecular bones, it may be stated as a mechanical requirement that the strength of the formulations must be at least as high as that of trabecular bones, which is close to 10 $\mathrm{MPa}[396]$. Three-dimensional (3D) complex load is applied during the orthopedic and dental applications because of a combination of different forces that may include bending, torsion, tension and compression. Unfortunately, calcium orthophosphate cements are strong enough at compression only[195]. In theory, after setting, they can reach the mechanical properties comparable to those of calcium orthophosphate blocks with the same porosity. However, in practice, the strength of the cements is lower than that of bones, teeth or sintered calcium orthophosphate bioceramics[144].

Having the ceramic origin, the set products of all calcium orthophosphate cements are brittle, have both a low impact resistance and a low tensile strength (within 1 to $10 \mathrm{MPa}$ ), whereas the compression strength varies within 10 to 100 $\operatorname{MPa}[141,195,196]$. The latter value exceeds the maximum compression strength of human trabecular bones. Furthermore, at 12 weeks after implantation the compressive strength of these cements was found to be still significantly higher (60 to $70 \mathrm{MPa}$ ) than that of normal bone[35]. In general, hardened brushite cements are slightly weaker than hardened apatite cements. A tensile strength of $\sim 10 \mathrm{MPa}$ and a compressive strength of $\sim 60 \mathrm{MPa}$ were obtained for brushite cements[397]. In comparison, apatite cements can reach a tensile strength of $\sim 16 \mathrm{MPa}$ [398] and a compressive strength of $\sim 83 \mathrm{MPa}$ [399]. However, due to the inherent brittleness of ceramics, these values are close to be meaningless. Namely, the indication of a mean compressive strength of, say, $50 \mathrm{MPa}$ measured on well-prepared (e.g., under vibrations and pressure) and perfectly shaped samples does not inform the readers with which probability this ce- 
ment will fail in situ under a cyclic load of e.g., $10 \mathrm{MPa}$. Furthermore, a comparison of the compressive strength of hardened cements with that of cancellous bone is not very helpful either because cancellous bone is much less brittle than the ceramic cements[125].

Moreover, the mechanical properties of hardened calcium orthophosphate cements are not narrowly distributed around a mean value (as for metals), but widespread over a very large range of values, which strongly reduces their clinical application[400]. In vivo, the difference between the hardened apatite and brushite cements boosts: namely, the mechanical properties of apatite cements were found to increase[356], whereas those of brushite cements decreased[35]. This is attributed to a higher solubility of DCPD when compared with that of CDHA (Table 1). However, the mechanical properties of the hardened cements may vary with implantation time. For example, animal studies indicated that the mechanical properties of apatite cements tended to increase continually[356], in contrast to those of brushite cements, which initially decreased and again increased when bone was growing[35]. Furthermore, shear and tensile forces play a very important role. Thus, these parameters should also be considered, for example, using the Mohr circle approach[401]. Besides, it is difficult to compare the mechanical properties of different cement formulations. For example, the following numeric values of the compression strength and setting time were obtained: (i) Norian $\operatorname{SRS}^{\circledR}(\sim 50 \%$ porosity): $33 \pm 5 \mathrm{MPa}$ and $8.5 \pm 0.5$ min, (ii) Cementek ${ }^{\circledR}: 8 \pm 2 \mathrm{MPa}$ and $17 \pm 1 \mathrm{~min}$, (iii) Biocement $\mathrm{D}^{\circledR}(\sim 40 \%$ porosity): $83 \pm 4 \mathrm{MPa}$ and $6.5 \pm 0.5 \mathrm{~min}$, (iv) $\alpha-\mathrm{BSM}^{\circledR}(\sim 80 \%$ porosity): $4 \pm 1 \mathrm{MPa}$ and $19 \pm 1 \mathrm{~min}$, respectively[399]. Among them, Biocement $D^{\circledR}$ has the highest compressive strength but the lowest porosity. A high compressive strength does not necessarily mean that Biocement $D^{\circledR}$ is the least breakable implant[197]. Further details on the major properties of Norian SRS $^{\circledR}$ are available elsewhere[203,402]. Besides, the interested readers are suggested to get through the mechanical characterization of a bone defect model filled with ceramic cements[200].

To improve the mechanical properties of the self-setting calcium orthophosphate formulations, addition of water-soluble polymers might be considered. For example, in early 1990-s, Miyazaki et al.[403,404] used a number of polymers, including polyacrylic acid and polyvinyl alcohol to improve the properties of a TTCP + DCPD cement. They noted marked increases (up to threefold) in mechanical properties but with an unacceptable reduction of workability and setting time. Later, another research group reported similar results using sodium alginate and sodium polyacrylate[405]. Afterwards, other researchers added several polyelectrolytes, polyethylene oxide and a protein bovine serum albumin into $\alpha-\mathrm{BSM}^{\circledR}$ cement pastes to create calcium orthophosphate - polymer biocomposites[406]. Biocomposites of $\alpha-$ BSM $^{\circledR}$ with polycations (polyethylenimine and polyallylamine hydrochloride) exhibited compressive strengths up to six times greater than that of pure $\alpha-\mathrm{BSM}^{\circledR}$ material. Biocomposites of $\alpha-\mathrm{BSM}^{\mathbb{B}}$ with bovine serum albumin developed compressive strengths twice that of the original $\alpha-\mathrm{BSM}^{\circledR}$ cement[406]. Similar strengthening effect was achieved by addition of some commercial superplasticizers[407]. The results showed that small additions, i.e. 0.5 vol. $\%$, in the aqueous liquid phase improved the maximum compressive strength ( $35 \mathrm{MPa}$ ) of Biocement- $\mathrm{H}^{\mathcal{O}}$ by $71 \%$, i.e. till $\sim 60 \mathrm{MPa}$. Moreover, the addition of high amounts of superplasticizers, i.e. $50 \mathrm{vol}$ \%, allowed for a significant increasing of the $\mathrm{P} / \mathrm{L}$ ratio from 3.13 to $3.91 \mathrm{~g} / \mathrm{ml}$, without affecting the maximum strength and/or the workability of the cement[407]. This effect was explained by an inhibiting effect of the aforementioned additives on the crystal growth kinetics of newly forming crystals of calcium orthophosphates, which resulted in smaller crystallites and, hence, a denser and more interdigitated microstructure. However, the increased strength was attributed mainly to the polymer's capacity to bridge between multiple crystallites (thus forming a more cohesive composite) and to absorb energy through a plastic flow[406]. Other factors affecting strength are the materials used in the solid phase, particle sizes, incorporation of fillers (see section 7. Reinforced self-setting formulations and concretes for details), the $\mathrm{P} / \mathrm{L}$ ratio and various additives to the liquid phase[106].

As presence of pores simplifies for cracks to run throughout the ceramic mass, the mechanical properties of the hardened cements were found to decrease exponentially with the porosity increase[408]. In theory, calcium orthophosphate cements can be made with almost any porosity. However, for most commercial formulations, the pores are of $8-12 \mu \mathrm{m}$ in diameter and, after the cement is set, porosity occupies about $40-50 \%$ of its volume[409]. Pressure can be applied to reduce the porosity of hardened cements[144,410,411]. Usually, the pore dimensions in hardened cements are too small to allow a fast bone ingrowth. Thus, there is a lack of macroporosity. Besides, unless special efforts have been performed, the available macroscopic pores are not interconnected. Due to these reasons, after injection, osteoclastic cells are able to degrade the hardened cements layer-by-layer only, starting at the bone-cement interface throughout its inner part (in other words, from the outside to the inside). This is the main drawback of the classical cement formulations when compared to calcium orthophosphate ceramic scaffolds with an open macroporosity[197,198].

Since compression strength is reciprocally proportional to porosity[371], the former might be adjusted by varying the $\mathrm{P} / \mathrm{L}$ ratio in the hardening mixture. Elevated compression strength would be applicable in cranioplasty for regions requiring significant soft-tissue support. For smaller bone defects, such as root canal fillings, low-compression cements might be used[137]. Concerning the tensile strength of calcium orthophosphate cements, as a rule of thumb, it appears to increase two-fold with each 10 vol. \% decrease of the porosity, i.e. $5,10,20,40$ and $80 \mathrm{MPa}$ for $80,70,60$, 50 and $40 \%$ porosity, respectively[197,198]. The effect of porosity on the compressive modulus of calcium orthophosphate cements is available as Fig. 4 in Ref.[411]. Ishi- 
kawa and Asaoka showed a linear relation $\left(\mathrm{R}^{2}=0.94\right)$ between $\ln$ diametral tensile strength and porosity of a calcium orthophosphate cement where porosity was controlled by compaction pressure (up to $173 \mathrm{MPa}$ )[141]. Besides, an empirical relationship between strength, $\mathrm{S}$, and porosity, $\mathrm{P}$, has been introduced[412]:

$$
\mathrm{S}=\mathrm{S}_{0} \mathrm{e}^{-b \mathrm{P}}
$$

where: $\mathrm{S}_{0}$ is the theoretical strength at $\mathrm{P}=0$ (fully dense) and $b$ is an empirical constant.

As the porosity is mainly due to an excess of water used in the cement compositions, attempts were made to reduce the amount of water. However, the amount of water determines the rheological properties of cement pastes: a decrease in water content leads to a large increase in viscosity, eventually leading to non-flowable pastes. As calcium orthophosphate cements set at an almost constant volume, the final porosity can be predicted from the initial composition[197,198]. A shrinkage degree of $\sim 1 \%$ causes no restrictions on clinical use[193]. Recent studies on the in vivo evaluation of an injectable macroporous calcium orthophosphate cements revealed a higher bioresorption rate due to both a higher surface contact with body fluids (which increases dissolution) and enhancing cellular activity due to particle degradation[273,329].

Besides the addition of porogens[296-318], the porosity level of the self-setting calcium orthophosphate formulations might be controlled to a certain extent by adjusting particle sizes and the $\mathrm{P} / \mathrm{L}$ ratio. When the $\mathrm{P} / \mathrm{L}$ ratio is high, the porosity of the apatite cement is low[197,198]. According to calculations, the tensile strength of the cements with zero porosity could be as high as $103 \mathrm{MPa}[141]$. However, a high density and a lack of pores decreases cement bioresorbability because a newly forming bone appears to be unable to grow into the implant; it might grow only simultaneously with dissolution of the cement. Thus, porosity of calcium orthophosphate cements is a very important factor for the cement biodegradability[197,198].

The strength of the cement-prosthesis interface might be studied by a pullout test. The details are available elsewhere[65].

\section{Reinforced Self-Setting Formulations and Concretes}

Being aware on the excellent bioresorbability of DCPD and CDHA, researchers are focused on attempts to overcome the mechanical weakness of the self-setting calcium orthophosphate formulations by using different fillers, fibers and reinforcing additives that give rise to formation of various multiphasic biocomposites [104,105,109,199,259, 274,409,412-418]. Even carbon nanotubes have been successfully tested to reinforce the self-setting formulations [419]. Although the biomaterials community does not use this term (just 1 paper has been published[420]), a substantial amount of such formulations might be defined as cal- cium orthophosphate concretes[421]. The idea behind the concretes is simple: if a strong filler is present in the matrix, it might stop crack propagation. However, adding fillers always reduced the porosity that negatively influenced the ability of the concretes to allow bone ingrowth into the pores. Hence, a denser formulation has a slower resorption rate and thus a slower bone substitution[141]. Moreover, due to the presence of fillers, injectability and other rheological properties of calcium orthophosphate concretes frequently appear to be worse than those ones of calcium orthophosphate cements. Thus, it is difficult to increase strength of the cement formulations without having a negative influence on the other properties.

Calcium orthophosphate concretes can be prepared from both apatite and brushite cement formulations. For example, in an attempt to improve the mechanical properties of calcium orthophosphate cements, a group of investigators prepared concretes by adding human cadaveric femur bone chips in amounts of 25,50 and $75 \%(\mathrm{w} / \mathrm{w})$ to $\alpha-\mathrm{BSM}^{\circledR}$ cement[414]. The mechanical tests revealed that the specimens of pure cement exhibited a relatively high stiffness but a low ductility. However, for the cement-bone concretes an increasing of bone content was found to result in the elastic modulus decreasing and the ductility increasing; however, the ultimate strength showed only small changes with no apparent trend[414]. A concrete of Biopex ${ }^{\circledR}$ cement with allografts taken from femurs and tibiae of rabbits is also available. Unfortunately, nothing is written on the mechanical properties improvement but, surprisingly, by the addition of allografts, the hydrolysis process of Biopex ${ }^{\circledR}$ was significantly changed[259]. By adding polymers, other researchers succeeded in improving the mechanical strength of the cement formulations up to $\sim 30 \mathrm{MPa}$; however, the kinetics of CDHA formation and, thus, the bioactivity of the material were decreased[110,422]. Xu et al., reported that incorporation of long carbon fibers at a volume fraction of $5.7 \%$ increased the flexural strength about 4 times and work of fracture $\sim 100$ times, if compared to un-reinforced formulations[423]. The reinforcement mechanisms were found to be crack bridging and fiber pullout, while fiber length and volume fraction were key microstructural parameters that determined the concrete properties[426]. Although addition of polypropylene, nylon and carbon fibers was found to reduce the compression strength of a double-setting calcium orthophosphate cement because of increased porosity, it strongly increased the cement's fracture toughness and tensile strength, relative to the values for the un-reinforced variant of this formulation[415]. A knitted two-dimensionally oriented polyglactin fiber-mesh was found to be effective in improving load-bearing behavior of a calcium orthophosphate cement for potential structural repair of bone defects[199]. To make the material stronger, fast setting and anti-washout, chitosan might be added[178,344,403,424-434]. Furthermore, anti-washout properties might appear by adding sodium alginate[435]. Calcium orthophosphate concretes containing $\mathrm{SiO}_{2}$ and $\mathrm{TiO}_{2}$ 
particles showed a significant $(\sim 80-100 \mathrm{MPa})$ increase in the compressive strength, whilst no change in the mechanical behavior of the formulations was observed when $\mathrm{ZrO}_{2}$ particles were added[416]. Additional examples of the properties improving comprise addition of calcium silicates [67], polypeptide copolymers[436] and collagen[437-443]. A strength improvement was found when DCPA and $\mathrm{TiO}_{2}$ crystals were used as fillers for mechanically activated $\alpha$-TCP cements[444]. Calcium orthophosphate concretes reinforced by whiskers of calcium carbonate[55] have been also developed.

Yet another team examined the effects of varying fiber type, fiber length and volume fraction of fiber-reinforced calcium orthophosphate concretes[424,445]. Four fiber types were studied: aramid, carbon, E-glass and polyglactin. Fiber length ranged within $3-200 \mathrm{~mm}$ and fiber volume fraction ranged within $1.9-9.5 \%$. The results indicated that a self-setting calcium orthophosphate cement was substantially strengthened via fiber reinforcement. Aramid contributed to the largest increase in the concrete strength, followed by carbon, E-glass and polyglactin. Fiber length, fiber volume fraction and fiber strength were found to be key microstructural parameters that controlled the mechanical properties of calcium orthophosphate concretes[424, 445]. Fiber reinforcement of porous formulations (mannitol was used as a porogen) was discovered as well[446]. Namely, reinforcement by aramid fibers (volume fraction of $6 \%$ ) was found to improve the properties of a calcium orthophosphate concrete with the strength increasing threefold at $0 \%$ mannitol, sevenfold at $30 \%$ mannitol and nearly fourfold at $40 \%$ mannitol. Simultaneously, the work of fracture increased by nearly 200 times, however the modulus was not changed as a result of fiber reinforcement[446]. Addition of $20 \mathrm{wt}$ \% of acrylamide and $1 \mathrm{wt} . \%$ ammonium polyacrylate to the liquid increased the compressive and tensile strength of $\alpha$-TCP bone cement by 149 and $69 \%$ (55 and $21 \mathrm{MPa}$ ), respectively[447]. A positive influence of polyamide fibers[448] and bioactive glass[449] is also known. Interestingly, but reinforcement of calcium orthophosphate cements might be performed by infiltration of a preset cement formulation by a reactive polymer and then cross-linking the polymer in situ[450].

In the cases, when bioresorbable reinforcement fibers are used, strength augmentation is attained at the initial stages[319-326]. For example, the initial strength of a concrete was threefold higher than that of the unreinforced cement control[319]. The work of fracture (toughness) was found to increase by two orders of magnitude for other biocomposites of calcium orthophosphate with resorbable fibers (namely, Vicryl polyglactin 910 (Ethicon, Somerville, NJ) [320] and a mesh of copolymer of polyglycolic and polylactic acids[324]). When implanted in vivo, bioresorbable fibers would provide initial strength and then dissolve to form interconnecting macroscopic channels, which could facilitate bone ingrowth into implants[143,144,319,324]. For example, interconnected macropores were formed in a hardened formulation at 84 days' immersion in a physio- logical solution[324]. One should note that, apart from the mechanical properties of the reinforcing materials, the structure of the incorporated fibers, regular or random, appears to be crucial for the resulting flexural strength and modulus of elasticity[322]. A higher strength might help extending the use of calcium orthophosphate cements to larger stress-bearing repairs, while the macropores might facilitate tissue ingrowth and integration of the hardened cement with an adjacent bone. To extend this idea further, several types of fibers with different rates of bioresorbability might be simultaneously incorporated into a cement formulation.

Besides the aforementioned, it is important to mention on concretes, after hardening consisting of calcium orthophosphates only[237,238,377,451-454]. The first biphasic composition consisting of a hardened DCPD matrix filled with $\beta$-TCP granules was introduced in 1992[452]. Further development of this formulation is well described in other papers[237,377]; unfortunately, neither mechanical nor rheological properties of this concrete have been disclosed. At physiological $\mathrm{pH}$, the in vitro solubility of DCPD is approximately 100 times higher than that of $\beta$-TCP (Table 1 and Fig. 1); roughly, the same order of magnitude applies for the in vivo resorption kinetics of these calcium orthophosphates. Thus, a new bone is formed in the space left after resorption of the DCPD matrix, while $\beta$-TCP granules act as guiding structures. This feature of the cement can be considered an inverse scaffolding effect[455]. Another group of investigators invented a formulation that incorporated as major powder components $\alpha-\mathrm{TCP}, \mathrm{ACP}$ and BCP $(\mathrm{HA}+\beta-\mathrm{TCP}$ in various HA/ $\beta$-TCP ratios)[413]. It was believed that after setting such a formulation could provide a porous ceramics in vivo due to preferential dissolution of a better soluble ACP component compared to the other calcium orthophosphates in the matrix. Further, this combination was extended to a multiphase concrete composition consisting of $70 \% \mathrm{w} / \mathrm{w}$ settable matrix (mixture of $45 \%$ $\alpha$-TCP, $5 \%$ MCPM and $25 \%$ ACP[456]) with the average particle dimensions of $15 \mu \mathrm{m}$ and $30 \%$ BCP granules (ranging between 80 and $200 \mu \mathrm{m}$ ) as a filler[451]. The role of BCP granules is quite interesting: after implantation of a formulation without BCP granules, the quality of newly formed bone was not identical to the host bone, while implantation of a concrete with BCP granules resulted in formation of a new bone identical to the host bone. The reason of this phenomenon is not clear yet; but, perhaps, it correlates with similar results for $\beta$-TCP granules, which act as bone anchors and encourage formation of a mature bone[237,238]. Other ACP-containing cement formulations were elaborated as well[457].

Effects of added $\alpha$-TCP and $\beta$-TCP were investigated to shed light on the setting reaction of apatite cement consisting of TTCP and DCPA[454]. Added $\beta$-TCP showed no reactivity, and thus resulted in extended setting time and decreased mechanical strength. In contrast, $\alpha$-TCP dissolved to supply calcium and orthophosphate ions after initial apatite crystal formation by the chemical reaction (1). 
Although setting time was delayed because $\alpha$-TCP was involved only in the latter reaction of apatite cement, larger apatite crystals were formed due to its addition. Because of larger apatite crystal formation, the mechanical strength of the $\alpha$-TCP-added formulation increased by approximately $30 \%$, as compared to $\alpha$-TCP-free apatite cement[454]. Besides, calcium orthophosphate cements might be reinforced by calcium polyphosphate fibers[458,459].

To conclude this part, one should briefly mention on the reverse situation: there are bone concretes made of various polymeric cements, reinforced by calcium orthophosphate powders or granules [460-468]. The calcium orthophosphates presented in these formulations act as fillers, which are necessary to both improve the mechanical properties and impart bioactivity; they do not participate in the hardening mechanisms. For example, the higher the amount of HA was in bioactive acrylic bone cements, the higher were the compressive and tensile moduli. Furthermore, as the percentage of HA increased to $20 \mathrm{wt} . \%$, the heterogeneity of the material was higher[466]. Polymerization of monomers is primarily responsible for setting of such types of biocomposites and concretes. However, that is another story.

\section{Clinical and Medical Applications}

Injectable and self-setting calcium orthophosphate formulations have been introduced as an adjunct to internal fixation for treating selected fractures. Different studies have already shown that they are highly biocompatible and osteoconductive materials, which can stimulate tissue regeneration[22,469]. The main purpose of calcium orthophosphate cements, concretes, pastes and putties is to fill voids in metaphyseal bone, thereby reducing the need for bone graft, although such formulations might also improve the holding strength around metal devices in osteoporotic bone. Bone augmentation (i.e., a reinforcement of osteoporotic bone through injection) appears to be a very promising application field of calcium orthophosphate cements. Such procedures ease the fixation of screws in mechanically poor bone (for example for osteosynthesis) and decrease pains associated with unstable vertebrae. The combination of a self-setting nature, biocompatibility, lack of any by-products and a great potential for replacement by bones make calcium orthophosphate cements, concretes, pastes and putties very promising materials for clinical and medical applications. In addition, they can easily be used by bone remodeling cells for reconstruction of damaged parts of bones[102,103,226, $392,470-472]$. The ability to be molded in place also is a very important property because these formulations can easily be delivered into the desired place and can be fitted perfectly with bone defects[103]. Besides, some formulations were found to possess an antimicrobial activity $[56,59,61,68,473]$, as well as promote osteoblast cell adhesion and gene expression in vitro[474].

Recent studies reported optimistic results in relation to the clinical application of the self-setting calcium orthophos- phate formulations. For example, the data on cytocompatibility and early osteogenic characteristics are available in literature[475]. The ratio of the cases determined to be "effective" or "better" among the 74 cases we found to be $97.3 \%[476]$. Besides, the results of intra-articular degradation and resorption kinetics of these cements revealed no signs of pronounced acute or chronic inflammation[477]. Injected Norian SRS ${ }^{\circledR}$ cement was mainly found as a single particle, anterior to the cruciate ligaments. The cement became surrounded by synovial tissues within 4 weeks and showed signs of superficial resorption[477]. Unfortunately, disintegration or washout of calcium orthophosphate cements has been reported as a potential clinical problem[141,210]. Perhaps, this problem could be solved by putting pressure on the paste during the setting period. In addition, sodium alginate might be added; however, the mechanical properties (strength) of this formulation are still poor[108].

According to the available information, the first animal study of calcium orthophosphate cements was performed in 1987[152]. Afterwards, in 1991, a cement consisting of TTCP and DCPA was investigated histologically by implanting disks made of this cement within the heads of nine cats[478]. Simultaneously, another research group evaluated the tissue reaction to this cement in the teeth of monkeys[479]. Important examples of the most significant directions of current medical applications of the self-setting calcium orthophosphate formulations are given below.

\subsection{Dental Applications}

A group of investigators extracted all mandibular premolar teeth from beagles[480]. After one month of healing, alveolar bone was reduced to make space for a previously fabricated calcium orthophosphate cement block. One more month later, 8-mm HA implants were placed in such a manner that the apical half was embedded into alveolar bone and the coronal half in the calcium orthophosphate cement block. The investigators observed that the cement block was gradually replaced by bone and histopathologic features of the cement area were similar to that of natural bone. Moreover, the coronal half of the implants, previously surrounded by the calcium orthophosphate cement, was firmly attached by natural bone[480]. In another study, the same researchers used fluorescent labeling analysis and electron microanalysis to measure the extent of new bone formation and elemental $(\mathrm{Ca}, \mathrm{P}, \mathrm{Mg})$ distribution[481]. The results indicated the presence of newly formed bone at $\sim 1$ month after surgery and similar elemental distributions in the calcium orthophosphate cement and natural bone areas at $\sim 6$ months after surgery[202]. Besides, calcium orthophosphate cements were tried as root canal fillers $[59,482,483]$ and for pulp capping[484].

A hydraulic calcium orthophosphate cement was injected as a bone filler for gaps around oral implants placed on the medial femoral condyles of six goats and found excellent bone formation around the graft material. Unfortunately, the 
Sergey V. Dorozhkin: Self-Setting Calcium Orthophosphate Formulations: Cements, Concretes, Pastes and Putties

degradation rate of the cement appeared to be very slow and no resorption was observed[485]. In another study, a cement was placed on artificially created periodontal defects but no significant difference was found between the cement and control. However, the cement acted as a scaffold for bone formation and provided histocompatible healing of periodontal tissues[486]. Still other investigators used a cement for direct pulp capping[487,488] and compared it to calcium hydroxide. Both materials were found to be equally capable of producing a secondary dentin at $\sim 24$ weeks[488]. Finally, injectable forms of calcium orthophosphate cements can be used as an adjunctive supportive agent for dental implants[489].

\subsection{Craniofacial and Maxillofacial Applications}

The use of self-setting calcium orthophosphate formulations for craniofacial applications seems logical, as there is little or no stress generated under these conditions. Moreover, the ability to mold the material at placement is an enormous advantage from a cosmetics standpoint[202]. For example, BoneSource $^{\mathrm{TM}}$ is indicated for the repair of neurosurgical burr holes, contiguous craniotomy cuts and other cranial defects with a surface area no larger than $25 \mathrm{~cm}^{2}$ per a defect. In addition, it may be used in the sinus region for facial augmentation[103,490] and the cement can be supported by metal hardware[103]. In dogs, BoneSource ${ }^{\mathrm{TM}}$ was employed to supplement the supraorbital ridge and to augment skull base defects[491]. Another group performed trials to ascertain the inflammation around the site and the degree of loss of the implanted BoneSource ${ }^{\mathrm{TM}}$. The material was found to be osteoconductive with both periosteal and endosteal bone formation[492]. One more group presented excellent results using the material combined with an underlying resorbable mesh in calvarian defects of Yorkshire pigs. They found progressive bone ingrowths in all defects at 180 days, with nearly complete replacement by host bone[325]. Besides, excellent results for over 100 human patients were reported when a calcium orthophosphate cement was used in cranial defects. The success rate of the cement after 6 years was $97 \%$ [94]. The results of still other medical trials are available elsewhere[220,493-505]. To conclude this part, one should stress that complications still occur: namely, two cases of apatite bone cement resorption and subsequent seroma formation have been recently reported for patients who had undergone retrosigmoid craniotomy[506].

\subsection{Orthopaedic Applications}

Self-setting calcium orthophosphate formulations have successfully been used for treatment of the distal radius fractures[206,507,508]. Besides, other successful attempts have been made to use these formulations for calcaneal fractures[509], hip fractures[510,511], augmentation of osteoporotic vertebral bodies[512], distal radius fractures[513], tibial plateau fractures[33,513-517], restoration of pedicle screw fixation[518,519], reinforcement of thoracolumbar burst fractures[520], cancellous bone screws
[521,522], in wrist arthrodesis[523] and for fixation of titanium implants[524]. A recent study on a cement augmentation of the femoral neck defect might be found elsewhere[525]. Considering their properties, calcium orthophosphate cements might potentially be applied to reinforce osteoporotic vertebral bodies[512,526]. Further details on this topic are available elsewhere[527,528]. Besides, calcium orthophosphate cements appear to be a reliable subchondral replacement material when the bone defect is adjacent to the articular cartilage[529].

\subsection{Vertebroplasty and Kyphoplasty Applications}

Vertebroplasty and kyphoplasty are two surgical procedures that recently have been introduced to medically manage of osteoporosis-induced vertebral compression fractures. Particularly, both procedures aim to augment the weakened vertebral body, stabilize it and/or restore it to as much of its normal height and functional state as possible. Both procedures involve injection of a self-setting paste of a calcium orthophosphate cement into the fractured vertebral body, which resulted in a faster healing[94,203,529-536]. Furthermore, prophylactic injections of calcium orthophosphate cements also have been performed.

\subsection{Drug Delivery Applications}

In general, a potential substrate to be used as a drug carrier must have the ability to incorporate a drug, retain it in a specific target site and deliver it progressively with time in the surrounding tissues. Additional advantages are provided if the material is injectable, biodegradable, sets at ambient temperature, has both near neutral $\mathrm{pHs}$ and a large surface area[36, 37]. These properties make self-setting calcium orthophosphate formulations to be very attractive candidates as drug carriers for therapeutic peptides[537], antibiotics [538-547], anticancer drugs[578], anti-inflammatory drugs [549, 550], cytokines[551], hormones[552] and bone morphogenetic proteins[432,553-557]. For example, a "growth factor cement" has been reported[558]. In that study, a combination of bone morphogenetic protein-2 (BMP-2), transforming growth factor-beta (TGF- $\beta 1$ ), platelet-derived growth factor and basic fibroblast growth factor (bFGF) was used in a calcium orthophosphate cement for treatment of peri-implant defects in a dog model. The findings indicated a significant effect of the "growth factor cement" on increased bone-to-implant contact and amount of bone per surface area if compared with both the cement-only and no-cement treatment groups[558]. Similar data were found for a combination of a calcium orthophosphate cement with an exogenous nerve growth factor[559]. Even more complicated combination of deproteinized osteoarticular allografts integrated with a calcium orthophosphate cement and recombinant human vascular endothelial cell growth factor plus recombinant human BMP-2 (rhBMP-2) has been studied as well[560]. Interestingly, but the drug delivery properties of calcium orthophosphate cements might be influenced by crystal morphology[561]. 
In the cement formulations, drugs might be incorporated into both a liquid and a powder phases. After setting, the drugs are slowly released through the cement pores[210, 543-546,562,563]. For example, a group of investigators added flomoxef sodium to a cement formulation and found that the release of antibiotic could be easily controlled in vivo by adjusting the content of sodium alginate in the formula[210]. In vitro elution of vancomycin from calcium orthophosphate cement has been studied as well[563]. The possibility of using self-setting calcium orthophosphate formulations as a drug-delivery system offers an attractive and efficient solution for the treatment of various bone diseases, e.g., tumours, osteoporosis and osteomyelitis, which normally require long and painful therapies.

The laboratory studies on drugs incorporation into self-setting calcium orthophosphate formulations cover different aspects. Firstly, it is necessary to verify that addition of a drug does not influence the setting reaction not only in terms of the setting and hardening mechanisms but also with respect to the rheological behavior and injectability. Secondly, it is necessary to determine the in vitro kinetics of drug release. Thirdly, the drug delivery properties of the formulation must be studied in vivo. Finally, but still importantly, the clinical performance of the drug delivery system must be evaluated as well[36,37]. For example, recombinant human transforming growth factor $\beta 1$ (rhTGF- $\beta 1$ ) was added to a calcium orthophosphate cement[564-567]. This resulted in formation of a bioactivated cement that could be used as a bone filler and for the replacement of bone[564]. It appeared that after 8 weeks the addition of growth factors stimulated and increased bone formation (50\% volume) and bone contact (65\%) in comparison to control calvarian defects in an animal study. Besides, the growth factor group reduced the remaining volume of the cement by $20 \%[565]$. Examples of rhBMP-2 release from a loaded porous calcium orthophosphate cement might be found elsewhere[567, 568], while an experimental study on calcium orthophosphate cement impregnated with dideoxykanamycin B is also available[569].

Although most materials currently used as drug carriers are polymers, in the specific field of the pharmacological treatment of skeletal disorders, self-setting calcium orthophosphate formulations have an added value due to their bioactive character and injectability. Further details and additional examples of the drug delivery application of calcium orthophosphate cements are well described elsewhere[29,36,37].

\subsection{Brief Conclusions on the Medical Applications}

To conclude this part, one should stress that despite several encouraging results, not every surgeon' expectation has been met yet[569]. First of all, self-setting calcium orthophosphate formulations are not superior to autografts, despite offering primary stability against compressive loading[570,571]. One of the main concerns of clinicians is to reach higher rates of bioresorption, an improvement of bone reconstruction and to a lesser extent, higher mechanical resistance[33]. Besides, clinical application of the cements in comminuted fractures revealed penetration of the viscous paste into the joint space[572-574]. The interested readers are referred to a paper on cement leakage during vertebroplasty[575]. To date, cadaveric studies have already shown that using calcium orthophosphate cements with conventional metal fixation in certain fractures of the distal radius, tibial plateau, proximal femur and calcaneus can produce better stability, stiffness and strength than metal fixation alone. Early clinical results have revealed a reduced time to full load bearing when the cements were used for augmentation of tibial plateau and calcaneal fractures, more rapid gain of strength and range of motion when used in distal radius fractures and improved stability in certain hip fractures[471,507]. However, surgeons reported on difficulties in filling the vertebral bodies (a bad injectability of present formulations) and other problems, such as filter pressing and cement decohesion, observed during vertebral body injection that resulted in bone instability due to low mechanical strength as well as long setting times of the cements[576]. This happens due to not only low mechanical properties of calcium orthophosphate cements but also some difficulties of filling vertebral bodies. In order to maintain a good cohesion and reduce filter pressing, calcium orthophosphate cements need to be more viscous (hence, less injectable)[197,198]. For example, calcium orthophosphate cements might be modified by addition of polysaccharides[97, 108, 335-338] and/or gelatin[278,339-344].

Another type of concerns has been raised that the use of self-setting calcium orthophosphate formulations for the augmentation of fractured and osteoporotic bones might aggravate cardiovascular deterioration in the event of pulmonary cement embolism by stimulating coagulation[577]. To investigate these potential problems, $2.0 \mathrm{ml}$ of either calcium orthophosphate or polymethylmethacrylate (PMMA) cement were injected intravenously in 14 sheep. Intravenous injection of calcium orthophosphate cement resulted in a more severe increase in pulmonary arterial pressure and decrease in arterial blood pressure compared to the PMMA cement. Disintegration of the calcium orthophosphate cement seemed to be the reason for more severe reaction that represents a risk of cardiovascular complications. The authors concluded that further research efforts should aim at improving cohesion of calcium orthophosphate cements in an aqueous environment for future clinical applications such as vertebral body augmentation[577].

To conclude the biomedical part of this review, one should mention that, although the long-term outcomes are still poorly documented, currently there are no doubts concerning a very great potential of the clinical applications of self-setting calcium orthophosphate formulations for healing of bone and dental defects. For example, a bioresorbable calcium orthophosphate cement was once found to be a better choice, at least in terms of the prevention of subsidence, than autogenous iliac bone graft for the treatment of 
subarticular defects associated with unstable tibial plateau fractures[578]. Furthermore, BoneSource ${ }^{\mathrm{TM}}$ was found to be safe and effective when used to fill traumatic metaphyseal bone voids and appeared to be at least as good as autograft for treatment of these defects[579]. However, in other studies, autologous cancellous grafts were demonstrated to lead to a significantly better bone regeneration compared to the application of calcium orthophosphate granules produced from a self-setting calcium orthophosphate cement powder after 6 weeks [580]. As this text is intended to be read mainly by chemists and materials researchers, the biological, medical and clinical aspects of self-setting calcium orthophosphate formulations have not been discussed in many details. For additional biomedical details, the interested readers are referred to other papers and reviews[22,29,36,37,137,471, 476,570].

\section{Future Developments}

As self-setting calcium orthophosphate formulations represent an intriguing group of new materials for bone augmentation and reconstruction, there is a great potential for further improvement of their properties, in which the ideal characteristics (Table 5) should be approached by manipulations with the chemical composition, powder particle size and distribution, as well as by means of various additives. Several commercial cement formulations have been already approved for a clinical application (Tables 2 and 3). New formulations of both apatite and brushite cements are expected to appear in the market soon. The forthcoming commercial formulations will need to be improved in order to take the advantage of a variety of possibilities offered by calcium orthophosphate cements. New formulations will include: (i) injectable and open macroporous formulations to optimize their osteoconduction[278], (ii) formulations containing only one calcium orthophosphate (single-phase cement powders)[17] and (iii) drug-loaded and hormone- loaded cements for the treatment of bone diseases[29,36,37]. Furthermore, incorporation of autologous or allogenic osteoprogenitor cells in the cement formulations will be favorable[581-583]. Obviously, the former two directions deal with both chemistry and material science, while the last two directions are more related to tissue engineering and medicine.

Concerning the material point of view, an innovative approach of injectable self-setting formulations has been introduced relatively recently. The researches combined a water-reactive apatite cement such as a mixture of TTCP and DCPD powders with a nonaqueous but water-miscible liquid (e.g., glycerol, polyethylene glycol) + a gelling agent (e.g., hydroxypropylmethylcellulose, carboxymethylcellulose, chitosan) + a hardening accelerator (e.g., tartaric, malic, malonic, citric or glycolic acids) to form a stable paste that can be directly injected into a bone defect [584-589]. In literature, this type of cement pastes is called "premixed calcium phosphate cements" (occasionally referred to as PCPC) in which the paste remains stable during storage and hardens only after placement into the defect. The paste can be obtained of different consistencies, from low viscosity ones to putty-like plastic pastes[122-124]. Setting occurs in vivo upon a contact with body fluids or in vitro in a physiological solution and results in CDHA formation. This approach eliminates the powder-liquid mixing stage during surgery, which might improve the cement performance. Besides, it allows shortening the surgical time and the risk of operator-induced error is considerably reduced. Unfortunately, the setting reaction of the premixed formulations is difficult to control and the mechanical properties of the hardened cements are poor. Besides, such formulations must be protected from the environmental moisture during storage [590,591]. Furthermore, little attention has been paid to the problem that the presence of water impurities in the non-aqueous liquid and/or the powdered solid can compromise the stability of the paste.

Table 5. Major advantages and disadvantages of the calcium orthophosphate cements[36,37,202]

\begin{tabular}{|c|c|}
\hline Advantages & Disadvantages \\
\hline $\begin{array}{l}\text { 1. Self-setting ability in vivo. } \\
\text { 2. Good injectability that allows cement implantation by minimally invasive surgical } \\
\text { techniques, which are less damageable than the traditional surgical techniques. } \\
\text { 3. Good osteoconductivity and occasional osteoinductivity: the initial biological properties } \\
\text { of the hardened cements are similar to those of CDHA or brushite. } \\
\text { 4. Can be replaced by newly formed bone after a period of time (osteotransductivity). } \\
\text { 5. Moldability: the perfect fit to the implant site, which assures good bone-material contact, } \\
\text { even in geometrically complex defects. } \\
\text { 6. Excellent biocompatibility and bioactivity. } \\
\text { 7. No toxicity. } \\
\text { 8. Low cost. } \\
\text { 9. Ease of preparation and handling. } \\
\text { 10. Setting at body temperature. } \\
\text { 11. Form chemical bonds to the host bone. } \\
\text { 12. Clinically safe materials in their powder components. } \\
\text { 13. Can be used to deliver antibiotics, anti-inflammatory drugs, growth factors, morpho- } \\
\text { genic proteins, etc. at local sites, which are able to stimulate certain biological responses. }\end{array}$ & $\begin{array}{l}\text { 1. Mechanical weakness: limited use due to } \\
\text { potential collapse of material followed by soft } \\
\text { tissue formation instead of bone formation } \\
\text { (loaded areas). Until cements with adequate } \\
\text { shear strength are available, most complex } \\
\text { fractures that can be repaired with cement also } \\
\text { will require metal supports. } \\
\text { 2. Can be washed out from surgical defect if } \\
\text { excess of blood. } \\
\text { 3. Lack of macroporosity (especially inter- } \\
\text { connected pores), which prevents fast bone } \\
\text { ingrowth and the cements degrade } \\
\text { layer-by-layer from the outside to the inside } \\
\text { only. } \\
\text { 4. The in vivo biodegradation of many for- } \\
\text { mulations is slower than the growth rate of a } \\
\text { newly forming bone. }\end{array}$ \\
\hline
\end{tabular}

*Further studies are necessary. 
Earlier formulations of the premixed calcium orthophosphate cements had a setting time of longer than $1 \mathrm{~h}$ and a low mechanical strength[584]. Afterwards, improved formulations have been developed. They exhibit a rapid setting when immersed in a physiological solution, yielding a hardened ceramics with a higher mechanical strength, approached the reported strengths of sintered porous HA implants and cancellous bone[585-587]. Brushite-forming premixed cement formulations have been introduced as well[590, 592-594]; they are expected to have a shorter setting time then the aforementioned apatite-forming premixed cement formulations. Creation of premixed macroporous calcium orthophosphate cement scaffolds reinforced by slow-dissolving fibers (in other words, premixed macroporous concrete scaffolds) is the latest achievement of this approach[326].

Other researchers invented cements in the form of two injectable pastes that could be mixed together and injected at the time of implantation (e.g., by a static twin-chambered mixer incorporated in the injection cannula that allows injection of the paste immediately after mixing)[593,594]. A wide range of possibilities appears by changing the calcium orthophosphate components. Furthermore, such formulations can also be modulated by adjoining different additives as setting retardants, polymeric adjuvants, visco-enhancing agents, suspension stabilizers, osteoinductive agents, radio-opaque fillers or macropore-forming agents[327]. Nevertheless, this approach is limited to acid-base cement formulations only[34].

Before recent publications[590,592-594], no study had been available on a possibility of the premixed brushite formulations at ambient temperatures. Thus, researchers developed a way to overcome this problem at low temperatures by creation of pre-mixed frozen calcium orthophosphate "slabs"[155]. By freezing, the setting reaction of a cement was slowed down or even inhibited. When the cement had to be applied, the "slab" was softened at room temperature and molded by hands. Three different pre-mixed brushite formulations were prepared by freezing the cement pastes following combination of the powder and liquid components. When frozen and stored at $\mathrm{t}=-80^{\circ} \mathrm{C}$ or less, significant degradation in compression strength did not occur for the duration of the study (28 days). Interestingly, in the case of the brushite cement formed from a combination of $\beta$-TCP with $2 \mathrm{M} \mathrm{H}_{3} \mathrm{PO}_{4}$ solution, freezing the paste had the effect of increasing mean compressive strength fivefold (from 4 to $20 \mathrm{MPa}$ ), which was accompanied by a reduction in the setting rate of the cement. This strength improvement was attributed to a modification of crystal morphology and a reduction in damage caused to the cement matrix during manipulation[155].

A lack of macropores is a substantial disadvantage of many current self-setting calcium orthophosphate formulations[273]. As a result, biodegradation takes place layer-bylayer on the surface, from outside to inside. To solve this problem, various types of porogens are used[296-318]. Using a hydrophobic liquid instead of soluble particles could be an alternative. At the turn of the millennium, an open macroporous structure was obtained using a mixture of oil and a cement paste[595]; however, since than no research papers on this subject have been published. Besides, by means of surfactants, air bubbles might be incorporated into the bulk of the cements[290]. Unfortunately, the mechanical strength and porosity are conflicting requirements. As porosity of calcium orthophosphate cements appears to be of paramount importance to achieve the excellent bioresorbability, other experimental approaches have to be developed[596].

Recently, a layered structure was designed by combining a macroporous layer of calcium orthophosphate cement with a strong fiber-reinforced calcium orthophosphate cement layer. The rationale for such construction was for the macroporous layer to accept tissue ingrowth, while the fiber-reinforced strong layer would provide the needed early-strength[597].

In the case of calcium orthophosphate concretes, future studies could combine in one formulation porogens and biodegradable fibers of different shapes and dissolution rates to form after in vivo hardening calcium orthophosphate scaffolds with sustained strength. In such a system, one porogen is quickly dissolved, which creates macropores to start a bone ingrowth process, while the second type of fibers provides the required strength to the implant. After significant bone ingrowth into the initial pores increased the implant strength, the second set of fibers would then be dissolved to create additional macropores for bone ingrowth [319]. Such complicated formulations have already been developed. For example, chitosan, sodium orthophosphate and hydroxypropylmethylcellulose were used to render calcium orthophosphate cements fast setting and resistant to washout, while absorbable fibers and mannitol porogen were incorporated for strength and macropores, respectively. Both strength and fracture resistance of this concrete were substantially increased and approached those values for sintered porous HA implants[598]. Turning on a bit of imagination, one might predict development of polymeric forms of drugs (already available[599,600]), hormones, growth factors, etc. (e.g., prepared by either incorporation into or cross-linking with either water-soluble or bioresorbable polymers). Coupled with reinforcing biodegradable fibers and porogens, such types of "healing fibers" might be added to calcium orthophosphate concretes, which not only will accelerate the remedial process, but also will allow simultaneous improvement in both their strength and injectability.

Stability (insolubility) in normal physiological fluid environment and resorbability under acidic conditions produced by osteoclasts appears to be among the most important in vivo characteristics of modern types of calcium orthophosphate bioceramics. For some clinical applications, such as cranioplasty, a relatively slow resorption and replacement by bone is quite acceptable, whereas in other applications, such as periodontal bone defects repair, sinus lift, etc., the ability of the hardened cement to be replaced quickly by bone is crucial. Experimental results suggest that a number of parameters of the self-setting calcium orthophosphate 
formulations, such as the $\mathrm{Ca} / \mathrm{P}$ ionic ratio, carbonate content, ionic substitution, crystallinity, etc. might affect the dissolution characteristics of the cements in slightly acidic solutions. This gives an opportunity to formulate compositions, possessing different resorption rates, which is suited for different biomedical applications[143,144].

The discovery of self-setting calcium orthophosphate formulations has already opened up new perspectives in synthesis of bioceramic scaffolds, possessing sufficient mechanical properties[298,302,303,412]. In the past, such scaffolds could only be manufactured by the sintering route at elevated temperatures[601]. Therefore, until recently it was impossible to produce resorbable preset low- temperature hydrated 3D bioceramics for various applications, e.g., scaffolds and granules, from low- temperature calcium orthophosphate phases, such as ACP, DCPA, DCPD, OCP and CDHA. Now, using the appropriate techniques, open macroporous 3D scaffolds consisting of the aforementioned low-temperature phases (currently, excluding ACP and OCP) can be produced via a cementitious reaction[297,327,333, $334,412,602-604]$, thus dramatically widening the application of these calcium orthophosphates as biomaterials and bioceramics. This type of biomaterials could be very promising for tissue engineering applications. Among them, CDHA is of a special interest due to its chemical similarity to bone material and a large specific surface area.

To conclude this part, one should stress, that the most promising direction of the future developments of self- setting calcium orthophosphate formulations is obviously seen in their functionalization by incorporation or impregnation of various hormones, growth factors, drugs, other bioorganic compounds, as well as incorporation of living cells and/or other tiny biological objects[605-616]. For example, silk fibroin can regular the mineralization process and bond with HA to form fibroin/HA nanodimensional biocomposites with increased gelation properties and, thus, it can be used as an additive to improve cohesion of calcium orthophosphate cements and decrease a risk of cardiovascular complications in its application in veterbroplasty and kyphoplasty[612].

While the simplicity in the processing of cements encourages the incorporation of cells, the principal difficulty remains to ensure cell survival. The harsh environment in terms of $\mathrm{pH}$ and high ionic strength together with the high stiffness achieved upon cement hardening can be thought as the principal threats for cell endurance. The initial attempts have already been performed but without a great success yet. For example, researchers have already found that unset calcium orthophosphate cements might have toxic effects when placed on cell monolayers, while the set formulations are biocompatible for the same type of cells (MC3T3-E1 osteoblast-like cells were tested). A gel encapsulation in alginate beads was found to be a possible solution to protect living cells for seeding into self-setting calcium orthophosphate pastes[582,617]. In vitro cytotoxic effect of a calcium orthophosphate cement based on $\alpha$-TCP was also observed [618]. In light of these results, the encapsulation approach [308] could potentially be used to seed a patient's ex vivo expanded stem cells into a cement to create an osteoinductive bone graft substitute that could be used to treat that patient. However, this becomes more related to tissue engineering and biology, rather than to chemistry and material science. A first possibility would be designing cement formulations that have setting reactions close to the physiological $\mathrm{pH}$ or by adding additives into the cement paste able to neutralize the acidic or basic ions released during the cementation reaction.

Finally, besides the aforementioned chemical, material and biomedical improvements of the self-setting calcium orthophosphate formulations, one should not forget on a better design of both the mixing equipment and delivery (injection) techniques. As an example, the interested readers are referred to a new cannula to ease cement injection during vertebroplasty[619]; however, this subject is beyond the scope of current review.

\section{Conclusions}

Thus, among the diverse range of bone replacing biomaterials, self-setting calcium orthophosphate formulations undoubtedly represent a distinct group because they are relatively simple materials formed by combining a calcium orthophosphate mixture with an aqueous solution. However, they symbolize an important breakthrough in the field of bone repair biomaterials, since they offer the possibility of obtaining thermally unstable calcium orthophosphates in a monolithic form at room or body temperature by means of a cementation reaction. This particular fabrication technique implies that the self-setting formulations are moldable and therefore can adapt easily to the bone cavity providing a good fixation and the optimum tissue-biomaterial contact, necessary for stimulating bone ingrowth into them and their subsequent osteotransduction[29].

Unfortunately, the perfect grafting material does not exist. The self-setting calcium orthophosphate formulations are not an exception to this statement. While possessing excellent biological properties (osteoconduction and, occasionally, osteoinduction), adequate setting time, excellent moldability and the capability to deliver different bone-enhancing proteins/antibiotics at a local level, unfortunately, the material lacks adequate mechanical properties for applications other than non-loaded surgical sites (see Table 5 for other details). Nevertheless, even in its present state, the self-setting calcium orthophosphate formulations appear to be suitable for a number of applications. They can be injected into osteoporotic bone to reinforce it or can be used to make granules and blocks out of low-temperature calcium orthophosphates. Several types of the self-setting formulations are now on the market (Tables 2 and 3), while scaffolds made of low- temperature calcium orthophosphates are being tested. The use of slightly different chemical compositions and various dopants affects both the setting time and tensile strength that enables further improvements. In addition, new trials are conducted with the reinforced formulations and concretes, 
which represent additional attempts to improve the existing products.

It is anticipated that the use of self-setting calcium orthophosphate formulations will enable a faster and more aggressive rehabilitation, as the strength of the hardened cements makes it possible to allow full weight-bearing earlier than when bone graft is used. Although, preliminary clinical trials have already confirmed the great potential of this novel therapeutic product, the self-setting calcium orthophosphate formulations need to be improved further; in particular, their bioresorption needs to be accelerated as well as their injectability and mechanical properties need to get better. Besides, extra clinical studies are required to define the most appropriate indications and limitations of calcium orthophosphate cements for fracture repair.

In the author's humble opinion, mentioning the Prof. James M. Anderson's opinion on the history of biomaterials field would be the best way to conclude this subject. According to Prof. Anderson, within 1950 - 1975 researchers studied bioMATERIALS, within 1975 - 2000 they studied BIOMATERIALS and since 2000 the time for BIOmaterials has been coming[620]. Here, the capital letters emphasis the major direction of the research efforts in the complex subject of biomaterials. As the real history of self-setting calcium orthophosphate formulations started only in 1983, the aforementioned periods were shifted along the time scale. Certainly, the bioMATERIALS-epoch for the self-setting formulations is almost over (every possible combination of calcium orthophosphates has been already studied and tested), while the BIOmaterials-era (where cells are the key factor) either has not started yet or is just at the very beginning. Most likely, current state-of-the-art of the self-setting calcium orthophosphate formulations corresponds to BIOMATERIALS-phase with an approximately equal contribution of the biological and materials directions. Therefore, still there is much room for versatile ideas and approaches.

\section{REFERENCES}

[1] Albee, F., assisted by Morrison, H., Studies in bone growth. Ann. Surg. 1920, 71, 32-38

[2] Haldeman, K., and Moore, J., Influence of a local excess of calcium and phosphorus on the healing of fractures. Arch. Surg. 1934, 29, 385-396

[3] Ray, R., Degge, J., Gloyd, P., and Mooney, G., Bone regeneration. J. Bone Joint Surg. Am. 1952, 34A, 638-647

[4] Getter, L., Bhaskar, S., Cutright, D., Perez, B., Brady, J., Driskell, T., and O'Hara, M., Three biodegradable calcium orthophosphate slurry implants in bone. J. Oral Surg. 1972, 30, 263-268

[5] Roy, D., and Linnehan, S., Hydroxyapatite formed from coral skeletal carbonate by hydrothermal exchange. Nature 1974, $247,220-222$
[6] Koster, K., Karbe, E., Kramer, H., Heide, H., and Konig, R., Experimenteller Knochenersatz durch resorbierbare Calciumphosphat-Keramik. Langenbecks Arch. Chir. 1976, 341, $77-86$

[7] Peelen, J., Rejda, B., Vermeiden, J., and de Groot, K., Sintered tri-calcium orthophosphate as bioceramic. Sci. Ceram. $1977,9,226-236$

[8] Jarcho, M., Kay, J., Gumaer, K., Doremus, R., and Drobeck, H., Tissue, cellular and subcellular events at a bone-ceramic hydroxyapatite interface. J. Bioeng. 1977, 1, 79-92

[9] Jarcho, M., Calcium phosphate ceramics as hard tissue prosthetics. Clin. Orthop. 1981, 157, 259-278

[10] LeGeros, R. Z., Calcium phosphates in oral biology and medicine, Karger: Basel, Switzerland, 1991; 210 pp

[11] Dorozhkin, S. V., Calcium orthophosphates in nature, biology and medicine. Materials 2009, 2, 399-498

[12] LeGeros, R. Z., Chohayeb, A., and Shulman, A., Apatitic calcium phosphates: possible dental restorative materials. J. Dent. Res. 1982, 61, Spec. Iss., 343

[13] Brown, W. E., and Chow, L. C., A new calcium phosphate setting cement. J. Dent. Res. 1983, 62, Spec. Iss., 672

[14] Brown, W. E., and Chow, L. C., A new calcium phosphate water setting cement. In: Cements Research Progress, Brown, P. W., Ed., Westerville, OH, American Ceramic Society, 1986, pp. 352-379

[15] Brown, W. E., and Chow, L. C., Dental restorative cement pastes. US Patent No. 4518430. May 21, 1985

[16] Gruninger, S. E., Siew, C., Chow, L. C., O’Young, A., Tsao N, K., and Brown, W, E., Evaluation of the biocompatibility of a new calcium phosphate setting cement. J. Dent. Res. 1984, 63, Spec. Iss., 200

[17] Tas, A. C., Porous, biphasic $\mathrm{CaCO}_{3}$-calcium phosphate biomedical cement scaffolds from calcite $\left(\mathrm{CaCO}_{3}\right)$ powder. Int. J. Appl. Ceram. Technol. 2007, 4, 152-163

[18] Driskell, T. D., Heller, A. L., and Koenigs, J. F., Dental treatments. US Patent No. 3913229. October 21, 1975

[19] Kingery, W. D., II. Cold setting properties. J. Am. Ceram. Soc. $1950,33,242-246$

[20] Driessens, F. C. M., Planell, J. A., and Gil, F. J., Calcium phosphate bone cements. In: Encyclopedic Handbook of Biomaterials and Bioengineering, Part B, Applications, Wise, D. L., Trantolo, D. J., Altobelli. D. E., Yaszemski, M. J., Gresser, J. D., Schwarz, E. R. Eds., Marcel Dekker, New York, USA, 1995; Vol. 2, pp. 855-877

[21] Bolarinwa, A., Gbureck, U., Purnell, P., Bold, M., and Grover, L. M., Cement casting of calcium pyrophosphate based bioceramics. Adv. Appl. Ceram. 2010, 109, 291-295

[22] Schmitz, J. P., Hollinger, J. O., and Milan, S. B., Reconstruction of bone using calcium phosphate bone cements: a critical review. J. Oral Maxillofac. Surg. 1999, 57, 1122-1126

[23] Gbureck, U., Barralet, J. E., Spatz, K., Grover, L. M., and Thull, R., Ionic modification of calcium phosphate cement viscosity. Part I: Hypodermic injection and strength improvement of apatite cement. Biomaterials 2004, 25, 


\section{$2187-2195$}

[24] Generosi, A., Rau, J. V., Komlev, V. S., Albertini, V. R., Fedotov, A. Y., and Barinov, S., M. Anomalous hardening behavior of a calcium phosphate bone cement. J. Phys. Chem. B 2010, 114, 973-979

[25] Rau, J. V., Generosi, A., Komlev, V. S., Fosca, M., Barinov, S. M, and Albertini, V. R., Real-time monitoring of the mechanism of poorly crystalline apatite cement conversion in the presence of chitosan, simulated body fluid and human blood. Dalton Trans. 2010, 21, 11412-11423

[26] Smirnov, V. V., Rau, J. V., Generosi, A., Albertini, V. R., Ferro, D., and Barinov, S. M., Elucidation of real-time hardening mechanisms of two novel high-strength calcium phosphate bone cements. J. Biomed. Mater. Res. B Appl. Biomater. 2010, 93B, 74-83

[27] Tagaya, M., Goto, H., Iinuma, M., Wakamatsu, N., Tamura Y., and Doi, Y., Development of self-setting Te-Cp/alpha-TCP cement for pulpotomy. Dent. Mater. J. 2005, 24, 555-561

[28] Driessens, F. C. M., Boltong, M. G., Khairoun, I., de Maeyer, E. A. P., Ginebra, M. P., Wenz, R., Planell, J. A., and Verbeeck, R. M. H., Applied aspects of calcium phosphate bone cement. In: Biomaterials Engineering and Devices: Human Applications, Wise, D. L., Trantolo, D. J., Lewandrowski, K. U., Gresser, J. D., Cattaneo, M. V. Eds., Orthopedic, Dental and Bone Graft Applications. Humana Press: Totowa, NJ, USA, 2000; Vol. 2, pp. 253-260.

[29] Driessens, F. C. M., Planell, J. A., Boltong, M. G., Khairoun, I., and Ginebra, M. P., Osteotransductive bone cements. Proc. Inst. Mech. Eng. H: J. Eng. Med. 1998, 212, 427-435

[30] Frankenburg, E. P., Goldstein, S. A., Bauer, T. W., Harris, S. A., and Poser, R. D., Biomechanical and histological evaluation of a calcium phosphate cement. J. Bone Joint Surg. Am. 1998, 80A, 1112-1124

[31] Frayssinet, P., Gineste, L., Conte, P., Fages, J., and Rouquet, N., Short-term implantation effects of a DCPD-based calcium phosphate cement. Biomaterials 1998, 19, 971-977

[32] Rey, C., Tofighi, A., Mounic, S., Combes, C., and Lee, D., Biomimetism and calcium phosphate cements, In: Actualités en Biomatériaux, Mainard, D., Louis, J. P. Eds. Editions Romillat: Paris, France, 2002; Vol. 6, pp. 27-37

[33] Combes, C., Bareille, R., and Rey, C., Calcium carbonate-calcium phosphate mixed cement compositions for bone reconstruction. J. Biomed. Mater. Res. A 2006, 79A, 318-328

[34] Bohner, M., Gbureck, U., and Barralet, J. E., Technological issues for the development of more efficient calcium phosphate bone cements: a critical assessment. Biomaterials 2005, 26, 6423-6429

[35] Ikenaga, M., Hardouin, P., Lemaitre, J., Andrianjatovo, H., and Flautre, B., Biomechanical characterization of a biodegradable calcium phosphate hydraulic cement: a comparison with porous biphasic calcium phosphate ceramics. J. Biomed. Mater. Res. 1998, 40, 139-144

[36] Ginebra, M. P., Traykova, T., and Planell, J. A., Calcium phosphate cements: competitive drug carriers for the musculoskeletal system? Biomaterials 2006, 27, 2171-2177

[37] Ginebra, M. P., Traykova, T., and Planell, J. A., Calcium phosphate cements as bone drug delivery systems: a review. J. Control. Release 2006, 113, 102-110

[38] It is interesting to note that calcium sulfate (gypsum or plaster of Paris) has been implanted into fracture gaps and voids of bones for more than 100 years[39-41]

[39] Dreesmann, H., Knochenplombierung bei Hohlenforigen Defekten des Knochens. Beitr. Klin. Chir. 1892, 9, 804-810

[40] Peltier, L. F., The use of plaster of Paris to fill defects in bone. Clin. Orthop. 1961, 21, 1-29

[41] Kelly, C. M., Wilkins, R. M., Gitelis, S., Hartjen, C., Watson, J. T., and Kim, P. T., The use of a surgical grade calcium sulfate as a bone graft substitute: results of a multicenter trial. Clin. Orthop. 2001, 382, 42-50

[42] Bohner, M., New hydraulic cements based on $\alpha$-tricalcium phosphate - calcium sulfate dihydrate mixtures. Biomaterials 2004, 25, 741-749

[43] Fernández, E., Vlad, M. D., Gel, M, M., Lopez, J., Torres, R., Cauich, J. V., and Bohner, M., Modulation of porosity in apatitic cements by the use of $\alpha$-tricalcium phosphate - calcium sulphate dihydrate mixtures. Biomaterials 2005, 26, 3395-3404

[44] Hu, G., Xiao, L., Fu, H., Bi, D., Ma, H., and Tong, P., Degradable and bioactive scaffold of calcium phosphate and calcium sulphate from self-setting cement for bone regeneration. J. Porous Mater. 2010, 17, 605-613

[45] Hu, G., Xiao, L., Fu, H., Bi, D., Ma, H., and Tong, P., Study on injectable and degradable cement of calcium sulphate and calcium phosphate for bone repair. J. Mater. Sci. Mater. Med. 2010, 21, 627-634

[46] Nilsson, M., Fernández, E., Sarda, S., Lidgren, L., and Planell, J. A., Characterization of a novel calcium phosphate/sulphate bone cement. J. Biomed. Mater. Res. 2002, 61, 600-607

[47] Vlad, M. D., Şindilar, E. V., Mariñoso, M. L., Poeată, I., Torres, R., López, J., Barracó, M., and Fernández, E., Osteogenic biphasic calcium sulphate dihydrate/iron-modified $\alpha$-tricalcium phosphate bone cement for spinal applications: in vivo study. Acta Biomater. 2010, 6, 607-616

[48] Grover, L. M., Gbureck, U., Wright, A. J., Tremaynec, M., and Barralet, J. E., Biologically mediated resorption of brushite cement in vitro. Biomaterials 2006, 27, 2178-2185

[49] Grover, L. M., Gbureck, U., Wright, A. J., and Barralet, J. E., Cement formulations in the calcium phosphate $\mathrm{H}_{2} \mathrm{O}-\mathrm{H}_{3} \mathrm{PO}_{4}$ $-\mathrm{H}_{4} \mathrm{P}_{2} \mathrm{O}_{7}$ system. J. Am. Ceram. Soc. 2005, 88, 3096-3103

[50] Grover, L. M., Gbureck, U., Young, A. M., Wright, A. J., and Barralet, J. E., Temperature dependent setting kinetics and mechanical properties of $\beta$-TCP - pyrophosphoric acid bone cement. J. Mater. Chem. 2005, 46, 4955-4962

[51] Oh, K. S., Jeong, Y. K., Yu, J. P., Chae, S. K., Kim, H. Y., Lee, H. Y., and Jeun, S. S., Preparation and in vivo studies of $\beta$-TCP based bone cement containing polyphosphate. Key Eng. Mater. 2005, 284-286, 93-96

[52] Lilley, K. J., Gbureck, U., Wright, A. J., Knowles, J. C., Farrar, D. F., and Barralet, J. E., Brushite cements from polyphosphoric acid, calcium phosphate systems. J. Am. Ceram. Soc. 2007, 90, 1892-1898 
[53] Fernández, E., Planell, J. A., and Best, S. M., Precipitation of carbonated apatite in the cement system $\alpha-\mathrm{Ca}_{3}\left(\mathrm{PO}_{4}\right)_{2}-$ $\mathrm{Ca}\left(\mathrm{H}_{2} \mathrm{PO}_{4}\right)_{2}-\mathrm{CaCO}_{3}$. J. Biomed. Mater. Res. 1999, 47, $466-471$

[54] Calafiori, A. R., di Marco, G., Martino, G., and Marotta, M., Preparation and characterization of calcium phosphate biomaterials. J. Mater. Sci. Mater. Med. 2007, 18, 2331-2338

[55] Kon, M., Hirakata, L. M., Miyamoto, Y., Kasahara, H., and Asaoka, K., Strengthening of calcium phosphate cement by compounding calcium carbonate whiskers. Dent. Mater. J. 2005, 24, 104-110

[56] Serraj, S., Michailesco, P., Margerit, J., Bernard, B., and Boudeville, P., Study of a hydraulic calcium phosphate cement for dental applications. J. Mater. Sci. Mater. Med. 2002, $13,125-131$

[57] Nurit, L., Margerit, J., Terol, A., and Boudeville, P., pHmetric study of the setting reaction of monocalcium phosphate monohydrate/calcium oxide-based cements. J. Mater Sci. Mater. Med. 2002, 13, 1007-1014

[58] Boudeville, P., Serraj, S., Leloup, J. M., Margerit, J., Pauvert, B., and Terol, A., Physical properties and self-setting mechanism of calcium phosphate cements from calcium bis-dihydrogenophosphate monohydrate and calcium oxide. J. Mater. Sci. Mater. Med. 1999, 10, 99-109

[59] Michaïlesco, P., Kouassi, M., Briak, H. E., Armynot, A., and Boudeville, P., Antimicrobial activity and tightness of a DCPD - CaO-based hydraulic calcium phosphate cement for root canal filling. J. Biomed. Mater. Res. B Appl. Biomater. 2005, 74B, 760-767

[60] Briak, H. E., Durand, D., Nurit, J., Munier, S., Pauvert, B., and Boudeville, P., Study of a hydraulic dicalcium phosphate dihydrate/calcium oxide-based cement for dental applications. J. Biomed. Mater. Res. Appl. Biomater. 2002, 63, 447-453

[61] Briak, H. E., Durand, D., and Boudeville, P., Study of a hydraulic DCPA/CaO-based cement for dental applications. J. Mater. Sci. Mater. Med. 2008, 19, 737-744

[62] Takagi, S., Chow, L. C., and Ishikawa, K., Formation of hydroxyapatite in new calcium phosphate cements. Biomaterials $1998,19,1593-1599$

[63] Yang, Q., Troczynski, T., and Liu, D. M., Influence of apatite seeds on the synthesis of calcium phosphate cement. Biomaterials 2002, 23, 2751-2760

[64] Hsu, H. C., Chiu, C. Y., Tuan, W. H., and Lee, H. Y., Structural stability of calcium phosphate cement during aging in water. Mater. Sci. Eng. C 2008, 28, 429-433

[65] Roemhildt, M. L., McGee, T. D., and Wagner, S. D., Novel calcium phosphate composite bone cement, strength and bonding properties. J. Mater. Sci. Mater. Med. 2003, 14, 137-141

[66] Roemhildt, M. L., Wagner, S. D., and McGee, T. D., Characterization of a novel calcium phosphate composite bone cement: flow, setting, and aging properties. J. Mater. Sci. Mater. Med. 2006, 17, 1127-1132

[67] Wang, X., Ye, J., Wang, Y., and Chen, L., Self-setting properties of a $\beta$-dicalcium silicate reinforced calcium phosphate cement. J. Biomed. Mater. Res. B Appl. Biomater. 2007, 82B, 93-99
[68] Huan, Z., and Chang, J., Novel tricalcium silicate/ monocalcium phosphate monohydrate composite bone cement. J. Biomed. Mater. Res. B Appl. Biomater. 2007, 82B, 352-359

[69] Huan, Z., and Chang, J., Calcium-phosphate-silicate composite bone cement, self-setting properties and in vitro bioactivity. J. Mater. Sci. Mater. Med. 2009, 20, 833-841

[70] Huan, Z., and Chang, J., Novel bioactive composite bone cements based on the $\beta$-tricalcium phosphate - monocalcium phosphate monohydrate composite cement system. Acta Biomater. 2009, 5, 1253-1264

[71] Shen, Q., Sun, J., Wu, J., Liu, C., and Chen, F., An in vitro investigation of the mechanical-chemical and biological properties of calcium phosphate/calcium silicate/bismutite cement for dental pulp capping. J. Biomed. Mater. Res. B Appl. Biomater. 2010, 94, 141-148

[72] Guo, D., Xu, K., Zhao, X., and Han, Y., Development of a strontium-containing hydroxyapatite bone cement. Biomaterials $2005,26,4073-4083$

[73] Wang, X., and Ye, J., Variation of crystal structure of hydroxyapatite in calcium phosphate cement by the substitution of strontium ions. J. Mater. Sci. Mater. Med. 2008, 19, $1183-1186$

[74] Pina, S., Torres, P. M. C., and Ferreira, J. M. F., Injectability of brushite-forming Mg-substituted and Sr-substituted $\alpha$-TCP bone cements. J. Mater. Sci. Mater. Med. 2010, 21, 431-438

[75] Wu, F., Su, J. C., Wei, J., Guo, H., and Liu, C. S., Injectable bioactive calcium-magnesium phosphate cement for bone regeneration. Biomed. Mater. 2008, 3, 044105 (7 pages)

[76] Wu, F., Wei, J., Guo, H., Chen, F. P., Hong, H., and Liu, C. S., Self-setting bioactive calcium-magnesium phosphate cement with high strength and degradability for bone regeneration. Acta Biomater. 2008, 4, 1873-1884

[77] Pina, S., Olhero, S. M., Gheduzzi, S., Miles A. W., and Ferreira, J. M. F., Influence of setting liquid composition and liquid-to-powder ratio on properties of a Mg-substituted calcium phosphate cement. Acta Biomater. 2009, 5, 1233-1240

[78] Klammert, U., Reuther, T., Blank, M., Reske, I., Barralet, J. E., Grover, L. M., Kübler, A. C., and Gbureck, U., Phase composition, mechanical performance and in vitro biocompatibility of hydraulic setting calcium magnesium phosphate cement. Acta Biomater. 2010, 6, 1529-1535

[79] Jia, J., Zhou, H., Wei, J., Jiang, X., Hua, H., Chen, F., Wei, S., Shin, J. W., and Liu, C., Development of magnesium calcium phosphate biocement for bone regeneration. J. Royal Soc. Interf. 2010, 7, 1171-1180

[80] Pina, S., Vieira, S. I., Torres, P. M. C., Goetz-Neunhoeffer, F., Neubauer, J., da Cruz E. Silva, O. A. B., da Cruz E. Silva, E. F., and Ferreira, J. M. F., In vitro performance assessment of new brushite-forming $\mathrm{Zn}$ - and $\mathrm{ZnSr}$-substituted $\beta$-TCP bone cements. J. Biomed. Mater. Res. B Appl. Biomater. 2010, 94B, 414-420

[81] Gbureck, U., Knappe, O., Grover, L. M., and Barralet, J. E., Antimicrobial potency of alkali ion substituted calcium phosphate cements. Biomaterials 2005, 26, 6880-6886

[82] Driessens, F. C. M., Boltong, M. G., de Mayer, E. A. P., Wenz, R., Nies, B., and Planell, J. A., The $\mathrm{Ca} / \mathrm{P}$ range of nanoapatitic calcium phosphate cements. Biomaterials 2002, 23, 4011- 
4017

[83] Gbureck, U., Thull, R., and Barralet, J. E., Alkali ion substituted calcium phosphate cement formation from mechanically activated reactants. J. Mater. Sci. Mater. Med. 2005, 16, 423-427

[84] Doi, Y., Shimizu, Y., Moriwaki, Y., Aga, M., Iwanaga, H., Shibutani, T., Yamamoto, K., and Iwayama, Y., Development of a new calcium phosphate cement that contains sodium calcium phosphate. Biomaterials 2001, 22, 847-854

[85] Lilley, J., Gbureck, U., Knowles, J. C., Farrar, D. F., and Barralet, J. E., Cement from magnesium substituted hydroxyapatite. J. Mater. Sci. Mater. Med. 2005, 16, 455-460

[86] Ni, G. X., Lu, W. W., Tang, B., Ngan, A. H. W., Chiu, K. Y., Cheung, K. M. C., Li, Z. Y., and Luk, K. D. K., Effect of weight-bearing on bone-bonding behavior of strontium-containing hydroxyapatite bone cement. J. Biomed. Mater. Res. A 2007, 83A, 570-576

[87] Alkhraisat, M. H., Mariño, F. T., Rodríguez, C. R., Jerez, L. B., and Cabarcos, E. L., Combined effect of strontium and pyrophosphate on the properties of brushite cements. Acta Biomater. 2008, 4, 664-670

[88] Yao, Z. P., Liu, W, G., and Ni, G. X., Biology characteristics and clinical application of strontium substituted hydroxyapatite bone cement. J. Clin. Rehabil. Tissue Eng. Res. 2008, 12, 7151-7154

[89] Li, S., Liu, B., Cheng, J., and Hu, J., Composite cement of magnesium-bearing phosphoaluminate-hydroxyapatite reinforced by treated raw silk fiber. Cement and Concrete Composites 2008, 30, 347-352

[90] Ni, G. X., Lin, J. H., Chiu, P. K. Y., Li, Z. Y., and Lu, W. W., Effect of strontium-containing hydroxyapatite bone cement on bone remodeling following hip replacement. J. Mater. Sci. Mater. Med. 2010, 21, 377-384

[91] Fadeeva, I. V., Barinov, S. M., Komlev, V. S., Fedotov, D. A., Durisin, J., and Medvecky, L., Apatite formation in the reaction-setting mixture of $\mathrm{Ca}(\mathrm{OH})_{2}-\mathrm{KH}_{2} \mathrm{PO}_{4}$ system. J. Biomed. Mater. Res. A 2004, 70A, 303-308

[92] Tas, A. C., Use of vaterite and calcite in forming calcium phosphate cement scaffolds. Ceram. Eng. Sci. Proc. 2008, 28, $135-150$

[93] Fernández, E., Vlad, M. D., Hamcerencu, M., Darie, A., Torres, R., and Lopez, J., Effect of iron on the setting properties of $\alpha$-TCP bone cements. J. Mater. Sci. 2005, 40, 3677-3682

[94] Vlad, M. D., del Valle, L. J., Poeata, I., Barracó, M., López, J., Torres, R., and Fernández, E., Injectable iron-modified apatitic bone cement intended for kyphoplasty, cytocompatibility study. J. Mater. Sci. Mater. Med. 2008, 19, 3575-3583

[95] http://en. wikipedia. org/wiki/Cement (accessed in November 2011)

[96] There are some differences between TTCP + DCPD and TTCP + DCPA cements. Due to a higher solubility of DCPD (Table 1 and Fig. 1), a TTCP + DCPD cement sets faster than a TTCP + DCPA cement. Besides, injectability of a TTCP + DCPD cement is better[97,98]

[97] Burguera, E. F., Xu, H. H. K., and Weir, M. D., Injectable and rapid-setting calcium phosphate bone cement with dicalcium phosphate dihydrate. J. Biomed. Mater. Res. B Appl. Biomater. 2006, 77B, 126-134

[98] Burguera, E. F., Guitian, F., and Chow, L. C., A water setting tetracalcium phosphate - dicalcium phosphate dihydrate cement. J. Biomed. Mater. Res. A 2004, 71A, 275-282

[99] Driessens, F. C. M., Boltong, M. G., Bermudez, O., and Planell, J. A., Formulation and setting times of some calcium orthophosphate cements, a pilot study. J. Mater. Sci. Mater. Med. 1993, 4, 503-508

[100] Chow, L. C., Markovic, M., and Takagi, S., Calcium phosphate cements. In: Cements research progress, Struble, L. J., Ed. Chapter 7. American Ceramic Society: Westerville, OH, USA, 1998; pp. 215-238

[101] Driessens, F. C. M., Boltong, M. G., Bermudez, O., Planell, J. A., Ginebra, M. P., and Fernández, E., Effective formulations for the preparation of calcium phosphate bone cements. J. Mater. Sci. Mater. Med. 1994, 5, 164-170

[102] Kurashina, K., Hirano, M., Kotani, A., Klein, C. P. A. T., and de Groot, K., In vivo study of calcium phosphate cements, implantation of an $\alpha$-tricalcium phosphate/dicalcium phosphate dibasic/tetracalcium phosphate monoxide cement paste. Biomaterials 1997, 18, 539-543

[103] Friedman, C. D., Costantino, P. D., Takagi, S., and Chow, L. C., BoneSource ${ }^{\mathrm{TM}}$ hydroxyapatite cement, a novel biomaterial for craniofacial skeletal tissue engineering and reconstruction. J. Biomed. Mater. Res. 1998, 43, 428-432

[104] Khairoun, I., Boltong, M. G., Driessens, F. C. M., and Planell J. A., Effect of calcium carbonate on the compliance of apatitic calcium phosphate bone cement. Biomaterials 1997, 18, $1535-1539$

[105] Fernández, E., Gil, F. J., Best, S. M., Ginebra, M. P., Driessens, F. C. M., and Planell, J. A., Improvement of the mechanical properties of new calcium phosphate bone cements in the $\mathrm{CaHPO}_{4}-\alpha-\mathrm{Ca}_{3}\left(\mathrm{PO}_{4}\right)_{2}$ system, compressive strength and microstructural development. J. Biomed. Mater. Res. $1998,41,560-567$

[106] Fukase, Y., Eanes, E. D., Takagi, S., Chow, L. C., and Brown, W. E., Setting reactions and compressive strengths of calcium phosphate cements. J. Dent. Res. 1990, 69, 1852-1856

[107] Xie, L., and Monroe, E. A., Calcium phosphate dental cements. Mat. Res. Soc. Symp. Proc. 1991, 179, 25-39

[108] Ishikawa, K., Miyamoto, Y., Kon, M., Nagayama, M., and Asaoka, K., Non-decay type fast-setting calcium orthophosphate cement composite with sodium alginate. Biomaterials $1995,16,527-532$

[109] Xu, H. H. K., Quinn, J. B., Takagi, S., and Chow, L. C., Processing and properties of strong and non-rigid calcium phosphate cement. J. Dent. Res. 2002, 81, 219-224

[110] Lee, Y. K., Lim, B. S., and Kim, C. W., Mechanical properties of calcium phosphate based dental filling and regeneration materials. J. Oral Rehabil. 2003, 30, 418-425

[111] Ginebra, M. P., Fernández, E., de Mayer, E. A. P., Verbeeck, R. M. H., Boltong, M. G., Ginebra, J., Driessens, F. C. M., and Planell, J. A., Setting reaction and hardening of an apatitic calcium phosphate cement. J. Dent. Res. 1997, 76, 905-912 
[112] Liu, C., Shen, W., Gu, Y., and Hu, L., Mechanism of the hardening process for a hydroxyapatite cement. J. Biomed. Mater. Res. 1997, 35, 75-80

[113] Driessens, F. C. M., de Mayer, E. A. P., Fernández, E., Boltong, M. G., Berger G., Verbeeck, R. M. H., Ginebra, M. P., and Planell, J. A., Amorphous calcium phosphate cements and their transformation into calcium deficient hydroxyapatite. Bioceramics 1996, 9, 231-234

[114] Driessens, F. C. M., Planell, J. A., and Gil, F., Calcium phosphate bone cements. In: Encyclopedic handbook of biomaterials and bioengineering, Wise, D. L., Trantolo, D. J., Altobelli, D. E., Yaszemski, M. J., Cresser, J. D., and Schwartz, E. R., Eds. Part B, Applications. Marcel Dekker: New York, USA, 1995; Vol. 2, pp. 855-877

[115] Lemaître, J., Injectable calcium phosphate hydraulic cements: new developments and potential applications. Inn. Tech. Biol. Med. 1995, 16, 109-120

[116] Neira, I. S., Kolen'ko, Y. V., Lebedev, O. I., van Tendeloo, G., Gupta, H. S., Matsushita, N., Yoshimura, M., and Guitián, F., Rational synthesis of a nanocrystalline calcium phosphate cement exhibiting rapid conversion to hydroxyapatite. Mater. Sci. Eng. C 2009, 29, 2124-2132

[117] Tañag, M. A., Yano, K., and Hosokawa, K., Orbital floor reconstruction using calcium phosphate cement paste: an animal study. Plast. Reconstr. Surg. 2004, 114, 1826-1831

[118] Hatoko, M., Tada, H., Tanaka, A., Yurugi, S., Niitsuma, K., and Iioka, H., The use of calcium phosphate cement paste for the correction of the depressed nose deformity. J. Craniofac. Surg. 2005, 16, 327-331

[119] Tañag, M. A., Madura, T., Yano, K., and Hosokawa, K., Use of calcium phosphate cement paste in orbital volume augmentation. Plast. Reconstr. Surg. 2006, 117, 1186-1193

[120] Meng, D., Xie, Q. F., and Xiao, J. J., Effects of two calcium phosphate cement pastes on osteoblasts during solidification. J. Clin. Rehabilit. Tiss. Eng. Res. 2009, 13, 471-474

[121] According to Wikipedia, the free encyclopedia: "Putty is a generic term for a plastic material similar in texture to clay or dough typically used in domestic construction and repair as a sealant or filler. " http://en. wikipedia. org/wiki/Putty (accessed in November 2011)

[122] Ishikawa, K., Miyamoto, Y., Takechi, M., Toh, T., Kon, M., Nagayama, M., and Asaoka, K., Non-decay type fast-setting calcium phosphate cement: hydroxyapatite putty containing an increased amount of sodium alginate. J. Biomed. Mater. Res. 1997, 36, 393-399

[123] Ishikawa, K., Miyamoto, Y., Takechi, M., Ueyama, Y., Suzuki, K., Nagayama, M., and Matsumura, T., Effects of neutral sodium hydrogen phosphate on setting reaction and mechanical strength of hydroxyapatite putty. J. Biomed. Mater. Res. 1999, 44, 322-329

[124] Momota, Y., Miyamoto, Y., Ishikawa, K., Takechi, M., Yuasa, T., Tatehara, S., and Nagayama, M., Effects of neutral sodium hydrogen phosphate on the setting property and hemostatic ability of hydroxyapatite putty as a local hemostatic agent for bone. J. Biomed. Mater. Res. B Appl. Biomater. 2004, 69B, 99-103

[125] Bohner, M., Design of ceramic-based cements and putties for bone graft substitution. Eur. Cell Mater. 2010, 20, 1-12
[126] In the vast majority cases, a precipitated poorly crystalline HA and CDHA are undistinguishable and might be considered as synonyms[11]

[127] To honor Prof. George Jarvis Brush (1831 - 1912), an American mineralogist, Yale University, New Haven, Connecticut, USA

[128] Xia, Z., Grover, L. M., Huang, Y., Adamopoulos, I. E., Gbureck, U., Triffitt, J. T., Shelton, R. M., and Barralet, J. E., In vitro biodegradation of three brushite calcium phosphate cements by a macrophage cell-line. Biomaterials 2006, 27, $4557-4565$

[129] Monma, H., Makishima, A., Mitomo, M., and Ikegami, T., Hydraulic properties of the tricalcium phosphate - dicalcium phosphate mixture. J. Ceram. Soc. Jpn. 1988, 96, 878-880

[130] Bermudez, O., Boltong, M. G., Driessens, F. C. M., and Planell, J. A., Development of an octacalcium phosphate cement. J. Mater. Sci. Mater. Med. 1994, 5, 144-146

[131] Sena, M., Yamashita, Y., Nakano, Y., Ohgaki, M., Nakamura, S., Yamashita, K., and Takagi, Y., Octacalcium phosphate-based cement as a pulp-capping agent in rats. Oral Surg. Oral Med. Oral Pathol. Oral Radiol. Endod. 2004, 97, 749-755

[132] Markovic, M., and Chow, L. C., An octacalcium phosphate forming cement. J. Res. Natl. Inst. Stand. Technol. 2010, 115, $257-265$

[133] In early 1990-s, depending on the type of calcium orthophosphate formed after the setting, five groups of the cement formulations were thought to exist: DCPD, CDHA, HA, ACP and $\mathrm{OCP}[101,134]$, while currently only two cement groups remain

[134] Khairoun, I., Boltong, M. G., Driessens, F. C. M., and Planell, J. A., Limited compliance of some apatitic calcium phosphate bone cements with clinical requirements. J. Mater. Sci. Mater. Med. 1998, 9, 667-671

[135] Lacout, J., Mejdoubi, E., and Hamad, M., Crystallization mechanisms of calcium orthophosphate cement for biological uses. J. Mater. Sci. Mater. Med. 1996, 7, 371-374

[136] Song, Y., Feng, Z., and Wang, T., In situ study on the curing process of calcium phosphate bone cement. J. Mater. Sci. Mater. Med. 2007, 18, 1185-1193

[137] Weiss, D. D., Sachs, M. A., and Woodard, C. R., Calcium phosphate bone cements: a comprehensive review. J. Long Term Eff. Med. Implants 2003, 13, 41-47

[138] Fernández, E., Gil, F. J., Ginebra, M. P., Driessens, F. C. M., Planell, J. A., and Best, S. M., Calcium phosphate bone cements for clinical applications. Part I: Solution chemistry. J. Mater. Sci. Mater. Med. 1999, 10, 169-176

[139] Brown, W. E., and Chow, L. C., A new calcium phosphate water-setting cement. In: Cements Research Progress, Brown, P. W., Ed., American Ceramic Society: Westerville, OH, USA, 1986; pp. 351-379

[140] Hatim, Z., Freche, M., Keribech, A., and Lacout, J. L., The setting mechanism of a phosphocalcium biological cement. Ann. Chim. Sci. Mat. 1998, 23, 65-68

[141] Ishikawa, K., and Asaoka, K., Estimation of ideal mechanical strength and critical porosity of calcium phosphate cement. J. 
Biomed. Mater. Res. 1995, 29, 1537-1543

[142] Chow, L. C., Development of self-setting calcium phosphate cements. J. Ceram. Soc. Jpn. 1991, 99, 954-964

[143] Chow, L. C., Calcium phosphate cements: chemistry, properties and applications. Mat. Res. Soc. Symp. Proc. 2000, 599, 27-37

[144] Chow, L. C., Calcium phosphate cements. In: Octacalcium Phosphate, Chow, L. C., Eanes, E. D., Eds., Monographs in Oral Science. Karger: Basel, Switzerland, 2001; Vol. 18, pp. $148-163$

[145] Brown, P. W., and Fulmer, M. T., Kinetics of hydroxyapatite formation at low temperature. J. Am. Ceram. Soc. 1991, 74, 934-940

[146] TenHuisen, K. S., and Brown, P. W., The formation of hydroxyapatite-ionomer cements at $38^{\circ} \mathrm{C}$. J. Dent. Res. 1994, 3, 598-606

[147] Ishikawa, K., Takagi, S., Chow, L. C., and Suzuki, K., Reaction of calcium phosphate cements with different amounts of tetracalcium phosphate and dicalcium phosphate anhydrous. J. Biomed. Mater. Res. 1999, 46, 504-510

[148] Matsuya, S., Takagi, S., and Chow, L. C., Effect of mixing ratio and $\mathrm{pH}$ on the reaction between $\mathrm{Ca}_{4}\left(\mathrm{PO}_{4}\right)_{2} \mathrm{O}$ and $\mathrm{CaHPO}_{4}$. J. Mater. Sci. Mater. Med. 2000, 11, 305-311

[149] Burguera, E. F., Guitian, F., and Chow, L. C., Effect of the calcium to phosphate ratio of tetracalcium phosphate on the properties of calcium phosphate bone cement. J. Biomed. Mater. Res. A 2008, 85A, 674-683

[150] Lemaître, J., Mirtchi, A. A., and Mortier, A., Calcium phosphate cements for medical use: state of the art and perspectives of development. Silic. Ind. 1987, 9-10, 141-146

[151] Bajpai, P., Fuchs, C., and McCullum, D., Development of tricalcium orthophosphate ceramic cement. In: Quantitative characterization and performance of porous implants for hard tissue applications, Lemons, J., Ed., ASTM STP 953. Am. Soc. Test. Mater. : Philadelphia, 1987; pp. 377-388

[152] Mirtchi, A. A., Lemaître, J., and Terao, N., Calcium phosphate cements: study of the $\beta$-tricalcium phosphate - monocalcium phosphate system. Biomaterials 1989, 10, 475-480

[153] Bohner, M., van Landuyt, P., Merkle, H. P., and Lemaitre, J., Composition effects on the $\mathrm{pH}$ of a hydraulic calcium orthophosphate cement. J. Mater. Sci. Mater. Med. 1997, 8, 675-681

[154] Bohner, M., Lemaître, J., and Ring, T. A., Effects of sulfate, pyrophosphate and citrate ions on the physiochemical properties of cements made of $\beta$-tricalcium phosphate - phosphoric acid - water mixtures. J. Am. Ceram. Soc. 1996, 79, $1427-1434$

[155] Grover, L. M., Hofmann M. P., Gbureck, U., Kumarasami B., and Barralet, J. E., Frozen delivery of brushite calcium phosphate cements. Acta Biomater. 2008, 4, 1916-1923

[156] Fernández, E., Gil, F. J., Best, S. M., Ginebra, M. P., Driessens, F. C. M., and Planell, J. A., The cement setting reaction in the $\mathrm{CaHPO}_{4}-\alpha-\mathrm{Ca}_{3}\left(\mathrm{PO}_{4}\right)_{2}$ system: an X-ray diffraction study. J. Biomed. Mater. Res. 1998, 42, 403-406

[157] Fernández, E., Gil, F. J., Ginebra, M. P., Driessens, F. C. M.,
Planell, J. A., and Best, S. M., Production and characterisation of new calcium phosphate bone cements in the $\mathrm{CaHPO}_{4}$ $\alpha-\mathrm{Ca}_{3}\left(\mathrm{PO}_{4}\right)_{2}$ system: $\mathrm{pH}$, workability and setting times. J. Mater. Sci. Mater. Med. 1999, 10, 223-230

[158] Barralet, J. E., Lilley, K. J., Grover, L. M., Farrar, D. F., Ansell, C., and Gbureck, U., Cements from nanocrystalline hydroxyapatite. J. Mater. Sci. Mater. Med. 2004, 15, 407-411

[159] Lilley, K. J., Gbureck, U., Wright, A. J., Farrar, D. F., and Barralet, J. E., Cement from nanocrystalline hydroxyapatite: effect of calcium phosphate ratio. J. Mater. Sci. Mater. Med. 2005, 16, 1185-1190

[160] Alge, D. L., Cruz, G. S., Goebel, W. S., and Chu, T. M. G., Characterization of dicalcium phosphate dihydrate cements prepared using a novel hydroxyapatite-based formulation. Biomed. Mater. 2009, 4, 025016

[161] Wang, X., Ye, J., Wang, Y., Wu, X., and Bai, B., Control of crystallinity of hydrated products in a calcium phosphate bone cement. J. Biomed. Mater. Res. A 2007, 81A, 781-790

[162] Wang, X., Ye, J., and Wang, H., Effects of additives on the rheological properties and injectability of a calcium phosphate bone substitute material. J. Biomed. Mater. Res. B Appl. Biomater. 2006, 78B, 259-264

[163] Tofighi, A., Schaffer, K., and Palazzolo, R., Calcium phosphate cement (CPC): a critical development path. Key Eng. Mater. 2008, 361-363, 303-306

[164] de Maeyer, E. A. P., Verbeeck, R. M. H., and Vercruysse, C. W. J., Conversion of octacalcium phosphate in calcium phosphate cements. J. Biomed. Mater. Res. 2000, 52, 95-106

[165] Nakano, Y., Ohgaki, M., Nakamura, S., Takagi, Y., and Yamashita, K., In vitro and in vivo characterization and mechanical properties of $\alpha$-TCP/OCP settings. Bioceramics $1999,12,315-318$

[166] Nakano, Y., Preparation and characterization of porous octacalcium phosphate setting improved by $\alpha$-tricalcium phosphate additive. J. Dent. Mater. 2000, 19, 65-76

[167] Wang, X., Ye, J., and Wang, Y., Hydration mechanism of a novel PCCP + DCPA cement system. J. Mater. Sci. Mater. Med. 2008, 19, 813-816

[168] Zoulgami, M., Lucas, A., Briard, P., and Gaudé, J., A self-setting single-component calcium phosphate cement. Biomaterials 2001, 22, 1933-1937

[169] Knaack, D., Goad, M. E., Aiolova, M., Rey, C., Tofighi, A., Chakravarthy, P., and Lee, D. D., Resorbable calcium phosphate bone substitute. J. Biomed. Mater. Res. 1998, 43, 399-409

[170] Tofighi, A., Mounic, S., Chakravarthy, P., Rey, C., and Lee, D., Setting reactions involved in injectable cements based on amorphous calcium phosphate. Key Eng. Mater. 2001, 192-195, 769-772

[171] Monma, H., and Kanazawa, T., Hydration of $\alpha$-tricalcium phosphate. J. Ceram. Soc. Jpn. 2000, 108, 575-580

[172] Fernández, E., Ginebra, M. P., Boltong, M. G., Driessens, F. C. M., Ginebra, J., de Maeyer, E. A. P., Verbeeck, R. M. H., and Planell, J. A., Kinetic study of the setting reaction of a calcium phosphate bone cement. J. Biomed. Mater. Res. 1996, $32,367-374$ 
[173] Gbureck, U., Barralet, J. E., Radu L., Klinger, H. G., and Thull, R., Amorphous $\alpha$-tricalcium phosphate, preparation and aqueous setting reaction. J. Am. Ceram. Soc. 2004, 87, $1126-1132$

[174] Bohner, M. Malsy, A. K., Camire, C. L., and Gbureck, U., Combining particle size distribution and isothermal calorimetry data to determine the reaction kinetics of $\alpha$-tricalcium phosphate - water mixtures. Acta Biomater. 2006, 2, 343-348

[175] Brunner, T. J., Grass, R. N., Bohner, M., and Stark, W. J., Effect of particle size, crystal phase and crystallinity on the reactivity of tricalcium phosphate cements for bone reconstruction. J. Mater. Chem. 2007, 38, 4072-4078

[176] Alves, H. L. R., dos Santos, L. A., and Bergmann, C. P., Injectability evaluation of tricalcium phosphate bone cement. J. Mater. Sci. Mater. Med. 2008, 19, 2241-2246

[177] Jack, V., Buchanan, F. J., and Dunne, N. J., Particle attrition of $\alpha$-tricalcium phosphate, effect on mechanical, handling, and injectability properties of calcium phosphate cements. Proc. Inst. Mech. Eng. H: J. Eng. Med. 2008, 222, 19-28

[178] Oh, S. A., Lee, G. S., Park, J. H., and Kim, H. W., Osteoclastic cell behaviors affected by the $\alpha$-tricalcium phosphate based bone cements. J. Mater. Sci. Mater. Med. 2010, 21, 3019-3027

[179] Gbureck, U., Grolms, O., Barralet, J. E., Grover, L. M., and Thull, R., Mechanical activation and cement formation of $\beta$-tricalcium phosphate. Biomaterials 2003, 24, 4123-4131

[180] Gbureck, U., Barralet, J. E., Hofmann, M. P., and Thull, R., Nanocrystalline tetracalcium phosphate cement. J. Dent. Res. 2004, 83, 425-428

[181] Gbureck, U., Barralet, J. E., Hofmann, M. P., and Thull, R., Mechanical activation of tetracalcium phosphate. J. Am. Ceram. Soc. 2004, 87, 311-313

[182] Tsai, C. H., Ju, C. P., and Lin, J. H. C., Morphology and mechanical behavior of TTCP-derived calcium phosphate cement subcutaneously implanted in rats. J. Mater. Sci. Mater. Med. 2008, 19, 2407-2415

[183] Tsai, C. H., Lin, R. M., Ju, C. P., and Lin, J. H. C., Bioresorption behavior of tetracalcium phosphate-derived calcium phosphate cement implanted in femur of rabbits. Biomaterials 2008, 29, 984-993

[184] Tsai, C. H., Lin, J. H. C., and Ju, C. P., $\gamma$-radiation-induced changes in structure and properties of tetracalcium phosphate and its derived calcium phosphate cement. J. Biomed. Mater. Res. B Appl. Biomater. 2007, 80B, 244-252

[185] Chow, L. C., Markovic, M., Frukhtbeyn, S. A., and Takagi, S., Hydrolysis of tetracalcium phosphate under a near-constant composition condition - effects of $\mathrm{pH}$ and particle size. Biomaterials 2005, 26, 393-401

[186] TenHuisen, K. S., and Brown, P. W., Formation of calcium-deficient hydroxyapatite from $\alpha$-tricalcium phosphate. Biomaterials 1998, 19, 2209-2217

[187] Ginebra, M. P., Fernández, E., Driessens, F. C. M., and Planell, J. A., Modeling of the hydrolysis of $\alpha$-TCP. J. Am. Ceram. Soc. $1999,82,2808-2812$

[188] Durucan, C., and Brown, P. W., $\alpha$-tricalcium phosphate hydrolysis to hydroxyapatite at and near physiological temper- ature. J. Mater. Sci. Mater. Med. 2000, 11, 365-371

[189] Durucan, C., and Brown, P. W., Kinetic model for $\alpha$-tricalcium phosphate hydrolysis. J. Am. Ceram. Soc. 2002, 85, 2013-2018

[190] Fulmer, M. T., and Brown, P. W., Hydrolysis of dicalcium phosphate dihydrate to hydroxyapatite. J. Mater. Sci. Mater. Med. 1998, 9, 197-202

[191] Ginebra, M. P., Driessens, F. C. M., and Planell, J. A., Effect of the particle size on the micro and nanostructural features of a calcium phosphate cement: a kinetic analysis. Biomaterials 2004, 25, 3453-3462

[192] Koshino, T., Kubota, W., and Morii, T., Bone formation as a reaction to hydraulic hydroxyapatite thermal decomposition product used as bone cement in rabbits. Biomaterials 1995, 16, $125-128$

[193] Liu, C., Huang, Y., and Chen, J., The physicochemical properties of the solidification of calcium phosphate cement. J. Biomed. Mater. Res. B Appl. Biomater. 2004, 69B, 73-78

[194] Liu, C., Gai, W., Pan, S., and Liu, Z., The exothermal behavior in the hydration process of calcium phosphate cement. Biomaterials 2003, 24, 2995-3003

[195] Charrière, E., Terrazzoni, S., Pittet, C., Mordasini, P., Dutoit, M., Lemaitre, J., and Zysset, P., Mechanical characterization of brushite and hydroxyapatite cements. Biomaterials 2001, 22, 2937-2945

[196] Morgan, H., and Dauskardt, R. H., Notch strength insensitivity of self-setting hydroxyapatite bone cements. J. Mater. Sci. Mater. Med. 2003, 14, 647-653

[197] Bohner, M., Calcium orthophosphates in medicine: from ceramics to calcium phosphate cements. Injury 2000, 31, Suppl. 4, S-D37-S-D47

[198] Bohner, M., Physical and chemical aspects of calcium phosphates used in spinal surgery. Eur. Spine J. 2001, 10, S114-S121

[199] von Gonten, A. S., Kelly, J. R., and Antonucci, J. M., Load-bearing behavior of a simulated craniofacial structure fabricated from a hydroxyapatite cement and bioresorbable fiber-mesh. J. Mater. Sci. Mater. Med. 2000, 11, 95-100

[200] Gisep, A., Kugler, S., Wahl, D., and Rahn, B., The mechanical characterization of a bone defect model filled with ceramic cements. J. Mater. Sci. Mater. Med. 2004, 15, 1065-107

[201] Takagi, S., Chow, L. C., Markovic, M., Friedman, C. D., and Costantino, P. D., Morphological and phase characterizations of retrieved calcium phosphate cement implants. J. Biomed. Mater. Res. Appl. Biomater. 2001, 58, 36-41

[202] Ambard, A. J., and Mueninghoff, L., Calcium phosphate cement: review of mechanical and biological properties. J. Prosthodont. 2006, 15, 321-328

[203] Lewis, G., Injectable bone cements for use in vertebroplasty and kyphoplasty, state-of-the-art review. J. Biomed. Mater. Res. B Appl. Biomater. 2006, 76B, 456-468

[204] Kenny, S. M., and Buggy, M., Bone cements and fillers: a review. J. Mater. Sci. Mater. Med. 2003, 14, 923-938

[205] Takagi, S., Frukhtbeyn, S., Chow, L. C., Sugawara, A., Fu- 
jikawa, K., Ogata, H., Hayashi, M., and Ogiso, B., In vitro and in vivo characteristics of fluorapatite-forming calcium phosphate cements. J. Res. Natl. Inst. Stand. Technol. 2010, $115,267-276$

[206] Constantz, B. R., Ison, I. C., Fulmer, M. T., Poser, R. D., Smith, S. T., van Wagoner, M., Ross, J., Goldstein, S. A., Jupiter, J. B., and Rosenthal, D. I., Skeletal repair by in situ formation of the mineral phase of bone. Science 1995, 267, 1796-1799

[207] Bohner, M., Reactivity of calcium phosphate cements. J. Mater. Chem. 2007, 38, 3980-3986

[208] Bohner, M., Brunner, T. J., and Stark, W. J., Controlling the reactivity of calcium phosphate cements. J. Mater. Chem. $2008,18,5669-5675$

[209] Yuan, H., Li, Y., de Bruijn, J. D., de Groot, K., and Zhang, X., Tissue responses of calcium phosphate cement, a study in dogs. Biomaterials 2000, 21, 1283-1290

[210] Takechi, M., Miyamoto, Y., Ishikawa, K., Toh, T., Yuasa, T., Nagayama, M., and Suzuki, K., Initial histological evaluation of anti-washout type fast-setting calcium phosphate cement following subcutaneous implantation. Biomaterials 1998, 19, 2057-2063

[211] Fulmer, M. T., and Brown, P. W., Effects of $\mathrm{Na}_{2} \mathrm{HPO}_{4}$ and $\mathrm{NaH}_{2} \mathrm{PO}_{4}$ on hydroxyapatite formation. J. Biomed. Mater. Res. 1993, 27, 1095-1102

[212] Otsuka, M., Matsuda, Y., Suwa, Y., Fox, J. L., and Higuchi, W. I., Effect of particle size of metastable calcium phosphates on mechanical strength of a novel self-setting bioactive calcium phosphate cement. J. Biomed. Mater. Res. 1995, 29, $25-32$

[213] Liu, C., Shao, H., Chen, F., and Zheng, H., Effects of granularity of raw materials on the hydration and hardening process of calcium phosphate cement. Biomaterials 2003, 24, 4103-4113

[214] Chen, W. C., Lin, J. H. C., and Ju, C. P., Transmission electron microscopic study on setting mechanism of tetracalcium phosphate/dicalcium phosphate anhydrous-based calcium phosphate cement. J. Biomed. Mater. Res. 2003, 64, 664-671

[215] Fernández, E., Gil, F. J., Ginebra, M. P., Driessens, F. C. M., Planell, J. A., and Best, S. M., Calcium phosphate bone cements for clinical applications. Part II: Precipitate formation during setting reactions. J. Mater. Sci. Mater. Med. 1999, 10, 177-183

[216] Brown, W. E., Crystal growth of bone mineral. Clin. Orthop. Rel. Res. 1966, 44, 205-220

[217] Tung, M. S., and Brown, W. E., An intermediate state in hydrolysis of amorphous calcium phosphate. Calcif. Tissue Int. $1983,35,783-790$

[218] Brown, W. E., Eidelman, N., and Tomazic, B. B., Octacalcium phosphate as a precursor in biomineral formation. Adv. Dent. Res. 1987, 1, 306-313

[219] Constantz, B. R., Barr, B. M., Ison, I. C., Fulmer, M. T., Baker, J., McKinney L. A., Goodman S. B., Gunasekaren, S., Delaney, D. C., Ross, J., and Poser, R. D., Histological, chemical and crystallographic analysis of four calcium phosphate cements in different rabbit osseous sites. J. Biomed. Mater. Res. Appl. Biomater. 1998, 43, 451-461
[220] Elliott, J. C., Structure and chemistry of the apatites and other calcium orthophosphates, Elsevier: Amsterdam, Holland, 1994; 404 pp

[221] Legrand, A. P., Sfihi, H., Lequeux, N., and Lemaitre, J., ${ }^{31} \mathrm{P}$ solid-state NMR study of the chemical setting process of a dual-paste injectable brushite cements. J. Biomed. Mater. Res. B Appl. Biomater. 2009, 91B, 46-54

[222] Bohner, M., Merkle, H. P., van Landuyt, P., Trophardy, G., and Lemaitre, J., Effect of several additives and their admixtures on the physico-chemical properties of a calcium phosphate cement. J. Mater. Sci. Mater. Med. 2000, 11, 111-116

[223] Vereecke, G., and Lemaitre, J., Calculation of the solubility diagrams in the system $\mathrm{Ca}(\mathrm{OH})_{2}-\mathrm{H}_{3} \mathrm{PO}_{4}-\mathrm{KOH}-\mathrm{HNO}_{3}-$ $\mathrm{CO}_{2}-\mathrm{H}_{2} \mathrm{O}$. J. Cryst. Growth 1990, 104, 820-832

[224] Klein, C. P., de Groot, K., Driessen, A. A., and van der Lubbe, H. B., Interaction of biodegradable $\beta$-whitlockite ceramics with bone tissue, an in vivo study. Biomaterials 1985, 6, 189-192

[225] Liu, C., Shen, W., and Chen, J., Solution property of calcium phosphate cement hardening body. Mater. Chem. Phys. 1999, $58,78-83$

[226] Apelt, D., Theiss, F., El-Warrak, A. O., Zlinszky, K., Bettschart-Wolfisberger, R., Bohner, M., Matter, S., Auer, J. A., and von Rechenberg, B., In vivo behavior of three different injectable hydraulic calcium phosphate cements. Biomaterials 2004, 25, 1439-1451

[227] Barralet, J. E., Grover, L. M., and Gbureck, U., Ionic modification of calcium phosphate cement viscosity. Part II: Hypodermic injection and strength improvement of brushite cement. Biomaterials 2004, 25, 2197-2203

[228] Sarda, S., Fernández, E., Nilsson, M., Balcells, M., and Planell, J. A., Kinetic study of citric acid influence on calcium phosphate bone cements as water-reducing agent. J. Biomed. Mater. Res. 2002, 61, 653-659

[229] Qi, X., Ye, J., and Wang, Y., Improved injectability and in vitro degradation of a calcium phosphate cement containing poly(lactide-co-glycolide) microspheres. Acta Biomater. 2008, 4, 1837-1845

[230] Grover, L. M., Knowles, J. C., Fleming, G. J. P., and Barralet, J. E., In vitro ageing of brushite calcium phosphate cement. Biomaterials 2003, 24, 4133-4141

[231] Mariño, F. T., Mastio, J., Rueda, C., Blanco, L., and Cabarcos, E. L., Increase of the final setting time of brushite cements by using chondroitin 4-sulfate and silica gel. J. Mater. Sci. Mater. Med. 2007, 18, 1195-1201

[232] Mariño, F. T., Torres, J., Hamdan, M., Rodríguez, C. R., and Cabarcos, E. L., Advantages of using glycolic acid as a retardant in a brushite forming cement. J. Biomed. Mater. Res. B Appl. Biomater. 2007, 83B, 571-579

[233] Flautre, B., Delecourt, C., Blary, M., van Landuyt, P., Lemaitre, J., and Hardouin, P., Volume effect on biological properties of a calcium phosphate hydraulic cement, experimental study on sheep. Bone 1999, 25, S35-S39

[234] Bohner, M., pH variations of a solution after injecting brushite cements. Key Eng. Mater. 2001, 192-195, 813-816 
[235] Xie, J., Riley, C., and Chittur, K., Effect of albumin on brushite transformation to hydroxyapatite. J. Biomed. Mater. Res. 2001, 57, 357-365

[236] Frayssinet, P., Roudier, M., Lerch, A., Ceolin, J. L., Depres, E., and Rouquet, N., Tissue reaction against a self-setting calcium phosphate cement set in bone or outside the organism. J. Mater. Sci. Mater. Med. 2000, 11, 811-815

[237] Ohura, K., Bohner, M., Hardouin, P., Lemaitre, J., Pasquier, G., and Flautre, B., Resorption of and bone formation from new $\beta$-tricalcium phosphate - monocalcium phosphate cements: an in vivo study. J. Biomed. Mater. Res. 1996, 30, 193-200

[238] Flautre, B., Maynou, C., Lemaître, J., van Landuyt, P., and Hardouin, $\mathrm{P}$., Bone colonization of $\beta$-TCP granules incorporated in brushite cements. J. Biomed. Mater. Res. Appl. Biomater. 2002, 63, 413-417

[239] Standard test method for time of setting of hydraulic cement paste by Gillmore needles. ASTM C266-89. In: Annual book of ASTM standards, Vol. 04. 01: Cement, Lime, Gypsum. American Society for Testing and Materials: Philadelphia, USA, 1993; pp. 189-191

[240] Standard test method for time of setting of hydraulic cement paste by Vicat needle. ASTM C191-92. In: Annual book of ASTM standards, Vol. 04. 01: Cement, Lime, Gypsum. American Society for Testing and Materials: Philadelphia, USA, 1993; pp. 158-160

[241] Nilsson, M., Carlson, J., Fernández, E., Planell, J. A. Monitoring the setting of calcium-based bone cements using pulse-echo ultrasound. J. Mater. Sci. Mater. Med. 2002, 13, $1135-1141$

[242] Carlson, J., Nilsson, M., Fernández, E., and Planell, J. A., An ultrasonic pulse-echo technique for monitoring the setting of $\mathrm{CaSO}_{4}$-based bone cement. Biomaterials 2003, 24, 71-77

[243] Hofmann, M. P., Nazhat, S. N., Gbureck, U., and Barralet, J. E., Real-time monitoring of the setting reaction of brushite-forming cement using isothermal differential scanning calorimetry. J. Biomed. Mater. Res. B Appl. Biomater. 2006, 79B, 360-364

[244] Martin, R. I., and Brown, P. W., The effects of magnesium on hydroxyapatite formation in vitro from $\mathrm{CaHPO}_{4}$ and $\mathrm{Ca}_{4}\left(\mathrm{PO}_{4}\right)_{2} \mathrm{O}$ at $37.4{ }^{\circ} \mathrm{C}$. Calcif. Tissue Int. 1997, 60, 538-546

[245] Brunner, T. J., Bohner, M., Dora, C., Gerber, C., and Stark, W. J., Comparison of amorphous TCP nanoparticles to micron-sized $\alpha$-TCP as starting materials for calcium phosphate cements. J. Biomed. Mater. Res. B Appl. Biomater. 2007, $83 \mathrm{~B}, 400-407$

[246] Gao, W. Y., Wang, Y. W., Dong, L. M., and Yu, Z. W., Thermokinetic analysis of the hydration process of calcium phosphate cement. J. Therm. Anal. Calorim. 2006, 85, 785-789

[247] Bohner, M., and Gbureck, U., Thermal reactions of brushite cements. J. Biomed. Mater. Res. B Appl. Biomater. 2008, 84B, 375-385.

[248] Hofmann, M. P., Young, A. M., Nazhat, S. N., Gbureck, U., and Barralet, J. E., Setting kinetics observation of a brushite cement by FTIR and DSC. Key Eng. Mater. 2006, 309-311, $837-840$
[249] Liu, C., Huang, Y., and Zheng, H., Study of the hydration process of calcium phosphate cement by AC impedance spectroscopy. J. Am. Ceram. Soc. 1999, 82, 1052-1057

[250] Hofmann, M. P., Young, A. M., Gbureck, U., Nazhat, S. N., and Barralet, J. E., FTIR-monitoring of a fast setting brushite bone cement: effect of intermediate phases. J. Mater. Chem. 2006, 16, 3199-3206

[251] Hsu, H. C., Tuan, W. H., and Lee, H. Y., In-situ observation on the transformation of calcium phosphate cement into hydroxyapatite. Mater. Sci. Eng. C 2009, 29, 950-954

[252] Rau, J. V., Generosi, A., Smirnov, V. V., Ferro, D., Rossi, A. V., and Barinov, S. M., Energy dispersive X-ray diffraction study of phase development during hardening of calcium phosphate bone cements with addition of chitosan. Acta Biomater. 2008, 4, 1089-1094

[253] Generosi, A., Smirnov, V. V., Rau, J. V., Rossi, A. V., Ferro, D., and Barinov, S. M., Phase development in the hardening process of two calcium phosphate bone cements: an energy dispersive X-ray diffraction study. Mater. Res. Bull. 2008, 43, 561-571

[254] Ginebra, M. P., Fernández, E., Driessens, F. C. M., Boltong, M. G., Muntasell, J., Font, J., and Planell, J. A., The effects of temperature on the behaviour of an apatitic calcium phosphate cement. J. Mater. Sci. Mater. Med. 1995, 6, 857-860

[255] Baroud, G., Bohner, M., Heini, P., and Steffen, T., Injection biomechanics of bone cements used in vertebroplasty. Biomed. Mater. Eng. 2004, 14, 487-504

[256] Leung, K. S., Siu, W. S., Li, S. F., Qin, L., Cheung, W. H., Tam, K. F., Po, P., and Lui, Y., An in vitro optimized injectable calcium phosphate cement for augmenting screw fixation in osteopenic goats. J. Biomed. Mater. Res. B Appl. Biomater. 2006, 78B, 153-160

[257] Eames, W. B., Monroe, S. D., Roan, J. D., and Oneal, S. J., Proportioning and mixing of cements - comparison of working times. Oper. Dent. 1977, 2, 97-104

[258] Baroud, G., Matsushita, C., Samara, M., Beckman, L., and Steffen, T., Influence of oscillatory mixing on the injectability of three acrylic and two calcium phosphate bone cements for vertebroplasty. J. Biomed. Mater. Res. B Appl. Biomater. 2004, 68B, 105-111

[259] Nomoto, T., Haraguchi, K., Yamaguchi, S., Sugano, N., Nakayama, H., Sekino, T., and Niihara, K., Hydrolyses of calcium phosphates-allografts composite in physiological solutions. J. Mater. Sci. Mater. Med. 2006, 17, 379-385

[260] Oda, M., Takeuchi, A., Lin, X., Matsuya, S., and Ishikawa, K., Effects of liquid phase on basic properties of $\alpha$-tricalcium phosphate-based apatite cement. Dent. Mater. J. 2008, 27, 672-677

[261] Sarda, S., Fernández, E., Llorens, J., Martinez, S., Nilsson, M., and Planell, J. A., Rheological properties of an apatitic bone cement during initial setting. J. Mater. Sci. Mater. Med. 2001, $12,905-909$

[262] Liu, C., Shao, H., Chen, F., and Zheng, H., Rheological properties of concentrated aqueous injectable calcium phosphate cement slurry. Biomaterials 2006, 27, 5003-5013

[263] Bohner, M., and Baroud, G., Injectability of calcium phosphate pastes. Biomaterials 2005, 26, 1553-1563 
[264] Khairoun, I., Boltong, M. G., Driessens, F. C. M., and Planell, J. A., Some factors controlling the injectability of calcium phosphate bone cements. J. Mater. Sci. Mater. Med. 1998, 9, 425-428

[265] Burguera, E. F., Xu, H. H. K., and Sun, L., Injectable calcium phosphate cement: effects of powder-to-liquid ratio and needle size. J. Biomed. Mater. Res. B Appl. Biomater. 2008, $84 \mathrm{~B}, 493-502$

[266] Habib, M., Baroud, G., Gitzhofer, F., and Bohner, M., Mechanisms underlying the limited injectability of hydraulic calcium phosphate paste. Acta Biomater. 2008, 4, 1465-1471

[267] Baroud, G., Cayer, E., and Bohner, M., Rheological characterization of concentrated aqueous beta-tricalcium phosphate suspensions: the effect of liquid-to-powder ratio, milling time and additives. Acta Biomater. 2005, 1, 357-363

[268] Ishikawa, K., Effects of spherical tetracalcium phosphate on injectability and basic properties of apatitic cement. Key Eng. Mater. 2003, 240-242, 369-372

[269] Habib, M., Baroud, G., Gitzhofer, F., and Bohner, M., Mechanisms underlying the limited injectability of hydraulic calcium phosphate paste. Part II: Particle separation study. Acta Biomater. 2010, 6, 250-256

[270] Bohner, M., Doebelin, N., and Baroud, G., Theoretical and experimental approach to test the cohesion of calcium phosphate pastes. Eur. Cell Mater. 2006, 12, 26-35

[271] Miyamoto, Y., Ishikawa, K., Takechi, M., Toh, T., Yuasa, T., Nagayama, M., and Suzuki, K., Histological and compositional evaluations of three types of calcium phosphate cements when implanted in subcutaneous tissue immediately after mixing. J. Biomed. Mater. Res. Appl. Biomater. 1999, $48,36-42$

[272] Bermudez, O., Boltong, M. G., Driessens, F. C. M., and Planell, J. A., Compressive strength and diametral tensile strength of some calcium-orthophosphate cements, a pilot study. J. Mater. Sci. Mater. Med. 1993, 4, 389-393

[273] del Valle, S., Miňo, N., Muňoz, F., González, A., Planell, J. A., and Ginebra, M. P., In vivo evaluation of an injectable macroporous calcium phosphate cement. J. Mater. Sci. Mater. Med. 2007, 18, 353-361

[274] Khairoun, I., Driessens, F. C. M., Boltong, M. G., Planell, J. A., and Wenz, R., Addition of cohesion promoters to calcium orthophosphate cements. Biomaterials 1999, 20, 393-398

[275] Alkhraisat, M. H., Rueda, C., Mariño, F. T., Torres, J., Jerez, L. B., Gbureck, U., and Cabarcos, E. L., The effect of hyaluronic acid on brushite cement cohesion. Acta Biomater. 2009, 5, 3150-3156

[276] Alkhraisat, M. H., Rueda, C., Jerez, L. B., Mariño, F. T., Torres, J., Gbureck, U., and Cabarcos, E. L., Effect of silica gel on the cohesion, properties and biological performance of brushite cement. Acta Biomater. 2010, 6, 257-265

[277] Low, K. L., Tan, S. H., Zein, S. H. S., Roether, J. A., Mouriño, V., and Boccaccini, A. R., Calcium phosphate-based composites as injectable bone substitute materials. J. Biomed. Mater. Res. B Appl. Biomater. 2010, 94B, 273-286

[278] Bigi, A., Bracci, B., and Panzavolta, S., Effect of added gelatin on the properties of calcium phosphate cement. Biomaterials 2004, 25, 2893-2899
[279] Ishikawa, K., Matsuya, S., Nakagawa, M., Udoh, K., and Suzuki, K., Basic properties of apatite cement containing spherical tetracalcium phosphate made with plasma melting method. J. Mater. Sci. Mater. Med. 2004, 15, 13-17

[280] Wang, X., Ye, J., and Wang, Y., Effect of additives on the morphology of the hydrated product and physical properties of a calcium phosphate cement. J. Mater. Sci. Technol. 2008, 24, 285-288

[281] Barralet, J. E., Hofmann, M., Grover, L. M., and Gbureck, U., High strength apatitic cement by modification with $\alpha$-hydroxy acid salts. Adv. Mater. 2003, 15, 2091-2095

[282] Barralet, J. E., Duncan, C. O., Dover, M. S., Bassett, D. C., Nishikawa, H., Monaghan, A., and Gbureck, U., Cortical bone screw fixation in ionically modified apatite cements. J. Biomed. Mater. Res. B Appl. Biomater. 2005, 73B, 238-243

[283] Ginebra, M. P., Boltong, M. G., Fernández, E., Planell, J. A., and Driessens, F. C. M., Effect of various additives and temperature on some properties of an apatitic calcium phosphate cement. J. Mater. Sci. Mater. Med. 1995, 6, 612-616

[284] Acarturk, O., Lehmicke, M., Aberman, H., Toms, D., Hollinger, J. O., and Fulmer, M. T., Bone healing response to an injectable calcium phosphate cement with enhanced radiopacity. J. Biomed. Mater. Res. B Appl. Biomater. 2008, 86B, $56-62$

[285] Wang, X., Ye, J., and Wang, Y., Influence of a novel radiopacifier on the properties of an injectable calcium phosphate cement. Acta Biomater. 2007, 3, 757-763

[286] Chen, F., Liu, C., and Mao, Y., Bismuth-doped injectable calcium phosphate cement with improved radiopacity and potent antimicrobial activity for root canal filling. Acta Biomater. 2010, 6, 3199-3207

[287] Romieu, G., Garric, X., Munier, S., Vert, M., and Boudeville, P., Calcium-strontium mixed phosphate as novel injectable and radio-opaque hydraulic cement. Acta Biomater. 2010, 6, $3208-3215$

[288] Watanabe, M., Tanaka, M., Sakurai, M., and Maeda, M., Development of calcium phosphate cement. J. Eur. Ceram. Soc. 2006, 26, 549-552

[289] Bercier, A., Gonçalves, S., Lignon, O., and Fitremann, J., Calcium phosphate bone cements including sugar surfactants: part one - porosity, setting times and compressive strength. Materials 2010, 3, 4695-4709

[290] Sarda, S., Nilsson, M., Balcells, M., and Fernández, E., Influence of surfactant molecules as air-entraining agent for bone cement macroporosity. J. Biomed. Mater. Res. A 2003, $65 \mathrm{~A}, 215-221$

[291] Friberg, J., Fernández, E., Sarda, S., Nilsson, M., Ginebra, M. P., Martinez, S., and Planell, J. A., An experimental approach to the study of the rheology behavior of synthetic bone calcium phosphate cements. Key Eng. Mater. 2001, 192-195, 777-780

[292] Reinstorf, A., Hempel, U., Olgemöller, F., Domaschke, H., Schneiders, W., Mai, R., Stadlinger, B, Rösen-Wolff, A., Rammelt, S., Gelinsky, M., and Pompe W.,O-phospho-L-ser ine modified calcium phosphate cements - material properties, in vitro and in vivo investigations. Mat. -Wiss. u. Werkstofftech. $2006,37,491-503$ 
[293] Lode, A., Reinstorf, A., Bernhardt, A., Wolf-Brandstetter, C., König, U., Gelinsky, M. Heparin modification of calcium phosphate bone cements for VEGF functionalization. J. Biomed. Mater. Res. A 2008, 86A, 749-759

[294] Mai, R., Lux, R., Proff, P., Lauer, G., Pradel, W., Leonhardt, H., Reinstorf, A., Gelinsky, M., Jung, R., Eckelt, U., Gedrange, T., and Stadlinger, B., O-phospho-L-serine: a modulator of bone healing in calcium-phosphate cements. Biomed. Tech. 2008, 53, 229-233

[295] Vater, C., Lode, A., Bernhardt, A., Reinstorf, A., Nies, B., and Gelinsky, M., Modifications of a calcium phosphate cement with biomolecules - influence on nanostructure, material, and biological properties. J. Biomed. Mater. Res. A 2010, 95A, 912-923

[296] Markovic, M., Takagi, S., and Chow, L. C., Formation of macropores in calcium phosphate cements through the use of mannitol crystals. Key Eng. Mater. 2001, 192-195, 773-776

[297] Tajima, S., Kishi, Y., Oda, M., Maruta, M., Matsuya, S., and Ishikawa, K., Fabrication of biporous low-crystalline apatite based on mannitol dissolution from apatite cement. Dent. Mater. J. 2006, 25, 616-620

[298] Xu, H. H. K., Weir, M. D., Burguera, E. F., and Fraser, A. M., Injectable and macroporous calcium phosphate cement scaffold. Biomaterials 2006, 27, 4279-4287

[299] Cama, G., Barberis, F., Botter, R., Cirillo, P., Capurro, M., Quarto, R., Scaglione, S., Finocchio, E., Mussi, V., and Valbusa, U., Preparation and properties of macroporous brushite bone cements. Acta Biomater. 2009, 5, 2161-2168

[300] Vazquez, D., Takagi, S., Frukhtbeyn, S., and Chow, L. C., Effects of addition of mannitol crystals on the porosity and dissolution rates of a calcium phosphate cement. J. Res. Natl. Inst. Stand. Technol. 2010, 115, 225-232

[301] Shimogoryo, R., Eguro, T., Kimura, E., Maruta, M., Matsuya, S., and Ishikawa, K., Effects of added mannitol on the setting reaction and mechanical strength of apatite cement. Dent. Mater. J. 2009, 28, 627-633

[302] Almirall, A., Larrecq, G., Delgado, J. A., Martínez, S., Planell, J. A., and Ginebra, M. P., Fabrication of low temperature macroporous hydroxyapatite scaffolds by foaming and hydrolysis of an $\alpha$-TCP paste. Biomaterials 2004, 25, 3671-3680

[303] Barralet, J. E., Grover, L., Gaunt, T., Wright, A. J., and Gibson, I. R., Preparation of macroporous calcium phosphate cement tissue engineering scaffold. Biomaterials 2002, 23, 3063-3072

[304] Takagi, S., and Chow, L. C., Formation of macropores in calcium phosphate cement implants. J. Mater. Sci. Mater. Med. 2001, 12, 135-139

[305] Simon, Jr. C. G., Khatri, C. A., Wight, S. A., and Wang, F. W., Preliminary report on the biocompatibility of a moldable, resorbable, composite bone graft consisting of calcium phosphate cement and poly(lactide-co-glycolide) microspheres. J. Orthop. Res. 2002, 20, 473-482

[306] Ruhe, P. Q., Hedberg, E. L., Padron, N. T., Spauwen, P. H. M., Jansen, J. A., and Mikos, A. G., Biocompatibility and degradation of poly(D,L-lactic-co-glycolic acid)/calcium phosphate cement composites. J. Biomed. Mater. Res. A 2005, $74 \mathrm{~A}, 533-544$
[307] Habraken, W. J. E. M., Wolke, J. G. C., Mikos, A. G., and Jansen, J. A., Injectable PLGA microsphere/calcium phosphate cements, physical properties and degradation characteristics. J. Biomater. Sci. Polym. Ed. 2006, 17, 1057-1074

[308] Habraken, W. J. E. M., Wolke, J. G. C., Mikos, A. G., and Jansen, J. A., PLGA microsphere/calcium phosphate cement composites for tissue engineering, in vitro release and degradation characteristics. J. Biomater. Sci. Polym. Ed. 2008, $19,1171-1188$

[309] Link, D. P., van den Dolder, J., van den Beucken, J. J. J. P., Cuijpers, V. M., Wolke, J. G. C., Mikos, A. G., and Jansen, J. A., Evaluation of the biocompatibility of calcium phosphate cement/PLGA microparticle composites. J. Biomed. Mater. Res. A 2008, 87A, 760-769

[310] Link, D. P., van den Dolder, J., Jurgens, W. J. F. M., Wolke, J. G. C., and Jansen, J. A., Mechanical evaluation of implanted calcium phosphate cement incorporated with PLGA microparticles. Biomaterials 2006, 27, 4941-4947

[311] Fullana, S. G., Ternet, H., Freche, M., Lacout, J. L., and Rodriguez, F., Controlled release properties and final macroporosity of a pectin microspheres-calcium phosphate composite bone cement. Acta Biomater. 2010, 6, 2294-2300

[312] Tas, A. C., Preparation of porous apatite granules from calcium phosphate cement. J. Mater. Sci. Mater. Med. 2008, 19, 2231-2239

[313] Tas, A. C., Preparation of self-setting cement-based microand macroporous granules of carbonated apatitic calcium phosphate. Ceram. Eng. Sci. Proc. 2006, 27, 49-60

[314] Li, M., Liu, X., Liu, X., Ge, B. and Chen, K., Creation of macroporous calcium phosphate cements as bone substitutes by using genipin - crosslinked gelatin microspheres. J. Mater. Sci. Mater. Med. 2009, 20, 925-934

[315] Habraken, W. J. E. M., de Jonge, L. T., Wolke, J. G. C., Yubao, L., Mikos, A. G., and Jansen, J. A., Introduction of gelatin microspheres into an injectable calcium phosphate cement. J. Biomed. Mater. Res. A 2008, 87A, 643-655

[316] Tang, P. F., Li, G., Wang, J. F., Zheng, Q. J., and Wang, Y., Development, characterization, and validation of porous carbonated hydroxyapatite bone cement. J. Biomed. Mater. Res. B Appl. Biomater. 2009, 90B, 886-893

[317] Wang, X. P., Ye, J. D., Li, X., and Dong H., Production of in-situ macropores in an injectable calcium phosphate cement by introduction of cetyltrimethyl ammonium bromide. J. Mater. Sci. Mater. Med. 2008, 19, 3221-3225

[318] Habraken, W. J. E. M., Zhang, Z., Wolke, J. G. C., Grijpma, D. W., Mikos, A. G., Feijen, J., and Jansen, J. A., Introduction of enzymatically degradable poly(trimethylene carbonate) microspheres into an injectable calcium phosphate cement. Biomaterials 2008, 29, 2464-2476

[319] Xu, H. H. K., and Simon, Jr. C. G., Self-hardening calcium phosphate composite scaffold for bone tissue engineering. J. Orthop. Res. 2004, 22, 535-543

[320] Burguera, E. F., Xu, H. H. K., Takagi, S., and Chow, L. C., High early strength calcium phosphate bone cement: effects of dicalcium phosphate dihydrate and absorbable fibers. J. Biomed. Mater. Res. A 2005, 75A, 966-975

[321] Xu, H. H. K., and Quinn, J. B., Calcium phosphate cement 
containing resorbable fibers for short-term reinforcement and macroporosity. Biomaterials 2002, 23, 193-202

[322] Gorst, N. J. S., Perrie, Y., Gbureck, U., Hutton, A. L., Hofmann, M. P., Grover, L. M., and Barralet, J. E., Effects of fiber reinforcement on the mechanical properties of brushite cement. Acta Biomater. 2006, 2, 95-102

[323] Zuo, Y., Yang, F., Wolke, J. G. C., Li, Y., and Jansen, J. A., Incorporation of biodegradable electrospun fibers into calcium phosphate cement for bone regeneration. Acta Biomater. $2010,6,1238-1247$

[324] Xu, H. H. K., and Simon, Jr. C. G., Self-hardening calcium phosphate cement-mesh composite: reinforcement, macropores, and cell response. J. Biomed. Mater. Res. A 2004, 69A, $267-278$

[325] Losee, J. E., Karmacharya, J., Gannon, F. H., Slemp, A. E., Ong, G., Hunenko, O., Gorden, A. D., Bartlett, S. P., and Kirschner, R. E., Reconstruction of the immature craniofacial skeleton with a carbonated calcium phosphate bone cement, interaction with bioresorbable mesh. J. Craniofac. Surg. 2003, $14,117-124$

[326] Xu, H. H. K., Carey, L. E., and Simon, Jr. C. G., Premixed macroporous calcium phosphate cement scaffold. J. Mater. Sci. Mater. Med. 2007, 18, 1345-1353

[327] Ginebra, M. P., Espanol, M., Montufar, E. B., Perez, R. A., and Mestres, G., New processing approaches in calcium phosphate cements and their applications in regenerative medicine. Acta Biomater. 2010, 6, 2863-2873

[328] del Real, R. P., Wolke, J. G. C., Vallet-Regi, M., and Jansen, J. A., A new method to produce macropores in calcium phosphate cements. Biomaterials 2002, 23, 3673-3680

[329] del Real, R. P., Ooms, E., Wolke, J. G. C., Vallet-Regi, M., and Jansen, J. A., In vivo bone response to porous calcium phosphate cement. J. Biomed. Mater. Res. A 2003, 65A, $30-36$

[330] Hesaraki, S., Moztarzadeh, F., and Sharifi, D., Formation of interconnected macropores in apatitic calcium phosphate bone cement with the use of an effervescent additive. J. Biomed. Mater. Res. A 2007, 83A, 80-87

[331] Hesaraki, S., Zamanian, A., and Moztarzadeh, F., The influence of the acidic component of the gas-foaming porogen used in preparing an injectable porous calcium phosphate cement on its properties, acetic acid versus citric acid. J. Biomed. Mater. Res. B Appl. Biomater. 2008, 86B, 208-216

[332] Hesaraki, S., Moztarzadeh, F., and Solati-Hashjin, M., Phase evaluation of an effervescent-added apatitic calcium phosphate bone cement. J. Biomed. Mater. Res. B Appl. Biomater. 2006, 79B, 203-209

[333] Ginebra, M. P., Delgado, J. A., Harr, I., Almirall, A., del Valle S., and Planell, J. A., Factors affecting the structure and properties of an injectable self-setting calcium phosphate foam. J. Biomed. Mater. Res. A 2007, 80A, 351-361

[334] Montufar, E. B., Aguirre, A., Gil, C., Engel, E., Traykova, T., Planell, J. A., and Ginebra, M. P., Foamed surfactant solution as a template for self-setting injectable hydroxyapatite scaffolds for bone regeneration. Acta Biomater. 2010, 6, 876-885

[335] Andrianjatovo, H., and Lemaître, J., Effects of polysaccharides on the cement properties in the monocalcium phos- phate/ $\beta$-tricalcium phosphate system. Innov. Tech. Biol. Med. $1995,16,140-147$

[336] Cherng, A., Takagi, S., and Chow, L. C., Effects of hydroxypropylmethylcellulose and other gelling agents on the handling properties of calcium phosphate cement. J. Biomed. Mater. Res. 1997, 35, 273-277

[337] Yokoyama, A., Matsuno, H., Yamamoto, S., Kawasaki, T., Kohgo, T., Uo, M., Watari, F., and Nakasu, M., Tissue response to a newly developed calcium phosphate cement containing succinic acid and carboxymethyl-chitin. J. Biomed. Mater. Res. A 2003, 64A, 491-501

[338] Jyoti, M. A., Thai, V. V., Min, Y. K., Lee, B. T., and Song, H. Y., In vitro bioactivity and biocompatibility of calcium phosphate cements using hydroxy-propyl-methyl-cellulose (HPMC). Appl. Surf. Sci. 2010, 257, 1533-1539

[339] Bigi, A., Torricelli, P., Fini, M., Bracci, B., Panzavolta, S., Sturba, L., and Giardino, R., A biomimetic gelatin-calcium phosphate bone cement. Int. J. Artif. Organs 2004, 27, 664-673

[340] Bigi, A., Panzavolta, S., Sturba, L., Torricelli, P., Fini, M., and Giardino, R., Normal and osteopenic bone-derived osteoblast response to a biomimetic gelatin - calcium phosphate bone cement. J. Biomed. Mater. Res. A 2006, 78A, 739-745

[341] Fujishiro, Y., Takahashi, K., and Sato, T., Preparation and compressive strength of $\alpha$-tricalcium phosphate/gelatin gel composite cement. J. Biomed. Mater. Res. 2001, 54, 525-530

[342] Bigi, A., Panzavolta, S., and Rubini, K., Setting mechanism of a biomimetic bone cement. Chem. Mater. 2004, 16, 3740 $-3745$

[343] Panzavolta, S., Torricelli, P., Sturba, L., Bracci, B., Giardino, R., and Bigi, A., Setting properties and in vitro bioactivity of strontium-enriched gelatin-calcium phosphate bone cements. J. Biomed. Mater. Res. A 2008, 84A, 965-972

[344] Xu, L. X., Shi, X. T., Wang, Y. P., and Shi, Z. L., Performance of calcium phosphate bone cement using chitosan and gelatin as well as citric acid as hardening liquid. J. Clin. Rehabil. Tissue Eng. Res. 2008, 12, 6381-6384

[345] Shie, M. Y., Chen, D. C. H., Wang, C. Y., Chiang, T. Y., and Ding, S. J., Immersion behavior of gelatin-containing calcium phosphate cement. Acta Biomater. 2008, 4, 646-655

[346] Majekodunmi, A. O., Deb, S., and Nicholson, J. W., Effect of molecular weight and concentration of poly(acrylic acid) on the formation of a polymeric calcium phosphate cement. J. Mater. Sci. Mater. Med. 2003, 14, 747-752

[347] Majekodunmi, A.O., and Deb, S., Poly(acrylic acid) modified calcium phosphate cements, the effect of the composition of the cement powder and of the molecular weight and concentration of the polymeric acid. J. Mater. Sci. Mater. Med. 2007, $18,1883-1888$

[348] Chen, W. C., Ju, C. P., Wang, J. C., Hung, C. C., and Lin, J. H. C., Brittle and ductile adjustable cement derived from calcium phosphate cement/polyacrylic acid composites. Dent. Mater. 2008, 24, 1616-1622

[349] Komath, M., and Varma, H. K., Development of a fully injectable calcium phosphate cement for orthopedic and dental applications. Bull. Mater. Sci. 2003, 26, 415-422 
[350] Bohner, M., Theiss, F., Apelt, D., Hirsiger, W., Houriet, R., Rizzoli, G., Gnos, E., Frei, C., Auer, J. A., and von Rechenberg, B., Compositional changes of a dicalcium phosphate dihydrate cement after implantation in sheep. Biomaterials 2003, 24, 3463-3474

[351] Leroux, L., Hatim, Z., Freche, M., and Lacout, J. L., Effects of various adjuvants (lactic acid, glycerol and chitosan) on the injectability of a calcium phosphate cement. Bone 1999, 25, S31-S34

[352] Barralet, J. E., Tremayne, M. J., Lilley, K. J., and Gbureck, U., Chemical modification of calcium phosphate cements with $\alpha$-hydroxy acids and their salts. Chem. Mater. 2005, 17, 1313-1319

[353] Driessens, F. C. M., Boltong, M. G., de Maeyer, E. A. P., Verbeeck, R. M. H., and Wenz, R., Effect of temperature and immersion on the setting of some calcium phosphate cements. J. Mater. Sci. Mater. Med. 2000, 11, 453-457

[354] Gbureck, U., Dembski, S., Thull, R., and Barralet, J. E., Factors influencing calcium phosphate cement shelf life. Biomaterials 2005, 26, 3691-3697

[355] Ishikawa, K., Takagi, S., Chow, L. C., and Ishikawa, Y., Properties and mechanisms of fast-setting calcium phosphate cements. J. Mater. Sci. Mater. Med. 1995, 6, 528-533

[356] Miyamoto, Y., Ishikawa, K., Fukao, K., Sawada, M., Nagayama, M., Kon, M., and Asaoka, K., In vivo setting behavior of fast-setting calcium phosphate cement. Biomaterials $1995,16,855-860$

[357] Kawai, T., Fujisawa, N., Suzuki, I., Ohtsuki, C., Matsushima, Y., and Unuma, H., Control of setting behavior of calcium phosphate paste using gelatinized starch. J. Ceram. Soc. Jpn. $2010,118,421-424$

[358] Bohner, M., Luginbühl, R., Reber, C., Doebelin, N., Baroud, G., and Conforto, E., A physical approach to modify the hydraulic reactivity of $\alpha$-tricalcium phosphate powder. Acta Biomater. 2009, 5, 3524-3535

[359] Takechi, M., Miyamoto, Y., Momota, Y., Yuasa, T., Tatehara, S., Nagayama, M., are Ishikawa, K., Effects of various sterilization methods on the setting and mechanical properties of apatite cement. J. Biomed. Mater. Res. B Appl. Biomater. 2004, 69B, 58-63

[360] Schneider, G., Blechschmidt, K., Linde, D., Litschko, P., Körbs, T., and Beleites, E., Bone regeneration with glass ceramic implants and calcium phosphate cements in a rabbit cranial defect model. J. Mater. Sci. Mater. Med. 2010, 21, 2853-2859

[361] Johal, H. S., Buckley, R. E., Le, I. L. D., and Leighton, R. K., A prospective randomized controlled trial of a bioresorbable calcium phosphate paste ( $\alpha$-BSM) in treatment of displaced intra-articular calcaneal fractures. J. Trauma - Injury, Infect. Crit. Care 2009, 67, 875-882

[362] Yuasa, T., Miyamoto, Y., Ishikawa, K., Takechi, M., Nagayama, M., and Suzuki, K., In vitro resorption of three apatite cements with osteoclasts. J. Biomed. Mater. Res. 2001, 54, 344-350

[363] Puricelli, E., Corsetti, A., Ponzoni, D., Martins, G. L., Leite, M. G., and Santos, L. A., Characterization of bone repair in rat femur after treatment with calcium phosphate cement and autogenous bone graft. Head and Face Medicine 2010, 6, art. no. 10

[364] Zhaoa, X., Lib, F., and Lic, S., Degradation characteristic of strontium-containing calcium phosphate cement in vivo. Adv. Mater. Res. 2010, 105-106, 553-556

[365] Khairoun, I., Magne, D., Gauthier, O. Bouler, J. M., Aguado, E., Daculsi, G., and Weiss, P., In vitro characterization and in vivo properties of a carbonated apatite bone cement. J. Biomed. Mater. Res. 2002, 60, 633-642

[366] Mao, K., Yang, Y., Li, J., Hao, L., Tang, P., Wang, Z., Wen, N., Du, M., Wang, J., and Wang, Y., Investigation of the histology and interfacial bonding between carbonated hydroxyapatite cement and bone. Biomed. Mater. 2009, 4, 045003

[367] Sanzana, E. S., Navarro, M., Macule, F., Suso, S., Planell, J. A., and Ginebra, M. P., Of the in vivo behavior of calcium phosphate cements and glasses as bone substitutes. Acta Biomater. 2008, 4, 1924-1933

[368] Bodde, E. W. H., Cammaert, C. T. R., Wolke, J. G. C., Spauwen, P. H. M., and Jansen, J. A., Investigation as to the osteoinductivity of macroporous calcium phosphate cement in goats. J. Biomed. Mater. Res. B Appl. Biomater. 2007, 83B, 161-168

[369] Miyamoto, Y., Ishikawa, K., Takeshi, M., Toh, T., Yoshida, Y., Nagayama, M., Kon, M., and Asaoka, K., Tissue response to fast-setting calcium phosphate cement in bone. J. Biomed. Mater. Res. 1997, 37, 457-464

[370] Young, S., Holde, M., Gunasekaran, S., Poser, R., and Constantz, B. R., The correlation of radiographic, MRI and histological evaluations over two years of a carbonated apatite cement in a rabbit model. In: Proceedings of the 44th Annual Meeting, Orthopedic Research Society, New Orleans, USA, March 16-19, 1998; p. 846

[371] Feng, B., Guolin, M., Yuan, Y., Changshen, L., Zhen, W., and Jian, L., Role of macropore size in the mechanical properties and in vitro degradation of porous calcium phosphate cements. Mater. Lett. 2010, 64, 2028-2031

[372] Kroese-Deutman, H. C., Wolke, J. G. C., Spauwen, P. H, M., and Jansen, J. A., Closing capacity of cranial bone defects using porous calcium phosphate cement implants in a rabbit animal model. J. Biomed. Mater. Res. A 2006, 79A, 503-511

[373] Bourgeois, B., Laboux, O., Obadia, L., Gauthier, O., Betti, E., Aguado, E., Daculsi, G., and Bouler, J. M., Calcium-deficient apatite: a first in vivo study concerning bone ingrowth. J. Biomed. Mater. Res. A 2003, 65A, 402-408

[374] Lu, J., Descamps, M., Dejou, J., Koubi, G., Hardouin, P., Lemaitre, J., and Proust, J. P., The biodegradation mechanism of calcium phosphate biomaterials in bone. J. Biomed. Mater. Res. Appl. Biomater. 2002, 63, 408-412

[375] Wenisch, S., Stahl, J. P., Horas, U., Heiss, C., Kilian, O., Trinkaus, K., Hild, A., and Schnettler, R., In vivo mechanisms of hydroxyapatite ceramic degradation by osteoclasts, fine structural microscopy. J. Biomed. Mater. Res. A 2003, 67A, $713-718$

[376] Ooms, E. M., Wolke, J. G. C., van der Waerden, J. P., and Jansen, J. A., Trabecular bone response to injectable calcium phosphate (Ca-P) cement. J. Biomed. Mater. Res. 2002, 61, 9-18 
[377] Theiss, F., Apelt, D., Brand, B., Kutter, A., Zlinszky, K., Bohner, M., Matter, S., Frei, C., Auer, J. A., and von Rechenberg, B., Biocompatibility and resorption of a brushite calcium phosphate cement. Biomaterials 2005, 26, 4383-4394

[378] Heymann, D., Pradal, G., and Benahmad, M., Cellular mechanisms of calcium phosphate degradation. Histol. Histopathol. 1999, 14, 871-877

[379] Penel, G., Leroy, N., van Landuyt, P., Flautre, B., Hardouin, P., Lemaitre, J., and Leroy, G., Raman microspectrometry studies of brushite cement: in vivo evolution in a sheep model. Bone 1999, 25, Suppl. 2, 81S-84S

[380] Dorozhkin, S. V., Inorganic chemistry of the dissolution phenomenon, the dissolution mechanism of calcium apatites at the atomic (ionic) level. Comment Inorg. Chem. 1999, 20, 285-299

[381] Dorozhkin, S. V., A review on the dissolution models of calcium apatites. Prog. Cryst. Growth Charact. 2002, 44, 45-61

[382] Knabe, C., Driessens, F. C. M., Planell, J. A., Gildenhaar, R., Berger, G., Reif, D., Fitzner, R., Radlanski, R. J., and Gross, U., Evaluation of calcium phosphates and experimental calcium phosphate bone cements using osteogenic cultures. J. Biomed. Mater. Res. 2000, 52, 498-508

[383] Teitelbaum, S. L., Bone resorption by osteoclasts. Science 2000, 289, 1504-1508

[384] Mostov, K., and Werb, Z., Journey across the osteoclast. Science 1997, 276, 219-220

[385] Rodan, G. A., and Martin, T. J., Therapeutic approaches to bone diseases. Science 2000, 289, 1508-1514

[386] Midy, V., Hollande, E., Rey, C., Dard, M., and Plouët, J., Adsorption of vascular endothelial growth factor to two different apatitic materials and its release. J. Mater. Sci. Mater. Med. 2001, 12, 293-298

[387] Hossain, M., Irwin, R., Baumann, M. J., and McCabe, L. R., Hepatocyte growth factor (HGF) adsorption kinetics and enhancement of osteoblast differentiation on hydroxyapatite surfaces. Biomaterials 2005, 26, 2595-2602

[388] Sun, L., Berndt, C. C., Gross, K. A., and Kucuk, A., Material fundamentals and clinical performance of plasma-sprayed hydroxyapatite coatings, a review. J. Biomed. Mater. Res. B Appl. Biomater. 2001, 58, 570-592

[389] Renault, F., Chabriere, E., Andrieu, JP., Dublet, B., Masson, P., and Rochu, D., Tandem purification of two HDL-associated partner proteins in human plasma., paraoxonase (PON1) and phosphate binding protein (HPBP) using hydroxyapatite chromatography. J. Chromatogr. B 2006, 836, $15-21$

[390] Yoshitake, T., Kobayashi, S., Ogawa, T., and Okuyama, T., Hydroxyapatite chromatography of guanidine denatured proteins: 1. guanidine containing phosphate buffer system. Chromatography 2006, 27, 19-26

[391] Ooms, E. M., Egglezos, E. A., Wolke, J. G. C., and Jansen, J. A., Soft-tissue response to injectable calcium phosphate cements. Biomaterials 2003, 24, 749-757

[392] Ooms, E. M., Wolke, J. G. C., van de Heuvel, MT., Jeschke, B., and Jansen, J. A., Histological evaluation of the bone re- sponse to calcium phosphate cement implanted in cortical bone. Biomaterials 2003, 24, 989-1000

[393] Kobayashi, N., Ong, K., Villarraga, M., Schwardt, J., Wenz, R., Togawa, D., Fujishiro, T., Turner, A. S., Seim, III H. B., and Bauer, T. W., Histological and mechanical evaluation of self-setting calcium phosphate cements in a sheep vertebral bone void model. J. Biomed. Mater. Res. A 2007, 81A, $838-846$

[394] Wen, C. Y., Qin, L., Lee, K. M., and Chan, K. M., The use of brushite calcium phosphate cement for enhancement of bone-tendon integration in an anterior cruciate ligament reconstruction rabbit model. J. Biomed. Mater. Res. B Appl. Biomater. 2009, 89B, 466-474

[395] Musha, Y., Umeda, T., Yoshizawa, S., Shigemitsu, T., Mizutani, K., and Itatani, K., Effects of blood on bone cement made of calcium phosphate: problems and advantages. J. Biomed. Mater. Res. B Appl. Biomater. 2010, 92B, 95-101

[396] Fernández, E., Ginebra, M. P., Bermudez, O., Boltong, M. G., Driessens, F. C. M., and Planell, J. A., Dimensional and thermal behaviour of calcium phosphate cements during setting compared to PMMA bone cements. J. Mater. Sci. Lett. $1995,14,4-5$

[397] Andrianjatovo, H., Jose, F., and Lemaitre, J., Effect of $\beta$-TCP granulometry on setting time and strength of calcium orthophosphate hydraulic cements. J. Mater. Sci. Mater. Med. 1996, 7, 34-39

[398] Ishikawa, K., Takagi, S., Chow, L. C., Ishikawa Y., Eanes, E. D., and Asaoka, K., Behavior of a calcium orthophosphate cement in simulated blood plasma in vitro. Dent. Mater. 1994, $10,26-32$

[399] Driessens, F. C. M., Chemistry and applied aspects of calcium orthophosphate bone cements. In: Concepts and clinical applications of ionic cements, $15^{\text {th }}$ European Conference on Biomaterials. Arcachon, Bordeaux, France. Sept. 8, 1999

[400] Yamamoto, H., Niwa, S., Hori, M., Hattori, T., Sawai, K., Aoki, S., Hirano, M., and Takeuchi, H., Mechanical strength of calcium phosphate cement in vivo and in vitro. Biomaterials $1998,19,1587-1591$

[401] Pittet, C., and Lemaitre, J., Mechanical characterization of brushite cements: a Mohr circles approach. J. Biomed. Mater. Res. Appl. Biomater. 2000, 53, 769-780

[402] Morgan, E. F., Yetkinler, D. N., Constantz, B. R., and Dauskardt, R. H., Mechanical properties of carbonated apatite bone mineral substitute: strength, fracture and fatigue behaviour. J. Mater. Sci. Mater. Med. 1997, 8, 559-570

[403] Miyazaki, K., Horibe, T., Antonucci, J. M., Takagi, S., and Chow, L. C., Polymeric calcium phosphate cements, analysis of reaction products and properties. Dent. Mater. 1993, 9, $41-45$

[404] Miyazaki, K., Horibe, T., Antonucci, J. M., Takagi, S., and Chow, L. C., Polymeric calcium phosphate cements: setting reaction modifiers. Dent. Mater. 1993, 9, 46-50

[405] dos Santos, L. A., de Oliveira, L. C., Rigo, E. C. S., Carrodeguas, R. G., Boschi, A. O., and de Arruda, A. C. F., Influence of polymeric additives on the mechanical properties of $\alpha$-tricalcium phosphate cement. Bone 1999, 25, 99S-102S

[406] Mickiewicz, R. A., Mayes, A. M., and Knaack, D., Polymer - 
calcium phosphate cement composites for bone substitutes. J. Biomed. Mater. Res. 2002, 61, 581-592

[407] Fernández, E., Sarda, S., Hamcerencu, M., Vlad, M. D., Gel, M., Valls, S., Torres, R., and López, J., High-strength apatitic cement by modification with superplasticizers. Biomaterials 2005, 26, 2289-2296

[408] Takahashi, T., Yamamoto, M., Ioku, K., and Goto, S., Relationship between compressive strength and pore structure of hardened cement pastes. Adv. Cement Res. 1997, 9, 25-30

[409] Costantino, P. D., Friedman, C. D., Jones, K., Chow, L. C., and Sisson, G. A., Experimental hydroxyapatite cement cranioplasty. Plast. Reconstr. Surg. 1992, 90, 174-185

[410] Chow, L. C., Hirayama, S., Takagi, S., and Parry, E., Diametral tensile strength and compressive strength of a calcium phosphate cement, effect of applied pressure. J. Biomed. Mater. Res. Appl. Biomater. 2000, 53, 511-517

[411] Barralet, J. E., Gaunt, T., Wright, A. J., Gibson I. R., and Knowles, J. C., Effect of porosity reduction by compaction on compressive strength and microstructure of calcium phosphate cement. J. Biomed. Mater. Res. Appl. Biomater. 2002, $63,1-9$

[412] Zhang, Y., Xu, H. H. K., Takagi, S., and Chow, L. C., In situ hardening hydroxyapatite-based scaffold for bone repair. J. Mater. Sci. Mater. Med. 2006, 17, 437-445

[413] Khairoun, I., LeGeros, R. Z., Daculsi, G., Bouler, J. M., Guicheux, J., and Gauthier, O., Macroporous, resorbable and injectable calcium phosphate-based cements (MCPC) for bone repair: augmentation, regeneration and osteoporosis treatment. US patent No. 7351280. April 1, 2008

[414] Speirs, A. D., Oxland, T. R., Masri, B. A., Poursartip, A., and Duncan, C. P., Calcium phosphate cement composites in revision hip arthroplasty. Biomaterials 2005, 26, 7310-7318

[415] dos Santos, L. A., Carrodeguas, R. G., Boschi, A. O., and de Arruda, A. C. F., Fiber-enriched double-setting calcium phosphate bone cement. J. Biomed. Mater. Res. A 2003, 65A, 244-250

[416] Gbureck, U., Spatz, K., and Thull, R., Improvement of mechanical properties of self-setting calcium phosphate bone cements mixed with different metal oxides. Mat. -Wiss. u. Werkstofftech. 2003, 34, 1036-1040

[417]Zhang, Y., and $\mathrm{Xu}, \mathrm{H}$. H. K., Effects of synergistic reinforcement and absorbable fiber strength on hydroxyapatite bone cement. J. Biomed. Mater. Res. A 2005, 75A, 832-840

[418] Buchanan, F., Gallagher, L., Jack, V., and Dunne, N., Short-fibre reinforcement of calcium phosphate bone cement. Proc. Inst. Mech. Eng. H: J. Eng. Med. 2007, 221, 203-212

[419] Wang, X., Ye, J., Wang, Y., and Chen, L., Reinforcement of calcium phosphate cement by bio-mineralized carbon nanotube. J. Am. Ceram. Soc. 2007, 90, 962-964

[420] Vélez, D., Arita, I. H., García-Garduño, M. V., and Castaño, V. M., Synthesis and characterization of a hydroxyapatite-zinc oxide-polyacrylic acid concrete. Mater. Lett. 1994, $19,309-315$

[421] According to Wikipedia, the free encyclopedia: "Concrete is a construction material that consists of a cement (commonly Portland cement), aggregates (generally gravel and sand) and water. It solidifies and hardens after mixing and placement due to a chemical process known as hydration. The water reacts with the cement, which bonds the other components together, eventually creating a stone-like material. " http://en. wikipedia. org/wiki/Concrete (accessed in November 2011)

[422] Dickens-Venz, S. H., Takagi, S., Chow, L. C., Bowen, R. L., Johnston, A. D., and Dickens, B., Physical and chemical properties of resin-reinforced calcium phosphate cements. Dent. Mater. 1994, 10, 100-106

[423] Xu, H. H. K., Eichmiller, F. C., and Barndt, P. R., Effects of fiber length and volume fraction on the reinforcement of calcium phosphate cement. J. Mater. Sci. Mater. Med. 2001, 12, $57-65$

[424] Xu, H. H. K., Quinn, J. B., Takagi, S., and Chow, L. C., Synergistic reinforcement of in situ hardening calcium phosphate composite scaffold for bone tissue engineering. Biomaterials 2004, 25, 1029-1037

[425] Yokoyama, A., Yamamoto, S., Kawasaki, T., Kohgo, T., and Nakasu, M., Development of calcium phosphate cement using chitosan and citric acid for bone substitute materials. Biomaterials 2002, 23, 1091-1101

[426] Takagi, S., Chow, L. C., Hirayama, S., and Eichmiller, F. C., Properties of elastomeric calcium phosphate cement-chitosan composites. Dent. Mater. 2003, 19, 797-804

[427] Xu, H. H. K., and Simon Jr., C. G., Fast setting calcium phosphate-chitosan scaffold: mechanical properties and biocompatibility. Biomaterials 2005, 26, 1337-1348

[428] Sun, L., Xu, H. H. K., Takagi, S., and Chow, L. C., Fast setting calcium phosphate cement - chitosan composite, mechanical properties and dissolution rates. J. Biomater. Appl. 2007, 21, 299-316

[429] Pan, Z. H., Jiang, P. P., Fan, Q. Y., Ma, B., and Cai, H. P., Mechanical and biocompatible influences of chitosan fiber and gelatin on calcium phosphate cement. J. Biomed. Mater. Res. B Appl. Biomater. 2007, 82B, 246-252

[430] Liu, H., Li, H., Cheng, W., Yang, Y., Zhu, M., and Zhou, C., Novel injectable calcium phosphate/chitosan composites for bone substitute materials. Acta Biomater. 2006, 2, 557-565

[431] Pan, Z. H., Cai, H. P., Jiang, P. P., and Fan, Q. Y., Properties of a calcium phosphate cement synergistically reinforced by chitosan fiber and gelatin. J. Polymer Res. 2006, 13, 323-327

[432] Weir, M. D., and Xu, H. H. K., High-strength, in situ-setting calcium phosphate composite with protein release. J. Biomed. Mater. Res. A 2008, 85A, 388-396

[433] Lian, Q., Li, D. C., He, J. K., and Wang, Z., Mechanical properties and in-vivo performance of calcium phosphate cement - chitosan fibre composite. Proc. Inst. Mech. Eng. H: J. Eng. Med. 2008, 222, 347-353

[434] Wang, X., Chen, L., Xiang, H., and Ye, J., Influence of anti-washout agents on the rheological properties and injectability of a calcium phosphate cement. J. Biomed. Mater. Res. B Appl. Biomater. 2007, 81B, 410-418

[435] Tanaka, S., Kishi, T., Shimogoryo, R., Matsuya, S., and Ishikawa, K., Biopex acquires anti-washout properties by adding sodium alginate into its liquid phase. Dent. Mater. J. 2003, 22, 301-312 
[436] Lin, J., Zhang, S., Chen, T., Liu, C., Lin, S., and Tian, X., Calcium phosphate cement reinforced by polypeptide copolymers. J. Biomed. Mater. Res. B Appl. Biomater. 2006, 76B, 432-439

[437] Miyamoto, Y., Ishikawa, K., Takechi, M., Toh, T., Yuasa, T., Nagayama, M., and Suzuki, K., Basic properties of calcium phosphate cement containing atelocollagen in its liquid or powder phases. Biomaterials 1998, 19, 707-715

[438] Knepper-Nicolai, B., Reinstorf, A., Hofinger, I., Flade, K., Wenz, R., and Pompe, W., Influence of osteocalcin and collagen I on the mechanical and biological properties of Biocement ${ }^{\circledR}$. Biomol. Eng. 2002, 19, 227-231

[439] Hempel, U., Reinstorf, A., Poppe, M., Fischer, U., Gelinsky, M., Pompe, W., and Wenzel, K. W., Proliferation and differentiation of osteoblasts on Biocement $\mathrm{D}^{\mathbb{R}}$ modified with collagen type I and citric acid. J. Biomed. Mater. Res. B Appl. Biomater. 2004, 71B, 130-143

[440] Reinstorf, A., Ruhnow, M., Gelinsky, M., Pompe, W., Hempel, U., Wenzel, K. W., and Simon, P., Phosphoserine - a convenient compound for modification of calcium phosphate bone cement collagen composites. J. Mater. Sci. Mater. Med. 2004, 15, 451-455

[441] Otsuka, M., Kuninaga, T., Otsuka, K., and Higuchi, W. I., Effect of nanostructure on biodegradation behaviors of self-setting apatite/collagen composite cements containing vitamin $\mathrm{K}_{2}$ in rats. J. Biomed. Mater. Res. B Appl. Biomater. 2006, 79B, 176-184

[442] Moreau, J. L., Weir, M. D., and Xu, H. H. K., Self-setting collagen - calcium phosphate bone cement: mechanical and cellular properties. J. Biomed. Mater. Res. A 2009, 91A, 605-613

[443] Otsuka, M., Nakagawa, H., Ito, A., and Higuchi, W. I., Effect of geometrical structure on drug release rate of a three-dimensionally perforated porous apatite/collagen composite cement. J. Pharm. Sci. 2010, 99, 286-292

[444] Gbureck, U., Spatz, K., Thull, R., and Barralet, J. E., Rheological enhancement of mechanically activated $\alpha$-tricalcium phosphate cements. J. Biomed. Mater. Res. B Appl. Biomater. $2005,73 \mathrm{~B}, 1-6$

[445] Xu, H. H. K., Eichmiller, F. C., and Giuseppetti, A. A., Reinforcement of a self-setting calcium phosphate cement with different fibers. J. Biomed. Mater. Res. 2000, 52, $107-114$

[446] Xu, H. H. K., Quinn, J. B., Takagi, S., Chow, L. C., and Eichmiller, F. C., Strong and macroporous calcium phosphate cement: effects of porosity and fiber reinforcement on mechanical properties. J. Biomed. Mater. Res. 2001, 57, 457-466

[447] dos Santos, L. A., Carrodeguas, R. G., Boschi, A. O., and de Arruda, A. C. F., Dual-setting calcium phosphate cement modified with ammonium polyacrylate. Artif. Organs 2003, $27,412-418$

[448] dos Santos, L. A., de Oliveira, L. C., da Silva Rigo, E. C., Carrodéguas, R. G., Boschi, A. O., and de Arruda, A. C. F., Fiber reinforced calcium phosphate cement. Artif. Organs 2000, 24, 212-216

[449] Liu, C. S., Chen, C. W., and Ducheyne, P., In vitro surface reaction layer formation and dissolution of calcium phosphate cement - bioactive glass composites. Biomed. Mater. 2008, 3,

\section{1 (11 pages)}

[450] Alge, D. L., and Chu, T. M. G., Calcium phosphate cement reinforcement by polymer infiltration and in situ curing: a method for 3D scaffold reinforcement. J. Biomed. Mater. Res. A 2010, 94A, 547-555

[451] Julien, M., Khairoun, I., LeGeros, R. Z., Delplace, S., Pilet, P. Weiss, P., Daculsi, G., Bouler, J. M., and Guicheux, J., Physico-chemical-mechanical and in vitro biological properties of calcium phosphate cements with doped amorphous calcium phosphates. Biomaterials 2007, 28, 956-965

[452] Lemaître, J., Munting, E., and Mirtchi, A. A., Setting, hardening and resorption of calcium phosphate hydraulic cements. Rev. Stomatol. Chir. Maxillofac. 1992, 93, 163-165

[453] Müller, F. A., Gbureck, U., Kasuga, T., Mizutani, Y., Barralet, J. E., and Lohbauer, U., Whisker-reinforced calcium phosphate cements. J. Am. Ceram. Soc. 2007, 90, 3694-3697

[454] Nakagawa, A., Matsuya, S., Takeuchi, A., and Ishikawa, K., Comparison of the effects of added $\alpha$ - and $\beta$-tricalcium phosphate on the basic properties of apatite cement. Dent. Mater. J. 2007, 26, 342-347

[455] Gisep, A., Wieling, R., Bohner, M., Matter, S., Schneider, E., and Rahn, B., Resorption patterns of calcium-phosphate cements in bone. J. Biomed. Mater. Res. A 2003, 66A, 532-540

[456] Ion-substituted ACPs contained other ions (carbonates, $\mathrm{Mg}$, $\mathrm{Zn}, \mathrm{F})$ were used in that study[451]

[457] van den Vreken, N. M. F., Pieters, I. Y., Declercq, H. A., Cornelissen, M. J., and Verbeeck, R. M. H., Characterization of calcium phosphate cements modified by addition of amorphous calcium phosphate. Acta Biomater. 2010, 6, $617-625$

[458] Zhou, L., Yan, J. L., and Hu, C. J., Degradation of bone repairing composite of calcium polyphosphate fiber, calcium phospate cement and micromorselized bone in vitro. J. Clin. Rehabilit. Tiss. Eng. Res. 2007, 11, 33-36

[459] Xu, L. X., Shi, X. T., Wang, Y. P., and Shi, Z. L., Mechanical effect of calcium polyphosphate fiber on reinforcing calcium phosphate bone cement composites. J. Clin. Rehabilit. Tiss. Eng. Res. 2009, 13, 7474-7476

[460] Castaldini, A., and Cavallini, A., Setting properties of bone cement with added synthetic hydroxyapatite. Biomaterials $1985,6,55-60$

[461] Sogal, A., and Hulbert, S. F., Mechanical properties of a composite bone cement, polymethylmethacrylate and hydroxyapatite. In: Proceedings of the $5^{\text {th }}$ International Symposium on Ceramics in Medicine, Bioceramics 1992, Vol. 5, pp. 213-224

[462] Harper, E. J., Behiri, J. C., and Bonfield, W., Flexural and fatigue properties of a bone cement based upon polyethylmethacrylate and hydroxyapatite. J. Mater. Sci. Mater. Med. $1995,6,799-803$

[463] Harper, E. J., Bioactive bone cements. Proc. Inst. Mech. Eng. H: J. Eng. Med. 1998, 212, 113-120

[464] Shinzato, S., Kobayashi, M., Mousa, W. F., Kamimura, M., Neo, M., Kitamura, Y., Kokubo, T., and Nakamura, T., Bioactive polymethylmethacrylate-based bone cement: compar- 
ison of glass beads, apatite- and wollastonite-containing glass-ceramic, and hydroxyapatite fillers on mechanical and biological properties. J. Biomed. Mater. Res. 2000, 51, 258-272

[465] Harper, E. J., Braden, M., and Bonfield, W., Mechanical properties of hydroxyapatite reinforced poly(ethylmethacrylate) bone cement after immersion in a physiological solution, Influence of a silane coupling agent. J. Mater. Sci. Mater. Med. 2000, 11, 491-497

[466] Espigares, I., Elvira, C., Mano, J. F., Vázquez, B., san Román, J., and Reis, R. L., New partially degradable and bioactive acrylic bone cements based on starch blends and ceramic fillers. Biomaterials 2002, 23, 1883-1895

[467] Pek, Y. S., Kurisawa, M., Gao, S., Chung, J. E., and Ying, J. Y., The development of a nanocrystalline apatite reinforced crosslinked hyaluronic acid-tyramine composite as an injectable bone cement. Biomaterials 2009, 30, 822-828

[468] Xu, H. H. K., and Quinn, J. B., Whisker-reinforced bioactive composites containing calcium phosphate cement fillers, Effects of filler ratio and surface treatments on mechanical properties. J. Biomed. Mater. Res. 2001, 57, 165-174

[469] Claes L., Höllen, I., and Ignatius, A., Resorbable bone cements. Orthopäde 1997, 26, 459-462

[470] Jansen, J. A., de Ruijter, J. E., Schaeken, H. G., van der Waerden, J. P. C., Planell, J. A., and Driessens, F. C. M., Evaluation of tricalciumphosphate/hydroxyapatite cement for tooth replacement, an experimental animal study. J. Mater. Sci. Mater. Med. 1995, 6, 653-657

[471] Larsson. S., and Bauer, T. W., Use of injectable calcium phosphate cement for fracture fixation: a review. Clin. Orthop. Rel. Res. 2002, 395, 23-32

[472] Oshtory, R., Lindsey, D. P., Giori, N. J., and Mirza, F. M., Bioabsorbable tricalcium phosphate bone cement strengthens fixation of suture anchors. Clin. Orthop. Rel. Res. 2010, 468, 3406-3412

[473] Gbureck, U., Knappe, O., Hofmann, N., and Barralet, J. E., Antimicrobial properties of nanocrystalline tetracalcium phosphate cements. J. Biomed. Mater. Res. B Appl. Biomater. 2007, 83B, 132-137

[474] Sethuraman, S., Nair, L. S., El-Amin, S., Nguyen, M. T. N., Greish, Y. E., Bender, J. D., Brown, P. W., Allcock, H. R., and Laurencin, C. T., Novel low temperature setting nanocrystalline calcium phosphate cements for bone repair: osteoblast cellular response and gene expression studies. J. Biomed. Mater. Res. A 2007, 82A, 884-891

[475] Link, D. P., van den Dolder, J., Wolke, J. G. C., and Jansen, J. A., The cytocompatibility and early osteogenic characteristics of an injectable calcium phosphate cement. Tissue Eng. 2007, $13,493-500$

[476] Oda, H., Nakamura, K., Matsushita, T., Yamamoto, S., Ishibashi, H., Yamazaki, T., and Morimoto, S., Clinical use of a newly developed calcium phosphate cement (XSB-671D). J. Orthop. Sci. 2006, 11, 167-174

[477] Braun, C., Rahn, B., Fulmer, M. T., Steiner, A., and Gisep, A., Intra-articular calcium phosphate cement, its fate and impact on joint tissues in a rabbit model. J. Biomed. Mater. Res. B Appl. Biomater. 2006, 79B, 151-158
[478] Costantino, P., Friedman, C., Jones, K., Chow, L. C., Pelzer, H., and Sisson, G., Hydroxyapatite cement. I. Basic chemistry and histologic properties. Arch. Otolaryngol. Head Neck Surg. $1991,117,379-384$

[479] Hong, Y. C., Wang, J. T., Hong, C. Y., Brown, W. E., and Chow, C. Y., The periapical tissue reactions to a calcium phosphate cement in the teeth of monkeys. J. Biomed. Mater. Res. 1991, 25, 485-498

[480] Sugawara, A., Fujikawa, K., Kusama, K., Nishiyama, M., Murai, S., Takagi, S., and Chow, L. C., Histopathologic reaction of calcium phosphate cement for alveolar ridge augmentation. J. Biomed. Mater. Res. 2002, 61, 47-52

[481] Fujikawa, K., Sugawara, A., Kusama, K., Nishiyama, M., Murai, S., Takagi, S., and Chow, L. C., Fluorescent labeling analysis and electron probe microanalysis for alveolar ridge augmentation using calcium phosphate cement. Dent. Mater. J. 2002, 21, 296-305

[482] Sugawara, A., Chow, L. C., Takagi, S., and Chohayeb, H., In vitro evaluation of the sealing ability of a calcium phosphate cement when used as a root canal sealer-filler. J. Endod. 1990, $16,162-165$

[483] Noetzel, J., Özer, K., Reisshauer, B. H., Anil, A., Rössler, R., Neumann, K., and Kielbassa, A. M., Tissue responses to an experimental calcium phosphate cement and mineral trioxide aggregate as materials for furcation perforation repair, a histological study in dogs. Clin. Oral Invest. 2006, 10, 77-83

[484] Zhang, W., Walboomers, X. F., and Jansen, J. A., The formation of tertiary dentin after pulp capping with a calcium phosphate cement, loaded with PLGA microparticles containing TGF- $\beta 1$. J. Biomed. Mater. Res. A 2008, 85A, $439-444$

[485] Comuzzi, L., Ooms, E., and Jansen, J. A., Injectable calcium phosphate cement as a filler for bone defects around oral implants, an experimental study in goats. Clin. Oral Implants Res. 2002, 13, 304-311

[486] Shirakata, Y., Oda, S., Kinoshita, A., Kikuchi, S., Tsuchioka, H., and Ishikawa, I., Histocompatible healing of periodontal defects after application of injectable calcium phosphate bone cement. A preliminary study in dogs. J. Periodontol. 2002, 73, 1043-1053

[487] Lee, S. K., Lee, S. K., Lee, S. I., Park, J. H., Jang, J. H., Kim, H. W., and Kim, E. C., Effect of calcium phosphate cements on growth and odontoblastic differentiation in human dental pulp cells. J. Endod. 2010, 36, 1537-1542

[488] Chaung, H. M., Hong, C. H., Chiang, C. P., Lin, S. K., Kuo, Y. S., Lan, W. H., and Hsieh, C. C., Comparison of calcium phosphate cement mixture and pure calcium hydroxide as direct pulp-capping agents. J. Formos Med. Assoc. 1996, 95, $545-550$

[489] Arisan, V., Anil, A., Wolke, J. G., and Özer, K., The effect of injectable calcium phosphate cement on bone anchorage of titanium implants: an experimental feasibility study in dogs. Int. J. Oral Maxillofac. Surg. 2010, 39, 463-468

[490] Aral, A., Yalcn, S., Karabuda, Z. C., Anıl, A., Jansen, J. A., and Mutlu, Z., Injectable calcium phosphate cement as a graft material for maxillary sinus augmentation: an experimental pilot study. Clin. Oral Implants Res. 2008, 19, 612-617

[491] Sliindo, M. L., Costantino, P. D., Friedman, C. D., and Chow, 
L. C., Facial skeletal augmentation using hydroxyapatite cement cranioplasty. Arch. Otolaryngol. Head Neck Surg. $1993,119,185-190$

[492] Bifano, C. A., Edgin, W. A., Colleton, C., Bifano, S. L., and Constantino, P. D., Preliminary evaluation of hydroxyapatite cement as an augmentation device in the edentulous atrophic canine mandible. Oral Surg. 1998, 85, 512-516

[493] Friedman, C. D., Constantino, P. D., Jones, K., Chow, L. C., Pelzer, H., and Sisson, G., Hydroxyapatite cement. II. Obliteration and reconstruction of the cat frontal sinus. Arch. Otolaryngol. Head Neck Surg. 1991, 117, 385-389

[494] Sinikovic, B., Kramer, F. J., Swennen, G., Lubbers, H. T., and Dempf, R., Reconstruction of orbital wall defects with calcium phosphate cement: clinical and histological findings in a sheep model. Int. J. Oral Maxillofac. Surg. 2007, 36, 54-61

[495] Smartt, J. M., Karmacharya, J., Gannon, F. H., Ong, G., Jackson, O., Bartlett. S. P., Poser, R. D., and Kirschner, R. E., Repair of the immature and mature craniofacial skeleton with a carbonated calcium phosphate cement: assessment of biocompatibility, osteoconductivity and remodeling capacity. Plast. Reconstr. Surg. 2005, 115, 1642-1650

[496] Reddi, S. P., Stevens, M. R., Kline, S. N., and Villanueva, P., Hydroxyapatite cement in craniofacial trauma surgery, indications and early experience. J. Cran. Maxillofac. Trauma $1999,5,7-12$

[497] Friedman, C. D., Costantino, P. D., Synderman, C. H., Chow, L. C., and Takagi, S., Reconstruction of the frontal sinus and frontofacial skeleton with hydroxyapatite cement. Arch. Facial Plast. Surg. 2000, 2, 124-129

[498] Kuemmerle, J. M., Oberle, A., Oechslin, C., Bohner, M., Frei, C., Boecken, I., and von Rechenberg, B., Assessment of the suitability of a new brushite calcium phosphate cement for cranioplasty - an experimental study in sheep. J. Cran. Maxillofac. Surg. 2005, 33, 37-44

[499] Luaces-Rey, R., García-Rozado, A., Crespo-Escudero, J. L., Seijas, B. P., Arenaz-Búa, J., and López-Cedrún, J. L., Use of carbonated calcium phosphate bone cement and resorbable plates for the treatment of frontal sinus fractures: two case reports. J. Plastic Reconstr. Aesthetic Surg. 2009, 62, 272-273

[500] Tamimi, F., Torres, J., Cabarcos, E. L., Bassett, D. C., Habibovic, P., Luceron, E., and Barralet, J. E., Minimally invasive maxillofacial vertical bone augmentation using brushite based cements. Biomaterials 2009, 30, 208-216

[501] Lee, D. W., Kim, J. Y., and Lew, D. H., Use of rapidly hardening hydroxyapatite cement for facial contouring surgery. J. Craniofac. Surg. 2010, 21, 1084-1088

[502] Singh, K. A., Burstein, F. D., and Williams, J. K., Use of hydroxyapatite cement in pediatric craniofacial reconstructive surgery: strategies for avoiding complications. J. Craniofac. Surg. 2010, 21, 1130-1135

[503] Bambakidis, N. C., Munyon, C., Ko, A., Selman, W. R., and Megerian, C. A., A novel method of translabyrinthine cranioplasty using hydroxyapatite cement and titanium mesh: a technical report. Skull Base 2010, 20, 157-161

[504] Abe, T., Anan, M., Kamida, T., and Fujiki, M., Surgical technique for anterior skull base reconstruction using hydroxyapatite cement and titanium mesh. Acta Neurochirur. $2009,151,1337-1338$
[505] Sanada, Y., Fujinaka, T., Yoshimine, T., and Kato, A., Optimal reconstruction of the bony defect after frontotemporal craniotomy with hydroxyapatite cement. J. Clin. Neurosci. $2011,18,280-282$

[506] Benson, A. G., and Djalilian, H. R., Complications of hydroxyapatite bone cement reconstruction of retrosigmoid craniotomy: two cases. Ear, Nose and Throat J. 2009, 88, E1

[507] Liverneaux, P., Osteoporotic distal radius curettage-filling with an injectable calcium phosphate cement. A cadaveric study. Eur. J. Orthop. Surg. Traumatol. 2005, 15, 1-6

[508] Liverneaux, P., Vernet, P., Robert, C., and Diacono, P., Cement pinning of osteoporotic distal radius fractures with an injectable calcium phosphate bone substitute, report of 6 cases. Eur. J. Orthop. Surg. Traumatol. 2006, 16, 10-16

[509] Thordarson, D., Hedman, T., Yetkinler, D., Eskander, E., Lawrence, T., and Poser, R., Superior compressive strength of a calcaneal fracture construct augmented with remodelable cancellous bone cement. J. Bone Joint Surg. Am. 1999, 81A, 239-246

[510] Stankewich, C. J., Swiontkowski, M. F., Tencer, A. F., Yetkinler, D. N., and Poser, R. D., Augmentation of femoral neck fracture fixation with an injectable calcium-phosphate bone mineral cement. J. Orthop. Res. 1996, 14, 786-793

[511] Goodman, S., Bauer, T., Carter, D., Casteleyn, P. P., Goldstein, S. A., Kyle, R. F., Larsson, S., Stankewich, C. J., Swiontkowski, M. F., Tencer, A. F., Yetkinler, D. N., and Poser, R. D., Norian SRS ${ }^{\circledR}$ cement augmentation in hip fracture treatment. Clin. Orthop. Rel. Res. 1998, 348, 42-50

[512] Bai, B., Jazrawi, L., Kummer, F., and Spivak, J., The use of an injectable, biodegradable calcium orthophosphate bone substitute for the prophylactic augmentation of osteoporotic vertebrae and the management of vertebral compression fractures. Spine 1999, 24, 1521-1526

[513] Ryf, C., Goldhahn, S., Radziejowski, M., Blauth, M., and Hanson, B., A new injectable brushite cement: first results in distal radius and proximal tibia fractures. Eur. J. Trauma Emerg. Surg. 2009, 35, 389-396

[514] Horstmann, W. G., Verheyen, C. C. P. M., and Leemans, R., An injectable calcium phosphate cement as a bone-graft substitute in the treatment of displaced lateral tibial plateau fractures. Injury 2003, 34, 141-144

[515] Simpson, D., and Keating, J. F., Outcome of tibial plateau fractures managed with calcium phosphate cement. Injury 2004, 35, 913-918

[516] Welch, R. D., Zhang, H., and Bronson, D. G., Experimental tibial plateau fractures augmented with calcium phosphate cement or autologous bone graft. J. Bone Joint Surg. Am. 2003, 85A, 222-231

[517] Keating, J. F., Hajducka, C. L., and Harper, J., Minimal internal fixation and calcium-phosphate cement in the treatment of fractures of the tibial plateau. J. Bone Joint Surg. Br. 2003, $85 \mathrm{~B}, 68-73$

[518] Moore, D., Maitra, R., Farjo, L., Graziano, G., and Goldstein, S., Restoration of pedicle screw fixation with an in situ setting calcium orthophosphate cement. Spine 1997, 22, 1696-1705

[519] Cho, W., Wu, C., Erkan, S., Kang, M. M., Mehbod, A. A., and Transfeldt, E. E., The effect on the pullout strength by the 
timing of pedicle screw insertion after calcium phosphate cement injection. J. Spinal Disorders and Techniques 2011, 24, 116-120

[520] Mermelstein, L. E., McLain, R. F., and Yerby, S. A., Reinforcement of thoracolumbar burst fractures with calcium phosphate cement. Spine 1998, 23, 664-671

[521] Mermelstein, L. E., Chow, L. C., Friedman, C., and Crisco, J., The reinforcement of cancellous bone screws with calcium orthophosphate cement. J. Orthop. Trauma 1996, 10, 15-20

[522] Stadelmann, V. A., Bretton, E., Terrier, A., Procter, P., and Pioletti, D. P., Calcium phosphate cement augmentation of cancellous bone screws can compensate for the absence of cortical fixation. J. Biomech. 2010, 43, 2869-2874

[523] Liverneaux, P., and Khallouk, R., Calcium phosphate cement in wrist arthrodesis: three cases. J. Orthop. Sci. 2006, 11, 289-293

[524] Ooms, E. M., Wolke, J. G. C., van der Waerden, J. P. C. M., and Jansen, J. A., Use of injectable calcium phosphate cement for the fixation of titanium implants: an experimental study in goats. J. Biomed. Mater. Res. B Appl. Biomater. 2003, 66B, $447-456$

[525] Strauss, E. J., Pahk, B., Kummer, F. J., and Egol, K., Calcium phosphate cement augmentation of the femoral neck defect created after dynamic hip screw removal. J. Orthop. Trauma 2007, 21, 295-300

[526] Schildhauer, T. A., Bennett, A. P., Wright, T. M., Lane, J. M., and O'Leary, P. F., Intravertebral body reconstruction with an injectable in situ-setting carbonated apatite: biomechanical evaluation of a minimally invasive technique. J. Orthop. Res. $1999,17,67-72$

[527] Jansen, J. A., Ooms, E., Verdonschot, N., and Wolke, J. G. C., Injectable calcium phosphate cement for bone repair and implant fixation. Orthop. Clin. North Am. 2005, 36, 89-95

[528] Maestretti, G., Cremer, C., Otten, P., and Jakob, R. P., Prospective study of standalone balloon kyphoplasty with calcium phosphate cement augmentation in traumatic fractures. Eur. Spine J. 2007, 16, 601-610

[529] Hisatome, T., Yasunaga, Y., Ikuta, Y., and Fujimoto, Y., Effects on articular cartilage of subchondral replacement with polymethylmethacrylate and calcium phosphate cement. J. Biomed. Mater. Res. 2002, 59, 490-498

[530] Lim, T. H., Brebach, G. T., Renner, S. M., Kim, W. J., Kim, J. G., Lee, R. E., Andersson, G. B., and An, H. S., Biomechanical evaluation of an injectable calcium phosphate cement for vertebroplasty. Spine 2002, 27, 1297-1302

[531] Belkoff, S. M., Mathis, J. M., Jasper, L. E., and Deramond, H., An ex vivo biomechanical evaluation of a hydroxyapatite cement for use with vertebroplasty. Spine 2001, 26, $1542-1546$

[532] Heini, P. F., Berlemann, U., Kaufmann, M., Lippuner, K., Fankhauser, C., and van Landuyt, P., Augmentation of mechanical properties in osteoporotic vertebral bones - a biomechanical investigation of vertebroplasty efficacy with different bone cements. Eur. Spine J. 2001, 10, 164-171

[533] Tomita, S., Kin, A., Yazu, M., and Abe, M., Biomechanical evaluation of kyphoplasty and vertebroplasty with calcium phosphate cement in a simulated osteoporotic compression fracture. J. Orthop. Sci. 2003, 8, 192-197

[534] Libicher, M., Hillmeier, J., Liegibel, U., Sommer, U., Pyerin, W., Vetter, M., Meinzer, H. P., Grafe, I., Meeder, P., Nöldge, G., Nawroth, P., and Kasperk, C., Osseous integration of calcium phosphate in osteoporotic vertebral fractures after kyphoplasty: initial results from a clinical and experimental pilot study. Osteoporos. Int. 2006, 17, 1208-1215

[535] Khanna, A. J., Lee, S., Villarraga, M., Gimbel, J., Steffey, D., and Schwardt, J., Biomechanical evaluation of kyphoplasty with calcium phosphate cement in a 2-functional spinal unit vertebral compression fracture model. Spine J. 2008, 8, 770-777

[536] Zhu, X. S., Zhang, Z. M., Mao, H. Q., Geng, D. C., Wang, G. L., Gan, M. F., and Yang, H. L., Biomechanics of calcium phosphate cement in vertebroplasty. J. Clin. Rehabil. Tissue Eng. Res. 2008, 12, 8071-8074

[537] Otsuka, M., Matsuda, Y., Suwa, Y., Fox, J. L., and Higuchi, W. I., A novel skeletal drug-delivery system using a self-setting calcium orthophosphate cement. 3. Physicochemical properties and drug-release rate of bovine insulin and bovine albumin. J. Pharm. Sci. 1994, 83, 255-258

[538] Yu, D., Wong, J., Matsuda, Y., Fox, J. L., Higuchi, W. I., and Otsuka, M., Self-setting hydroxyapatite cement: a novel skeletal drug-delivery system for antibiotics. J. Pharm. Sci. $1992,81,529-531$

[539] Bohner, M., Lemaître, J., van Landuyt, P., Zambelli, P., Merkle, H. P., and Gander, B., Gentamicin-loaded hydraulic calcium orthophosphate bone cement as antibiotic delivery system. J. Pharm. Sci. 1997, 86, 565-572

[540] Bohner, M., Lemaître, J., Merkle, H. P., and Gander, B., Control of gentamicin release from a calcium phosphate cement by admixed poly(acrylic acid). J. Pharm. Sci. 2000, 89, $1262-1270$

[541] Ratier, A., Freche, M., Locout, J. L., and Rodriguez, F., Behaviour of an injectable calcium phosphate cement with added tetracycline. Int. J. Pharm. 2004, 274, 261-268

[542] Kisanuki, O., Yajima, H., Umeda, T., and Takakura, Y., Experimental study of calcium phosphate cement impregnated with dideoxy-kanamycin B. J. Orthop. Sci. 2007, 12, 281-288

[543] McNally, A., Sly, K., Lin, S., Bourges, X., and Daculsi, G., Release of antibiotics from macroporous injectable calcium phosphate cement. Key Eng. Mater. 2008, 361-363, 359-362

[544] Hofmann, M. P., Mohammed, A. R., Perrie, Y., Gbureck, U., and Barralet, J. E., High-strength resorbable brushite bone cement with controlled drug-releasing capabilities. Acta Biomater. 2009, 5, 43-49

[545] Tamimi, F., Torres, J., Bettini, R., Ruggera, F., Rueda, C., López-Ponce, M., and Cabarcos, E. L., Doxycycline sustained release from brushite cements for the treatment of periodontal diseases. J. Biomed. Mater. Res. A 2008, 85A, 707-714

[546] Young, A. M., Ng, P. Y. J., Gbureck, U., Nazhat, S. N., Barralet, J. E., and Hofmann, M. P., Characterization of chlorhexidine-releasing, fast-setting, brushite bone cements. Acta Biomater. 2008, 4, 1081-1088

[547] Hesaraki, S., and Nemati, R., Cephalexin-loaded injectable 
macroporous calcium phosphate bone cement. J. Biomed. Mater. Res. B Appl. Biomater. 2009, 89B, 342-352

[548] Otsuka, M., Matsuda, Y., Suwa, Y., Fox, J. L., and Higuchi, W. I., A novel skeletal drug delivery system using a self-setting calcium orthophosphate cement. 5. Drug release behavior from a heterogeneous drug-loaded cement containing an anticancer drug. J. Pharm. Sci. 1994, 83, 1565-1568

[549] Otsuka, M., Matsuda, Y., Suwa, Y., Fox, J. L., and Higuchi, W. I., A novel skeletal drug delivery system using a self-setting calcium orthophosphate cement. 2. Physicochemical properties and drug release rate of the cement-containing indomethacin. J. Pharm. Sci. 1994, 83, 611-615

[550] Panzavolta, S., Torricelli, P., Bracci, B., Fini, M., and Bigi, A., Alendronate and pamidronate calcium phosphate bone cements, setting properties and in vitro response of osteoblast and osteoclast cells. J. Inorg. Biochem. 2009, 103, 101-106

[551] le Nihouannen, D., Hacking, SA., Gbureck, U., Komarova, S. V., and Barralet, J. E., The use of RANKL-coated brushite cement to stimulate bone remodeling. Biomaterials 2008, 29, 3253-3259

[552] Li, D. X., Fan, H. S., Zhu, X. D., Tan, Y. F., Xiao, W. Q., Lu, J., Xiao, Y. M., Chen, J. Y., and Zhang, X. D., Controllable release of salmon-calcitonin in injectable calcium phosphate cement modified by chitosan oligosaccharide and collagen polypeptide. J. Mater. Sci. Mater. Med. 2007, 18, 2225-2231

[553] Kamegai, A., Shimamura, N., Naitou, K., Nagahara, K., Kanematsu, N., and Mori, M., Bone formation under the influence of bone morphogenetic protein/self-setting apatite cement composite as delivery system. Biomed. Mater. Eng. 1994, 4, 291-307

[554] Fei, Z., Hu, Y., Wu, D., Wu, H., Lu, R., Bai, J., and Song, H., Preparation and property of a novel bone graft composite consisting of rhBMP-2 loaded PLGA microspheres and calcium phosphate cement. J. Mater. Sci. Mater. Med. 2008, 19, 1109-1116

[555] Ruhé, P. Q., Kroese-Deutman, H. C., Wolke, J. G. C., Spauwen, P. H. M., and Jansen, J. A., Bone inductive properties of rhBMP-2 loaded porous calcium phosphate cement implants in cranial defects in rabbits. Biomaterials 2004, 25, 2123-2132

[556] Bodde, E. W. H., Boerman, O. C., Russel, F. G. M., Mikos, A. G., Spauwen, P. H. M., and Jansen, J. A., The kinetic and biological activity of different loaded rhBMP-2 calcium phosphate cement implants in rats. J. Biomed. Mater. Res. A 2008, 87A, 780-791

[557] Perrier, M., Lu, Y., Nemke, B., Kobayashi, H., Peterson, A., and Markel, M., Acceleration of second and fourth metatarsal fracture healing with recombinant human bone morphogenetic protein-2/calcium phosphate cement in horses. Vet. Surg. 2008, 37, 648-655

[558] Meraw, S. J., Reeve, C. M., Lohse, C. M., and Sioussat, T. M., Treatment of perimplant defects with combination growth factor cement. J. Periodont. 2000, 71, 8-13

[559] Liu, H., Zang, X. F., Zhao, Z. P., Wang, J. L., and Mi, L., Co-transplantation of exogenous nerve growth factor and calcium phosphate cement composite for repairing rabbit radial bone defects. J. Clin. Rehabil. Tissue Eng. Res. 2008, $12,8037-8041$
[560] Qu, X. Y., Jiang, D. M., Li, M., Zhang, D. W., Qin, J. Q., and Liu, C. K., Deproteinized osteoarticular allografts integrated with calcium phosphate cement and recombinant human vascular endothelial cell growth factor plus recombinant human bone morphogenetic protein-2, an immunological study. J. Clin. Rehabil. Tissue Eng. Res. 2008, 12, 8067-8070

[561] Yu, T., Ye, J., Gao, C., Yu, L., and Wang, Y., Synthesis and drug delivery property of calcium phosphate cement with special crystal morphology. J. Am. Ceram. Soc. 2010, 93, $1241-1244$

[562] Stallmann, H. P., de Roo, R., Faber, C., Amerongen, A. V, N., and Wuisman, P. I. J. M., In vivo release of the antimicrobial peptide hLFi-11 from calcium phosphate cement. J. Orthop. Res. 2008, 26, 531-538

[563] Sasaki, T., Ishibashi, Y., Katano, H., Nagumo, A., and Toh, S., In vitro elution of vancomycin from calcium phosphate cement. J. Arthroplasty 2005, 20, 1055-1059

[564] Blom, E. J., Klein-Nulend, J., Wolke, J. G. C., van Waas, M. A. J., Driessens, F. C. M., and Burger, E. H., Transforming growth factor- $\beta 1$ incorporation in a calcium phosphate bone cement, Material properties and release characteristics. J. Biomed. Mater. Res. 2002, 59, 265-272

[565] Blom, E. J., Klein-Nulend, J., Yin, L., van Waas, M. A. J., and Burger, E. H., Transforming growth factor- $\beta 1$ incorporated in calcium phosphate cement stimulates osteotransductivity in rat calvarial bone defects. Clin. Oral Implants Res. 2001, 12, 609-616

[566] Link, D. P., van den Dolder, J., van den Beucken, J. J., Wolke, J. G. C., Mikos, A. G., and Jansen, J. A., Bone response and mechanical strength of rabbit femoral defects filled with injectable $\mathrm{CaP}$ cements containing TGF- $\beta 1$ loaded gelatin microparticles. Biomaterials 2008, 29, 675-682

[567] Habraken, W. J. E. M., Boerman, O. C., Wolke, J. G. C., Mikos, A. G., and Jansen, J. A., In vitro growth factor release from injectable calcium phosphate cements containing gelatin microspheres. J. Biomed. Mater. Res. A 2009, 91A, 614-622

[568] Ruhé, P. Q., Boerman, O. C., Russel, F. G. M., Mikos, A. G., Spauwen, P. H. M., and Jansen, J. A., In vivo release of rhBMP-2 loaded porous calcium phosphate cement pretreated with albumin. J. Mater. Sci. Mater. Med. 2006, 17, 919-927

[569] Naito, K., Obayashi, O., Mogami, A., Itoi, A., and Kaneko, K., Fracture of the calcium phosphate bone cement which used to enchondroma of the hand, a case report. Eur. J. Orthop. Surg. Traumatol. 2008, 18, 405-408

[570] Blattert, T. R., Delling, G., and Weckbach, A., Evaluation of an injectable calcium phosphate cement as an autograft substitute for transpedicular lumbar interbody fusion: a controlled, prospective study in the sheep model. Eur. Spine J. 2003, 12, 216-223

[571] Cavalcanti, S. C., Santos, S. C., Pereira, C. L., Mazzonetto, R., de Moraes, M., and Moreira, R. W. F., Histological and histomorphometric analyses of calcium phosphate cement in rabbit calvaria. J. Cran. Maxillofac. Surg. 2008, 36, 354-359

[572] Sanchez-Sotelo, J., Munuera, L., and Madero, R., Treatment of fractures of the distal radius with a remodellable bone cement: a prospective, randomised study using Norian $\mathrm{SRS}^{\mathbb{R}}$. J. Bone Joint Surg. Br. 2000, 82B, 856-863

[573] Lobenhoffer, P., Gerich, T., Witte, F., and Tscherne, H., Use 
of an injectable calcium phosphate bone cement in the treatment of tibial plateau fractures: a prospective study of twenty-six cases with twenty-month mean follow-up. J. Orthop. Trauma 2002, 16, 143-149

[574] Cassidy, C., Jupiter, J. B., Cohen, M., Delli-Santi, M., Fennell, C., Leinberry, C., Husband, J., Ladd, A., Seitz, W. R., and Constantz, B. R., Norian SRS ${ }^{\circledR}$ cement compared with conventional fixation in distal radial fractures, a randomized study. J. Bone Joint Surg. Am. 2003, 85A, 2127-2137

[575] Schmidt, R., Cakir, B., Mattes, T., Wegener, M., Puhl, W., and Richter, M., Cement leakage during vertebroplasty, an underestimated problem? Eur. Spine J. 2005, 14, 466-473

[576] Vlad, M. D., Torres, R., López, J., Barracó, M., Moreno, J. A., and Fernández, E., Does mixing affect the setting of injectable bone cement? An ultrasound study. J. Mater. Sci. Mater. Med. 2007, 18, 347-352

[577] Krebs, J., Aebli, N., Goss, B. G., Sugiyama, S., Bardyn, T., Boecken, I., Leamy, P. J., and Ferguson, S. J., Cardiovascular changes after pulmonary embolism from injecting calcium phosphate cement. J. Biomed. Mater. Res. B Appl. Biomater. 2007, 82B, 526-532

[578] Russell, T. A., and Leighton, R. K., Comparison of autogenous bone graft and endothermic calcium phosphate cement for defect augmentation in tibial plateau fractures. A multicenter, prospective, randomized study. J. Bone Joint Surg. Am. 2008, 90A, 2057-2061

[579] Dickson, K. F., Friedman, J., Buchholz, J. G., and Flandry, F. D., The use of BoneSource ${ }^{\mathrm{TM}}$ hydroxyapatite cement for traumatic metaphyseal bone void filling. J. Trauma 2002, 53, $1103-1108$

[580] Jungbluth, P., Hakimi, M., Grassmann, J. P., Schneppendahl, J., Kessner, A., Sager, M., Hakimi, A. R., Becker, J., Windolf, J., and Wild, M., The progress of early phase bone healing using porous granules produced from calcium phosphate cement. Eur. J. Med. Res. 2010, 15, 196-203

[581] Yoshikawa, T., Suwa, Y., Ohgushi, H., Tamai, S., and Ichijima, K., Self-setting hydroxyapatite cement as a carrier for bone-forming cells. Biomed. Mater. Eng. 1996, 6, 345-351

[582] Simon, Jr. C. G., Guthrie, W. F., and Wang, F. W., Cell seeding into calcium phosphate cement. J. Biomed. Mater. Res. A 2004, 68A, 628-639

[583] Xu, H. H. K., Weir, M. D., and Simon, Jr. C. G., Injectable and strong nano-apatite scaffolds for cell/growth factor delivery and bone regeneration. Dent. Mater. 2008, 24, $1212-1222$

[584] Takagi, S., Chow, L. C., Hirayama, S., and Sugawara, A., Premixed calcium phosphate cement pastes. J. Biomed. Mater. Res. B Appl. Biomater. 2003, 67B, 689-696

[585] Carey, L. E., Xu, H. H. K., Simon, Jr. C. G., Takagi, S., and Chow, L. C., Premixed rapid-setting calcium phosphate composites for bone repair. Biomaterials 2005, 26, $5002-5014$

[586] Xu, H. H. K., Carey, L. E., Simon, Jr. C. G., Takagi, S., and Chow, L. C., Premixed calcium phosphate cements: synthesis, physical properties, and cell cytotoxicity. Dent. Mater. 2007, $23,433-441$

[587] Shimada, Y., Chow, L. C., Takagi, S., and Tagami, J., Prop- erties of injectable apatite-forming premixed cements. J. Res. Natl. Inst. Stand. Technol. 2010, 115, 233-241

[588] Sugawara, A., Fujikawa, K., Hirayama, S., Takagi, S., and Chow, L. C., In vivo characteristics of premixed calcium phosphate cements when implanted in subcutaneous tissues and periodontal bone defects. J. Res. Natl. Inst. Stand. Technol. 2010, 115, 277-290

[589] Rajzer, I., Castaño, O., Engel, E., and Planell, J. A., Injectable and fast resorbable calcium phosphate cement for body-setting bone grafts. J. Mater. Sci. Mater. Med. 2010, 21, 2049-2056

[590] Han, B., Ma, P. W., Zhang, L. L., Yin, Y. J., Yao, K. D., Zhang, F. J., Zhang. Y. D., Li, X. L., and Nie, W., $\beta$-TCP/MCPM-based premixed calcium phosphate cements. Acta Biomater. 2009, 5, 3165-3177

[591] Chow, L.C., and Takagi, S., Premixed self-hardening bone graft pastes. US Patent Application No. 20060263443, November 23, 2006

[592] Aberg, J., Brisby, H., Henriksson, H. B., Lindahl, A., Thomsen, P., and Engqvist, H., Premixed acidic calcium phosphate cement: characterization of strength and microstructure. J. Biomed. Mater. Res. B Appl. Biomater. 2010, 93, 436-441

[593] Lemaître, J., Pittet, C., and Brendlen, D., Pasty or liquid multiple constituent compositions for injectable calcium phosphate cements. US Patent No. 7407542, May 8, 2008

[594] Chow, L. C., and Takagi, S., Dual-phase cement precursor systems for bone repair. US Patent Application No. 20070092580, April 26, 2007

[595] Bohner, M., Calcium phosphate emulsions: possible applications. Key Eng. Mater. 2001, 192-195, 765-768

[596] Troczynski, T., A concrete solution. Nature Mater. 2004, 3, $13-14$

[597] Xu, H. H. K., Burguera, E. F., and Carey, L. E., Strong, macroporous and in situ-setting calcium phosphate cement-layered structures. Biomaterials 2007, 28, 3786-3796

[598] Xu, H. H. K., Takagi, S., Quinn, J. B., and Chow, L. C., Fast-setting calcium phosphate scaffolds with tailored macropore formation rates for bone regeneration. J. Biomed. Mater. Res. A 2004, 68A, 725-734

[599] Ginebra, M. P., Rilliard, A., Fernández, E., Elvira, C., san Roman, J., and Planell, J. A., Mechanical and rheological improvement of a calcium phosphate cement by the addition of a polymeric drug. J. Biomed. Mater. Res. 2001, 57, 113-118

[600] García-Fernández, L., Halstenberg, S., Unger, R. E., Aguilar, M. R., Kirkpatrick, C. J., and san Román, J., Anti-angiogenic activity of heparin-like polysulfonated polymeric drugs in 3D human cell culture. Biomaterials 2010, 31, 7863-7872

[601] Andriotis, O., Katsamenis, O. L., Mouzakis, D. E., and Bouropoulos, N., Preparation and characterization of bioceramics produced from calcium phosphate cements. Cryst. Res. Technol. 2010, 45, 239-243

[602] Steffen, T., Stoll, T., Arvinte, T., and Schenk, R. K., Porous tricalcium phosphate and transforming growth factor used for anterior spine surgery. Eur. Spine J. 2001, 10, S132-S140 
[603] Guo, H., Su, J., Wei, J., Kong, H., and Liu, C., Biocompatibility and osteogenicity of degradable Ca-deficient hydroxyapatite scaffolds from calcium phosphate cement for bone tissue engineering. Acta Biomater. 2009, 5, 268-278

[604] Guo, H., Wei, J., Kong, H., Liu, C., and Pan, K., Biocompatibility and osteogenesis of calcium phosphate cement scaffolds for bone tissue engineering. Adv. Mater. Res. 2008, 47-50, 1383-1386

[605] Weir, M. D., Xu, H. H. K., and Simon, Jr. C. G., Strong calcium phosphate cement-chitosan-mesh construct containing cell-encapsulating hydrogel beads for bone tissue engineering. J. Biomed. Mater. Res. A 2006, 77A, 487-496

[606] Xu, J. H., Tan, W. Q., and Lin, J., Repair of madibular bone defect by combining calcium phosphate cement with bone morphogenetic protein composite as a bone graft material. Chinese J. Biomed. Eng. 2007, 26, 153-156

[607] Niikura, T., Tsujimoto, K., Yoshiya, S., Tadokoro, K., Kurosaka, M., and Shiba, R., Vancomycin-impregnated calcium phosphate cement for methicillin-resistant staphylococcus aureus femoral osteomyelitis. Orthopedics 2007, 30, 320-321

[608] Lode, A., Wolf-Brandstetter, C., Reinstorf, A., Bernhardt, A., König, U. Pompe, W., and Gelinsky, M., Calcium phosphate bone cements, functionalized with VEGF: release kinetics and biological activity. J. Biomed. Mater. Res. A 2007, 81A, $474-483$

[609] Yoshikawa, M., and Toda, T., In vivo estimation of periapical bone reconstruction by chondroitin sulfate in calcium phosphate cement. J. Eur. Ceram. Soc. 2004, 24, 521-531

[610] Wang, J. L., Mi, L., Hou, G. H., and Zheng, Z., Repair of radial defects using calcium phosphate cements/poly lactic-co-glycolic acid materials combined with mesenchymal stem cells in rabbits. J. Clin. Rehabil. Tissue Eng. Res. 2008, $12,8001-8005$

[611] Zhao, L., Weir, M. D., and Xu, H. H. K., Human umbilical cord stem cell encapsulation in calcium phosphate scaffolds for bone engineering. Biomaterials 2010, 31, 3848-3857

[612] Ding, T., Yang, H., Maltenfort, M., and Xie, R., Silk fibroin added to calcium phosphate cement to prevent severe cardiovascular complications. Case Reports Clin. Pract. Rev. 2010,
$16,23-26$

[613] Panzavolta, S., Torricelli, P., Bracci, B., Fini, M., and Bigi, A., Functionalization of biomimetic calcium phosphate bone cements with alendronate. J. Inorg. Biochem. 2010, 104, 1099-1106

[614] Xu, H. H. K., Zhao, L., Detamore, M. S., Takagi, S., and Chow, L. C., Umbilical cord stem cell seeding on fast-resorbable calcium phosphate bone cement. Tiss. Eng. A 2010, 16, 2743-2753

[615] Li, M., Liu, X., Liu, X., and Ge, B., Calcium phosphate cement with BMP-2-loaded gelatin microspheres enhances bone healing in osteoporosis: a pilot study. Clin. Orthop. Rel. Res. 2010, 468, 1978-1985

[616] Weir, M. D., and Xu, H. H. K., Human bone marrow stem cell-encapsulating calcium phosphate scaffolds for bone repair. Acta Biomater. 2010, 6, 4118-4126

[617] Zhao, L., Weir, M. D., and Xu, H. H. K., An injectable calcium phosphate-alginate hydrogel-umbilical cord mesenchymal stem cell paste for bone tissue engineering. Biomaterials $2010,31,6502-6510$

[618] dos Santos, L. A., Carrodéguas, R. G., Rogero, S. O., Higa, O. Z., Boschi, A. O., and de Arruda, A. C., Alpha-tricalcium phosphate cement: "in vitro" cytotoxicity. Biomaterials 2002, 23, 2035-2042

[619] Baroud, G., and Steffen, T., A new cannula to ease cement injection during vertebroplasty. Eur. Spine J. 2005, 14, 474-479

[620] Anderson, J. M., The future of biomedical materials. J. Mater. Sci. Mater. Med. 2006, 17, 1025-1028

[621] Chow, L. C., Next generation calcium phosphate-based biomaterials. Dent. Mater. J. 2009, 28, 1-10

[622] Ishikawa, K., Bone substitute fabrication based on dissolution-precipitation reactions. Materials 2010, 3, 1138-1155

[623] Bohner, M., Resorbable biomaterials as bone graft substitutes. Mater. Today 2010, 13, 24-30

[624] Dorozhkin, S. V., Calcium orthophosphate cements and concretes. Materials 2009, 2, 221-291 